Provided for non-commercial research and educational use. Not for reproduction, distribution or commercial use.

This article was originally published in the Comprehensive Nuclear Materials published by Elsevier, and the attached copy is provided by Elsevier for the author's benefit and for the benefit of the author's institution, for non-commercial research and educational use including without limitation use in instruction at your institution, sending it to specific colleagues who you know, and providing a copy to your institution's administrator.

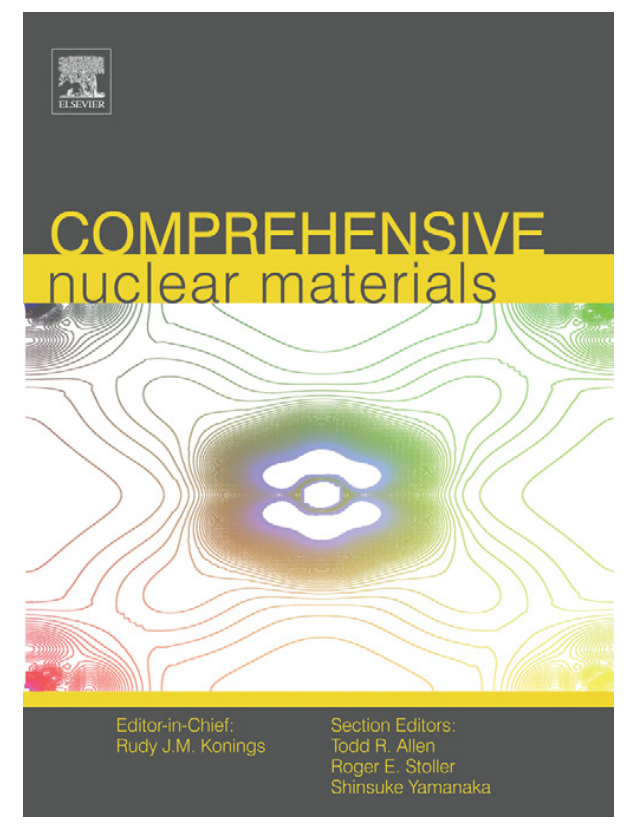

All other uses, reproduction and distribution, including without limitation commercial reprints, selling or licensing copies or access, or posting on open internet sites, your personal or institution's website or repository, are prohibited. For exceptions, permission may be sought for such use through Elsevier's permissions site at:

http://www.elsevier.com/locate/permissionusematerial

Zinkle S.J. (2012) Radiation-Induced Effects on Microstructure. In: Konings R.J.M., (ed.) Comprehensive Nuclear Materials, volume 1, pp. 65-98 Amsterdam: Elsevier.

(C) 2012 Elsevier Ltd. All rights reserved. 


\subsection{Radiation-Induced Effects on Microstructure*}

\section{S. J. Zinkle}

Oak Ridge National Laboratory, Oak Ridge, TN, USA

(C) 2012 Elsevier Ltd. All rights reserved.

1.03 .1

1.03 .2

1.03 .3

1.03.3.1

1.03.3.2

1.03.3.3

1.03.3.3.1

1.03.3.3.2

1.03.3.3.3

1.03.3.3.4

1.03.3.3.5

1.03.3.4

1.03.3.5

1.03.3.6

1.03.3.7

1.03.3.8

1.03.3.9

1.03 .4

1.03.4.1

1.03 .4 .2

1.03.4.3

1.03.4.4

1.03 .4 .5

1.03.4.6

1.03 .5

1.03.5.1

1.03.5.2

1.03.5.3

1.03.5.4

1.03.5.5

1.03.5.6

1.03.5.7

1.03.6

References

Introduction 66

Overview of Defect Cluster Geometries in Irradiated Materials 66

Influence of Experimental Conditions on Irradiated Microstructure $\quad 67$

$\begin{array}{ll}\text { Irradiation Dose } & 67\end{array}$

Role of Primary Knock-on Atom (PKA) Spectra 68

Role of Irradiation Temperature $\quad 70$

Very low temperature regime: immobile SIAs ( $T<$ Stage I) 71

Low temperature regime: mobile SIAs, immobile vacancies (Stage I $<T<$ Stage III) 72

Medium temperature regime: mobile SIAs and vacancies

$\begin{array}{ll}\text { (Stage } I I l<T<\text { Stage V) } & 72\end{array}$

High temperature regime: mobile defects and vacancy loop

dissociation ( $T>$ Stage $V$ )

Very high temperature regime: He cavities ( $T \gg$ Stage $V$ )

$\begin{array}{ll}\text { Role of Atomic Weight } & 77\end{array}$

$\begin{array}{ll}\text { Role of Crystal Structure } & 78\end{array}$

$\begin{array}{ll}\text { Role of Atomic Bonding } & 78\end{array}$

$\begin{array}{ll}\text { Role of Dose Rate } & 79\end{array}$

Role of lonizing Radiation $\quad 80$

Role of Solute Segregation and Precipitation 82

Overview of Key Radiation-Induced Property Degradation Phenomena 83

Radiation-Induced Amorphization $\quad 83$

Radiation-Induced Hardening 84

Thermal and Electrical Conductivity Degradation $\quad 85$

Radiation-Induced Segregation and Precipitation $\quad 85$

Dimensional Instabilities: Irradiation Growth, Creep, and Swelling 86

High Temperature Embrittlement $\quad 87$

Examples of Radiation-Induced Microstructural Changes 88

Dislocation Loop Formation $\quad 88$

$\begin{array}{ll}\text { Network Dislocation Formation } & 89\end{array}$

$\begin{array}{ll}\text { Stacking Fault Tetrahedra } & 89\end{array}$

Dislocation Channeling and Flow Localization $\quad 90$

Crystalline to Amorphous Phase Transitions $\quad 91$

Radiation-Induced Precipitation $\quad 91$

$\begin{array}{ll}\text { Cavity Formation } & 92\end{array}$

$\begin{array}{ll}\text { Summary } & 93\end{array}$

\section{Abbreviations \\ appm Atomic parts per million \\ bcc Body-centered cubic \\ dpa Displacements per atom}

*Prepared for the Oak Ridge National Laboratory under Contract No. DE-AC05-000R22725

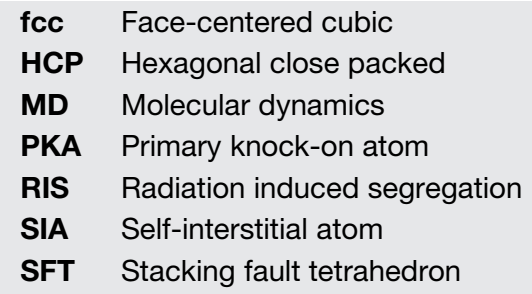


TEM Transmission electron microscope

$\mathbf{T}_{\mathbf{M}} \quad$ Melting temperature

\subsubsection{Introduction}

Irradiation of materials with particles that are sufficiently energetic to create atomic displacements can induce significant microstructural alteration, ranging from crystalline-to-amorphous phase transitions to the generation of large concentrations of point defect or solute aggregates in crystalline lattices. These microstructural changes typically cause significant changes in the physical and mechanical properties of the irradiated material. A variety of advanced microstructural characterization tools are available to examine the microstructural changes induced by particle irradiation, including electron microscopy, atom probe field ion microscopy, X-ray scattering and spectrometry, Rutherford backscattering spectrometry, nuclear reaction analysis, and neutron scattering and spectrometry. ${ }^{1,2}$ Numerous reviews, which summarize the microstructural changes in materials associated with electron ${ }^{3-6}$ and heavy ion or neutron ${ }^{4,7-20}$ irradiation, have been published. These reviews have focused on pure metals ${ }^{5-10,12-14,16,19}$ as well as model alloys, ${ }^{3,9,13,14}$ steels, ${ }^{11,20}$ and ceramic ${ }^{3,4,15,17,18}$ materials.

In this chapter, the commonly observed defect cluster morphologies produced by particle irradiation are summarized and an overview is presented on some of the key physical parameters that have a major influence on microstructural evolution of irradiated materials. The relationship between microstructural changes and evolution of physical and mechanical properties is then summarized, with particular emphasis on eight key radiation-induced property degradation phenomena. Typical examples of irradiated microstructures of metals and ceramic materials are presented. Radiation-induced changes in the microstructure of organic materials such as polymers are not discussed in this overview.

\subsubsection{Overview of Defect Cluster Geometries in Irradiated Materials}

A wide range of defect cluster morphologies can be created by particle irradiation. $8,21,22$ The thermodynamic stability of these defect cluster geometries is dependent on the host material and defect cluster size as well as the potential presence of impurities. There are four common geometric configurations for clusters of vacancies and self-interstitial atoms (SIAs): two planar dislocation loop configurations (faulted and perfect loops) that occur for both vacancies and SIAs, and two three-dimensional configurations that occur only for vacancy clusters (the stacking fault tetrahedron, SFT, and cavities).

The faulted loop (also called Frank loop) is most easily visualized as either insertion or removal of a layer of atoms, creating a corresponding extrinsic or intrinsic stacking fault associated with condensation of a planar monolayer of vacancies and SIAs, respectively. The faulted loop generally forms on close packed planes, i.e., $\{111\}$ habit planes with a Burgers vector of $b=1 / 3\langle 111\rangle$ for face-centered cubic (fcc) materials, $\{110\}$ habit planes with $b=1 / 2\langle 110\rangle$ for body-centered cubic (bcc) metals, and $\{10 \overline{10}\}$ habit planes with $b=a / 2\langle 10 \overline{1} 0\rangle$ for hexagonal close packed (HCP) metals. ${ }^{23}$ Faulted loops with $b=a / 2$ [0001] on the (0001) basal plane are also observed in many irradiated HCP materials. All of these faulted loops are immobile (sessile). The high stacking fault energy of bcc metals inhibits faulted loop nucleation and growth, and favors formation of perfect loops. There have been several observations of faulted loops consisting of multiple atomic layers. ${ }^{8,21}$

The perfect loop in fcc materials is typically created from initially formed faulted loops by nucleation of an $a / 6\langle 112\rangle$ Shockley partial dislocation that sweeps across the surface of the faulted loop and thereby restores perfect stacking order by this atomic shear of one layer of atoms. The resultant Burgers vector in fcc materials is $a / 2\langle 110\rangle$, maintaining the $\{111\}$ loop habit planes. After unfaulting, rotation on the glide cylinder gradually changes the habit plane of the fcc perfect loop from $\{111\}$ to $\{110\}$ to create a pure edge loop geometry. After the loop rotates to the $\{110\}$ habit plane, the perfect loop is glissile. Experimental studies of irradiated fcc materials typically observe perfect loops on either $\{111\}$ or $\{110\}$ habit planes (or both), depending on the stage of the glide cylinder rotation process. The glissile perfect loop configurations for bcc materials consist of $b=a / 2\langle 111\rangle$ loops on $\{111\}$ habit planes and $b=a\langle 100\rangle$ loops on $\{100\}$ habit planes. The typical corresponding HCP perfect loop configuration is $b=a / 3\langle 11 \overline{2} 0\rangle$ on $\{11 \overline{2} 0\}$ prismatic habit planes.

SFTs are only observed in close-packed cubic structures (i.e. fcc materials). The classic SilcoxHirsch $^{24}$ mechanism for SFT formation is based on dissociation of $b=1 / 3\langle 111\rangle$ faulted loops into $a / 6\langle 110\rangle$ stair rod and $a / 6\langle 121\rangle$ Shockley partial dislocations on the acute intersecting $\{111\}$ planes. Interaction between the climbing Shockley partials creates $a / 6\langle 011\rangle$ stair rod dislocations along the 


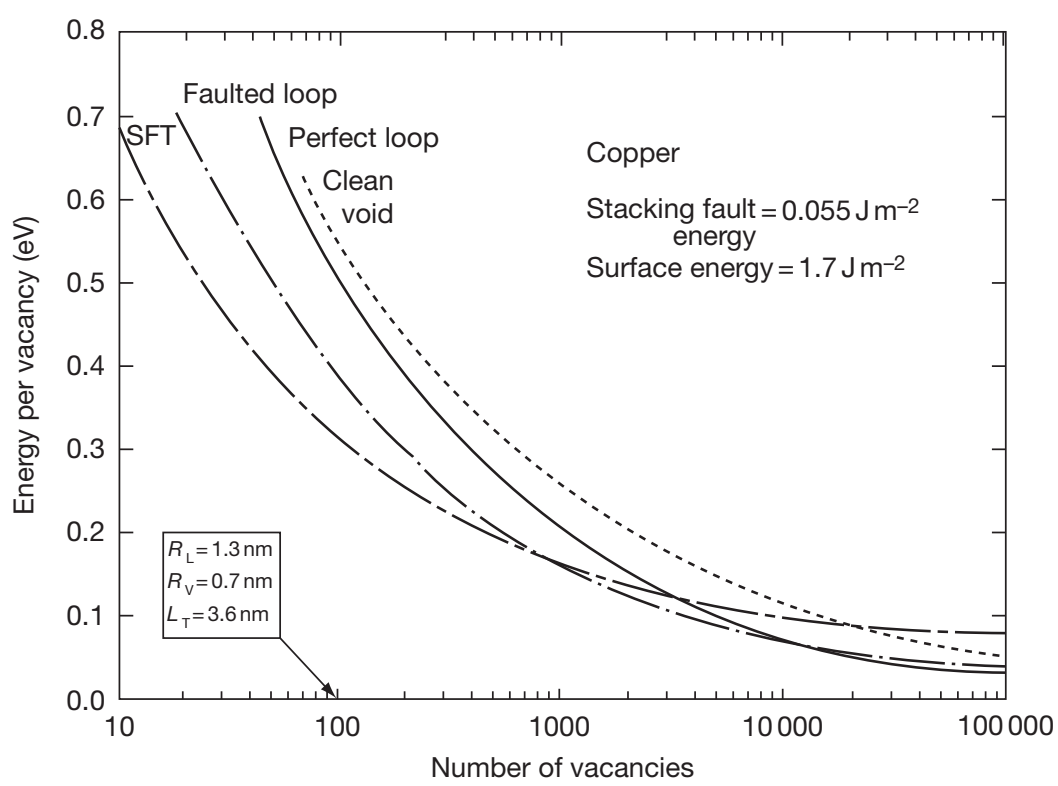

Figure 1 Comparison of calculated size-dependent energies for different vacancy cluster geometries in pure copper. Reproduced from Zinkle, S. J.; Seitzman, L. E.; Wolfer, W. G., Philos. Mag. A 1987, 55(1), 111-125.

tetrahedron edges. The Silcox-Hirsch mechanism has been verified during in situ transmission electron microscope (TEM) observation of vacancy loops in quenched gold. ${ }^{25}$ Evidence from molecular dynamics (MD) simulations ${ }^{26-29}$ and TEM observations ${ }^{12,19,30-32}$ during in situ or postirradiation studies indicate that SFT formation can occur directly within the vacancyrich cascade core during the 'thermal spike' phase of energetic displacement cascades.

There is an important distinction between the definitions for the terms void, bubble, and cavity, all of which describe a three-dimensional vacancy cluster that is roughly spherical in shape. Void refers to an object whose stability is not dependent on the presence of internal pressurization from a gaseous species such as helium. Bubbles are defined as pressurized cavities. The term cavity can be used to refer to either voids or bubbles and is often used as a generic term for both cases. In many cases, voids exhibit facets (e.g. truncated octahedron for fcc metals) that correspond with closepacked planes of the host lattice, whereas bubbles are generally spherical in shape. However, the absence of facets cannot be used as conclusive evidence to discriminate between a void and a bubble.

Figure 1 shows the calculated energy for different vacancy geometries in pure fcc copper. ${ }^{22}$ The SFT is calculated to be the most energetically favorable configuration in copper for small sizes (up to about $4 \mathrm{~nm}$ edge lengths). Faulted loops are calculated to be stable at intermediate sizes, and perfect loops are calculated to be most stable at larger sizes. In practice, many metastable defect cluster geometries may occur. For example, it is well established that the transition from faulted to perfect loops is typically triggered by localized stress such as physical impingement of adjoining loops, and not simply by loop energies; the activation energy barrier for unfaulting may be on the order of $1 \mathrm{eV}$ atom $^{-1.8}$. Similarly, large activation energy barriers exist for the conversion between planar loops and voids. ${ }^{33}$

\subsubsection{Influence of Experimental Conditions on Irradiated Microstructure}

\subsubsection{Irradiation Dose}

As discussed in Chapter 1.01, Fundamental Properties of Defects in Metals; Chapter 1.02, Fundamental Point Defect Properties in Ceramics; and Chapter 1.11, Primary Radiation Damage Formation, the international standardized displacement per atom (dpa) unit for radiation damage ${ }^{34}$ is a useful parameter for comparing displacement damage levels in a variety of irradiation environments. The calculated damage level is directly proportional to the product of the fluence and the average kinetic energy transferred to the host lattice atoms (damage energy). The effective damage cross-sections for $1 \mathrm{MeV}$ particles incident on copper range from $\sim 30$ barns ( 1 barn $=1 \times 10^{-24} \mathrm{~cm}^{2}$ ) for electrons ${ }^{35}$ to $\sim 600$ barns for neutrons $^{36}$ and $\sim 2 \times 10^{9}$ barns for $\mathrm{Cu}$ ions. $^{37}$ 
The dpa unit is remarkably effective in correlating the initial damage production levels over a wide range of materials and irradiating particles and is the singular most important parameter for quantifying radiation effects in materials. Numerous aspects of microstructural evolution are qualitatively equivalent on a dpa basis for materials irradiated in widely different irradiation environments. However, the dpa unit does not accurately capture some of the complex differences in primary damage production for energetic displacement cascade conditions compared to isolated Frenkel pair production. ${ }^{38}$ For example, defect production at cryogenic temperatures (where long-range defect migration and annihilation does not occur) for neutron and heavy ion-irradiated materials is about $20-30 \%$ of the calculated dpa value due to athermal in-cascade recombination processes. ${ }^{38,39}$ In addition, the accumulated damage, as evident in the form of point defect clusters or other microstructural features, typically exhibits a complex nonlinear relationship with irradiation dose that depends on irradiation temperature and several other factors. The impact of other experimental variables on the dosedependent damage accumulation behavior is discussed in Sections 1.03.3.2-1.03.3.9.

\subsubsection{Role of Primary Knock-on Atom (PKA) Spectra}

Displacement damage can occur in materials when the energy transferred to lattice atoms exceeds a critical value known as the threshold displacement energy $\left(E_{\mathrm{d}}\right)$, which has a typical value of $30-50 \mathrm{eV}^{8,18,40}$ Figure 2 shows an example of the effect of bombarding energy on the microstructure of $\mathrm{CeO}_{2}$ during electron irradiation near room temperature. ${ }^{41}$ The loop density increases rapidly with increasing energy above $200 \mathrm{keV}$, suggesting that $200 \mathrm{keV}$ electrons transfer elastic energy that is slightly above the threshold displacement energy. High-resolution microstructural analysis determined that the dislocation loops were associated with aggregation of oxygen ions only (i.e., no Ce displacement damage) for electron energies up to $1250 \mathrm{keV}$, whereas perfect interstitial-type dislocation loops were formed for electron energies of $1500 \mathrm{keV}$ and higher. Therefore, the corresponding displacement energies in $\mathrm{CeO}_{2}$ are $\sim 30$ and $\sim 50 \mathrm{eV}$ for the $\mathrm{O}$ and Ce sublattices, respectively. ${ }^{41}$

A wide range of PKA energies can be achieved during irradiation, depending on the type and energy of irradiating particle. For example, the average PKA energies transferred to a $\mathrm{Cu}$ lattice for $1 \mathrm{MeV}$ electrons, protons, $\mathrm{Ne}$ ions, $\mathrm{Xe}$ ions, and neutrons are $25 \mathrm{eV}, 0.5 \mathrm{keV}, 9 \mathrm{keV}, 50 \mathrm{keV}$, and $45 \mathrm{keV}$, respectively. ${ }^{42}$ Irradiation of materials with electrons and light ions introduces predominantly isolated SIAs and vacancies (together known as Frenkel pairs) and small clusters of these point defects, because of the low average recoil atom energies of $\sim 0.1-1 \mathrm{keV}$. Conversely, energetic neutron or heavy ion irradiations produce energetic displacement cascades that can lead to direct formation of defect clusters within isolated displacement cascades due to more energetic average recoil atom energies that exceed $10 \mathrm{keV}$. Figure 3 compares the weighted PKA energy values for several irradiation species. 40,42

These differences in PKA energy produce significant changes in primary damage state that can have a pronounced effect on the microstructural evolution observed during irradiation. As briefly mentioned in Section 1.03.3.1, the defect production efficiency per dpa determined from electrical resistivity measurements during irradiation near absolute zero and MD simulation studies is significantly lower (by about
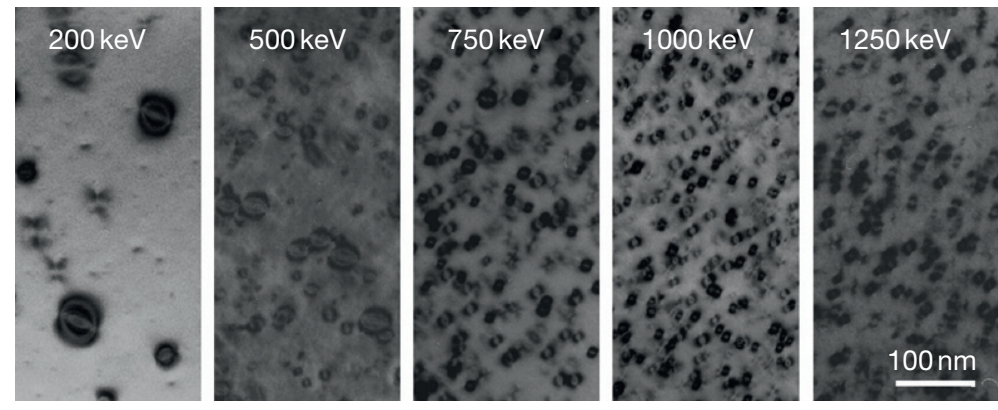

Figure 2 Bright-field images of interstitial-type nonstoichiometric dislocation loops formed in $\mathrm{CeO}_{2}$ during 200-1250 keV electron irradiation to a fluence of $\sim 3 \times 10^{26}$ electrons per square meter at room temperature. The beam direction is along [011] and the diffraction vector is $g=11 \overline{1}$. Reproduced from Yasunaga, K.; Yasuda, K.; Matsumura, S.; Sonoda, T. Nucl. Instrum. Methods Phys. Res. B 2008, 266(12-13), 2877-2881. 


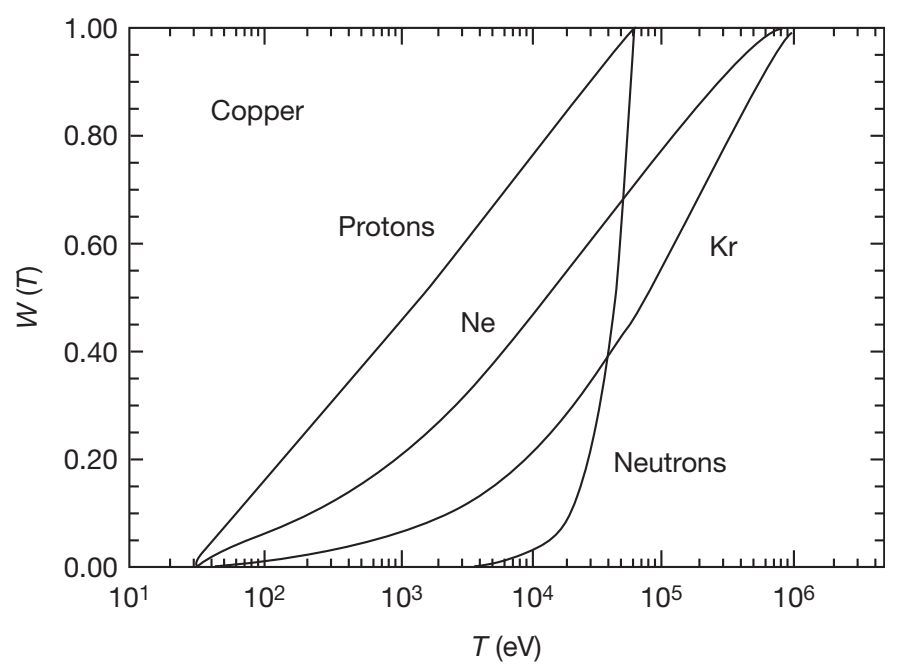

Figure 3 Weighted average recoil atom energy for $1 \mathrm{MeV}$ particles in copper, plotted as a function of recoil energy $(T)$. Reproduced from Averback, R. S. J. Nucl. Mater. 1994, 216, 49-62.

a factor of 3-4) for energetic displacement cascade conditions compared to isolated Frenkel pair conditions, due to pronounced in-cascade recombination and clustering processes. ${ }^{38,39}$ MD computer simulations ${ }^{43-46}$ and in situ or postirradiation thin foil experimental studies ${ }^{13,14,47,48}$ (where interaction between different displacement damage events is minimal due to the strong influence of the surface as a point defect sink) have found that defect clusters visible by transmission electron microscopy (TEM) can be produced directly in displacement cascades if the average PKA energy exceeds 5-10 keV. Irradiations with particles having significantly lower PKA energies typically produce isolated Frenkel pairs and submicroscopic defect clusters that can nucleate and coarsen via diffusional processes. The microstructural evolution of an irradiated material is controlled by different kinetic equations if initial defect clustering occurs directly within the displacement cascade $(\sim 0.1-1$ ps timescale) versus three-dimensional random walk diffusion to produce defect cluster nucleation and growth, particularly if some of the in-cascade created defect clusters exhibit one-dimensional glide. ${ }^{4-52}$ As discussed in Chapter 1.13, Radiation Damage Theory, this can produce significant differences in the microstructural evolution for features such as voids and dislocation loops. Figure 4 compares the microstructure produced in copper following irradiation near $200^{\circ} \mathrm{C}$ with fission neutrons ${ }^{53}$ and $1 \mathrm{MeV}$ electrons. ${ }^{54,55}$ Vacancies and SIAs are fully mobile in copper at this temperature. The $1 \mathrm{MeV}$ electron produces a steady flux of point defects that leads to the

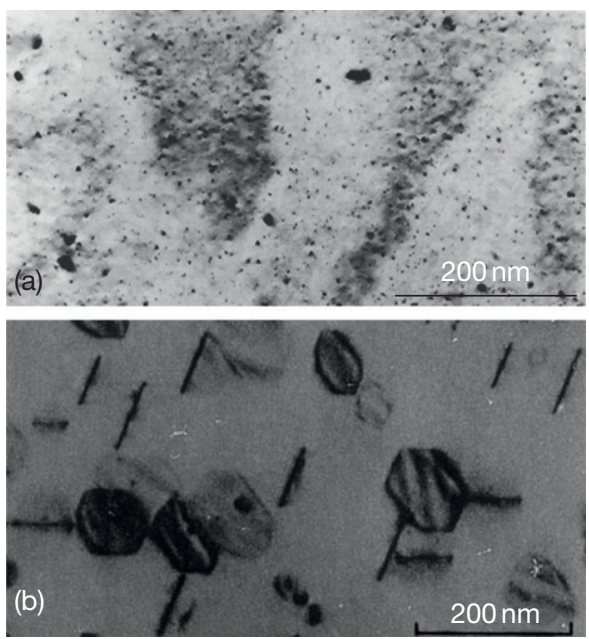

Figure 4 Comparison of the microstructure of copper irradiated near $200^{\circ} \mathrm{C}$ with (a) fission neutrons (reproduced from Zinkle, S. J.; Sindelar, R. L. J. Nucl. Mater. 1988, 155-157, 1196-1200) and (b) $1 \mathrm{MeV}$ electrons (modified from Kiritani, M. Ultramicroscopy 1991, 39(1-4), 180-186; Kiritani, M.; Takata, H. J. Nucl. Mater. 1978, 69-70, 277-309).

creation of a moderate density of large faulted interstitial loops. On the other hand, the creation of SFTs and small dislocation loops directly in fission neutron displacement cascades creates a high density $\left(\sim 2 \times 10^{23} \mathrm{~m}^{-3}\right)$ of small defect clusters, and the high point defect sink strength associated with these defect clusters inhibits the growth of dislocation loops. As shown in Figure 4, the net result is a dramatic qualitative and quantitative 
difference in the irradiated microstructure due to differences in the PKA spectrum.

Electron microscopy ${ }^{48,56}$ and binary collision ${ }^{48,57}$ and MD simulation ${ }^{45}$ studies have found that irradiation with PKA energies above a critical materialdependent value of $\sim 10-50 \mathrm{keV}$ results in formation of multiple subcascades (rather than an everincreasing single cascade size), with the size of the largest subcascades being qualitatively similar to an isolated cascade at a PKA energy near the critical value. Figure 5 compares MD simulations of the peak displacement configurations of PKAs in iron with energies ranging from 1 to $50 \mathrm{keV}^{58}$ At low PKA energies, the size of the displacement cascade increases monotonically with PKA energy. When the PKA energy in Fe exceeds a critical value of $\sim 10 \mathrm{keV}$, multiple subcascades begin to appear, with the largest subcascade having a size comparable to the $10 \mathrm{keV}$ cascades. The number of subcascades increases with increasing PKA energy, reaching $\sim 5$ subcascades for a PKA energy of $50 \mathrm{keV}$ in Fe. A fortunate consequence of subcascade formation is that fission reactor irradiations $(\sim 1 \mathrm{MeV}$ neutrons) can be used for initial radiation damage screening studies of potential future fusion reactor ( $\sim 14 \mathrm{MeV}$ neutrons) materials, since both would have comparable primary damage subcascade structures. ${ }^{59,60}$ Further details on the effect of PKA spectrum on primary damage formation



Figure 5 Comparison of the molecular dynamics simulations of 1-50 keV PKA displacement cascades in iron. PKA energies of 1 (red), 10 (green), and 50 (blue) keV for times corresponding to the transient peak number of displaced atoms are shown. The length of the $Z$ (horizontal) dimension of the simulation box is 170 lattice parameters $(49 \mathrm{~nm})$. Adapted from Stoller, R. E., Oak Ridge National Lab, Private communication, 2010. are given in Chapter 1.11, Primary Radiation Damage Formation.

\subsubsection{Role of Irradiation Temperature}

Irradiation temperature typically invokes a very large influence on the microstructural evolution of irradiated materials. There are several major temperature regimes delineated by the onset of migration of point defects. Early experimental studies used isochronal annealing electrical resistivity measurements on metals irradiated near absolute zero temperature to identify five major defect recovery stages. ${ }^{61-64}$ Figure 6 shows the five major defect recovery stages for copper irradiated with electrons at $4 \mathrm{~K}^{65}$ The quantitative magnitude of the defect recovery in each of the stages generally depends on material, purity, PKA spectrum, and dose. Based on the currently accepted one-interstitial model, Stage I corresponds to the onset of long-range SIA migration. Stage I often consists of several visible substages that have been associated with close-pair (correlated) recombination of Frenkel defects from the same displacement event and long range uncorrelated recombination of defects from different primary displacement events. Stage II involves migration of small SIA clusters and SIA-impurity complexes. Stage III corresponds to the onset of vacancy motion. Stage IV involves migration of vacancy-impurity clusters, and Stage $V$ corresponds to thermal dissociation of sessile vacancy clusters. It should be noted that the specific recovery stage temperature depends on the annealing time (typically 10 or $15 \mathrm{~min}$ in the resistivity studies), and therefore needs to be adjusted to lower values when considering the onset temperatures for defect migration in typical

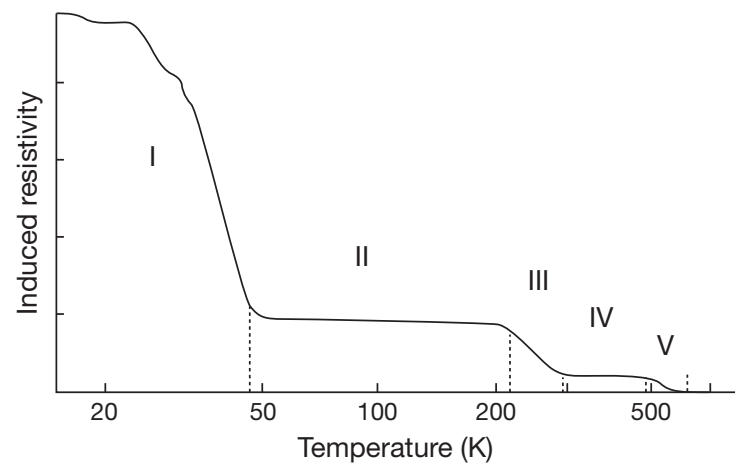

Figure 6 Electrical resistivity defect recovery stages for copper following electron irradiation at $4 \mathrm{~K}$. Reproduced from Agullo-Lopez, F.; Catlow, C. R. A.; Townsend, P. D., Point Defects in Materials. Academic Press: San Diego, CA, 1988; p 445. 
Table 1 Summary of defect recovery stage temperatures for materials ${ }^{8,18,63,66-69}$

\begin{tabular}{|c|c|c|c|c|c|}
\hline Material & Melting temperature (K) & Crystal structure & Stage I (K) & Stage III (K) & Stage $V(K)$ \\
\hline $\mathrm{Pb}$ & 601 & fcc & 5 & 150 & 300 \\
\hline $\mathrm{Al}$ & 933 & fcc & 35 & 220 & \\
\hline $\mathrm{Ag}$ & 1233 & fcc & 35 & 240 & 540 \\
\hline $\mathrm{Au}$ & 1337 & fcc & $<4$ & 290 & 530 \\
\hline $\mathrm{Cu}$ & 1357 & fcc & 50 & 270 & 550 \\
\hline $\mathrm{Ni}$ & 1726 & fcc & 60 & 350 & \\
\hline $\mathrm{Pd}$ & 1825 & fcc & 50 & $\sim 350$ & \\
\hline $\mathrm{Pt}$ & 2045 & fcc & 30 & $\sim 350$ & \\
\hline $\mathrm{Rh}$ & 2236 & fcc & 32 & $\sim 500$ & \\
\hline $\mathrm{SiC}$ & 3103 & cubic & 220 (C) 450 (Si) & $\sim 1400$ (C) 1050 (Si) & \\
\hline$\alpha-\mathrm{Fe}$ & 1809 & bcc & 110 & 230 & \\
\hline $\mathrm{Cr}$ & 2130 & bcc & 40 & 380 & \\
\hline V & 2175 & bcc & $<6$ & 220 & \\
\hline $\mathrm{Nb}$ & 2740 & bcc & 5 & 230 & \\
\hline Mo & 2890 & $\mathrm{bcc}$ & 40 & 470 & \\
\hline $\mathrm{Ta}$ & 3287 & $\mathrm{bcc}$ & 10 & 270 & \\
\hline W & 3680 & bcc & 30 & 650 & \\
\hline $\mathrm{Cd}$ & 594 & $\mathrm{HCP}$ & $<4$ & 120 & \\
\hline $\mathrm{Zn}$ & 693 & $\mathrm{HCP}$ & 18 & 125 & \\
\hline $\mathrm{Mg}$ & 922 & $\mathrm{HCP}$ & 13 & 130 & \\
\hline $\mathrm{Ti}$ & 1043 & $\mathrm{HCP}$ & 120 & 250 & \\
\hline $\mathrm{Be}$ & 1560 & $\mathrm{HCP}$ & 45 & 280 & \\
\hline Co & 1768 & $\mathrm{HCP}$ & 55 & 310 & \\
\hline $\mathrm{Zr}$ & 2125 & HCP & 150 & 270 & \\
\hline $\mathrm{Re}$ & 3453 & $\mathrm{HCP}$ & 100 & 630 & 1180 \\
\hline $\mathrm{Al}_{2} \mathrm{O}_{3}$ & 2324 & $\mathrm{HCP}$ & $\sim 150$ & $\sim 850$ & \\
\hline
\end{tabular}

Source: Eyre, B. L. J. Phys. F 1973, 3(2), 422-470.

Zinkle, S. J.; Kinoshita, C. J. Nucl. Mater. 1997, 251, 200-217.

Schilling, W.; Ehrhart, P.; Sonnenberg, K. In Fundamental Aspects of Radiation Damage in Metals, CONF-751006-P1; Robinson, M. T.; Young, F. W., Jr., Eds. National Tech. Inform. Service: Springfield, VA, 1975; Vol. I, pp 470-492.

Hautojarvi, P.; Pollanen, L.; Vehanen, A.; Yli-Kauppila, J. J. Nucl. Mater. 1983, 114(2-3), 250-259.

Lefevre, J.; Costantini, J. M.; Esnouf, S.; Petite, G. J. Appl. Phys. 2009, 106(8), 083509.

Schultz, H. Mater. Sci. Eng. A 1991, 141, 149-167.

Xu, Q.; Yoshiie, T.; Mori, H. J. Nucl. Mater. 2002, 307-311(2), 886-890.

Young, F. W., Jr. J. Nucl. Mater. 1978, 69/70, 310.

Hoffmann, A.; Willmeroth, A.; Vianden, R. Z. Phys. B 1986 62, 335.

Takamura, S.; Kobiyama, M. Rad. Eff. Def. Sol. 1980, 49(4), 247.

Kobiyama, M.; Takamura, S. Rad. Eff. Def. Sol. 1985, 84(3\&4), 161.

neutron irradiation experiments that may occur over time scales of months or years. Table 1 provides a summary of defect recovery stage temperatures for several fcc, bcc, and HCP materials. ${ }^{8,18,63,66-69}$ Although there is a general correlation of the recovery temperatures with melting temperature, Table 1 shows there are several significant exceptions. For example, Pt has one of the lowest Stage I temperatures among fcc metals despite having a very high melting temperature. Similarly, Cr has a much higher Stage III temperature than $\mathrm{V}$ or $\mathrm{Nb}$ that have higher melting points. As illustrated later in this chapter, the microstructures of different materials with the same crystal structure and irradiated within the same recovery stage temperature regime are generally qualitatively similar.
Several analytic kinetic rate theory models have been developed to express the dose dependence of defect cluster accumulation in materials at different temperature regimes. ${ }^{6,70-72}$ In the following, summaries are provided on the experimental microstructural observations for five key irradiation temperature regimes.

\subsection{Very low temperature regime: immobile SIAs ( $T<$ Stage I)}

At very low temperatures where defect migration does not occur, defect accumulation is typically proportional to dose until the defect concentration approaches the level where defects created in displacement events begin to overlap and annihilate preexisting defects created earlier in the irradiation 


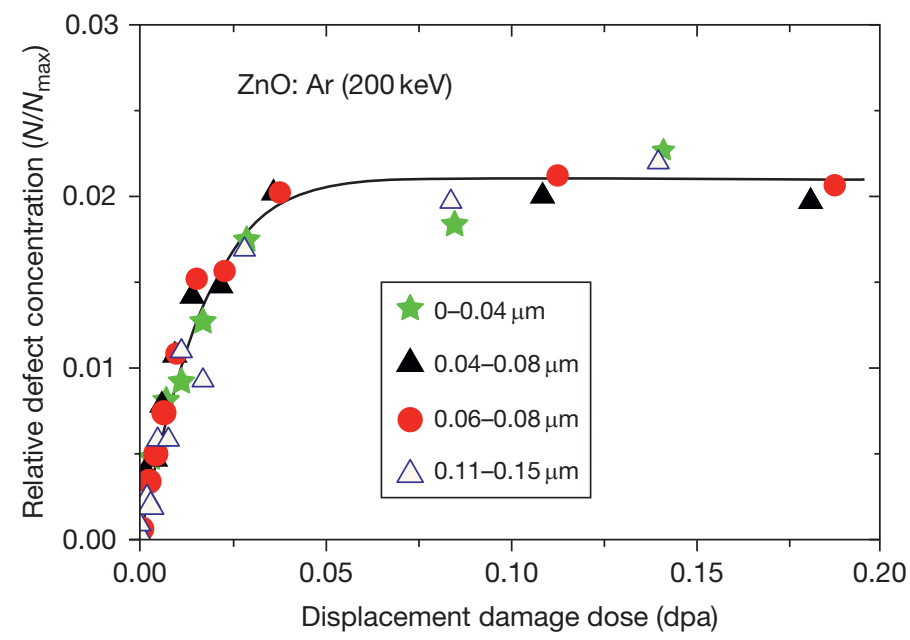

Figure 7 Defect concentration normalized to the total atom concentration $\mathrm{N}_{\max }$ at four different depths in $\mathrm{ZnO}$ irradiated with $200 \mathrm{keV}$ Ar ions at $15 \mathrm{~K}$ as determined by Rutherford backscattering spectrometry. Reproduced from Wendler, E.; Bilani, O.; Gärtner, K.; et al. Nucl. Instrum. Methods Phys. Res. B 2009, 267(16), 2708-2711.

exposure. The defect accumulation kinetics ${ }^{73}$ can be described by $N=N_{\max }[1-\exp (-A \phi t)]$, where the parameter $A$ is determined by the spontaneous recombination volume for point defects or the cascade overlap annihilation volume for defect clusters and $\phi t$ is the product of the irradiation flux and time. Due to the lack of defect mobility, defect clusters resolvable by TEM are usually not visible in this irradiation temperature regime unless they are created directly in displacement cascades by energetic PKAs. ${ }^{74}$ Saturation in the defect concentration typically occurs after $\sim 0.1 \mathrm{dpa}$ as monitored by atomic disorder, ${ }^{75-77}$ electrical resistivity, ${ }^{78-82}$ and dimensional change. ${ }^{83-85}$ Due to the large increase in free energy associated with lattice disordering and defect accumulation, amorphization typically occurs in this temperature regime in many ceramics ${ }^{15,85,86}$ and ordered metallic alloys ${ }^{87,88}$ for doses above $\sim 0.1$ $0.5 \mathrm{dpa}$. Figure 7 shows an example of the dosedependent defect concentration in ion-irradiated $\mathrm{ZnO}$ at $15 \mathrm{~K}$ as determined by Rutherford backscattering spectrometry. ${ }^{89}$

\subsection{Low temperature regime: mobile SIAs, immobile vacancies (Stage $I<T<$ Stage III)}

Between recovery Stage I and Stage III, the SIA point defects and small SIA clusters have sufficient mobility to migrate and form visible dislocation loops as well as recombine with sessile monovacancies and vacancy clusters. The defect accumulation in this temperature regime is initially linear with dose when the defect concentration is too low for uncorrelated recombination to be a significant contribution, but then transitions to a square root dependence at an intermediate dose in pure materials when interaction between defects from different PKA events becomes important. ${ }^{6,70-72,90}$ The critical dose for this kinetic transition is dependent on the concentration of other defect sinks in the lattice (dislocations, grain boundaries, precipitates, etc.). The high sink strength associated with the immobile vacancies limits the growth rate (i.e., size) of the SIA loops for doses above $\sim 0.1 \mathrm{dpa}$, and the observable defect cluster size and density typically approach a constant value at higher doses. Figure 8 shows an example of the microstructure of AIN following ion irradiation at $80 \mathrm{~K}$ (mobile SIAs, immobile vacancies) to a damage level of about $5 \mathrm{dpa}^{91}$ The microstructure consists of small ( $<5 \mathrm{~nm}$ diameter) interstitial dislocation loops.

\subsection{Medium temperature regime: mobile SIAs and vacancies (Stage III $<T<$ Stage V)}

At temperatures where both SIAs and vacancies are mobile, the defect cluster evolution is complex due to the wide range of defect cluster geometries that can be nucleated. ${ }^{8,47,92,93}$ The predominant visible features in this temperature regime are vacancy and interstitial loops and SFTs for irradiated fcc materials and vacancy and interstitial loops and voids for irradiated bcc materials. For medium- to highatomic number fcc metals exposed to energetic displacement cascades (e.g., fast neutron and heavy ion irradiation), most of the vacancies are tied up in 


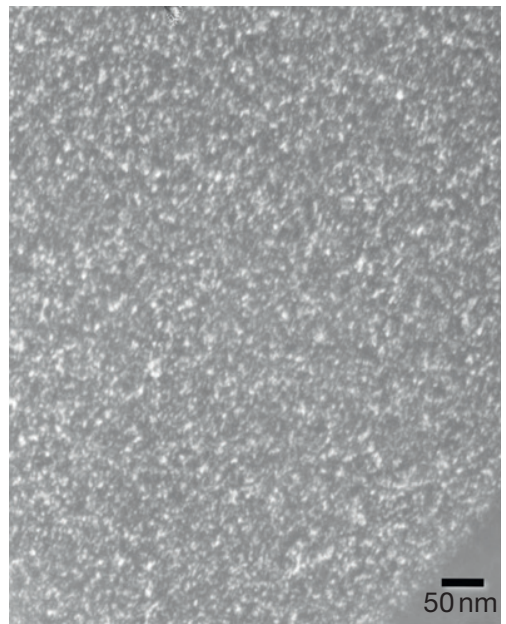

Figure 8 Weak beam microstructure of dislocation loops in AIN after $2 \mathrm{MeV}$ Si ion irradiation to $\sim 5 \mathrm{dpa}$ at $80 \mathrm{~K}$. The TEM figure is based on irradiated specimens described in Zinkle et al. ${ }^{91}$

sessile vacancy clusters (SFTs, vacancy loops) that are formed directly in the displacement cascades. As a consequence, the majority of observed dislocation loops in fcc metals in this temperature and PKA regime are extrinsic (interstitial type), and void nucleation and growth is strongly suppressed. For bcc metals, the amount of in-cascade clustering into sessile defect clusters is less pronounced, and therefore, vacancy loop and void swelling are observed in addition to interstitial dislocation loop evolution. Due to the typical high sink strength of interstitial clusters in this temperature regime, the magnitude of void swelling is generally very small $(<1 \%$ for doses up to $10 \mathrm{dpa}$ or higher). The loop density and nature in bcc metals is strongly dependent on impurity content in this temperature regime. ${ }^{5,8,55}$ For example, the loop concentration in molybdenum irradiated with fission neutrons at $200{ }^{\circ} \mathrm{C}$ is much higher in low-purity Mo with $\sim 99 \%$ of the loops identified as interstitial type, whereas $\sim 90 \%$ of the loops were identified to be vacancy type in high-purity Mo irradiated under the same conditions. ${ }^{8}$

The dose dependence of defect cluster accumulation in this temperature regime is dependent on the material and defect cluster type. For dislocation loops and SFTs in fcc metals, the defect accumulation is initially linear and may exhibit an extended intermediate regime with square root kinetics before reaching a maximum concentration level. The maximum defect cluster density is largely determined by displacement cascade annihilation of preexisting defect clusters. In fcc metals, the defect cluster

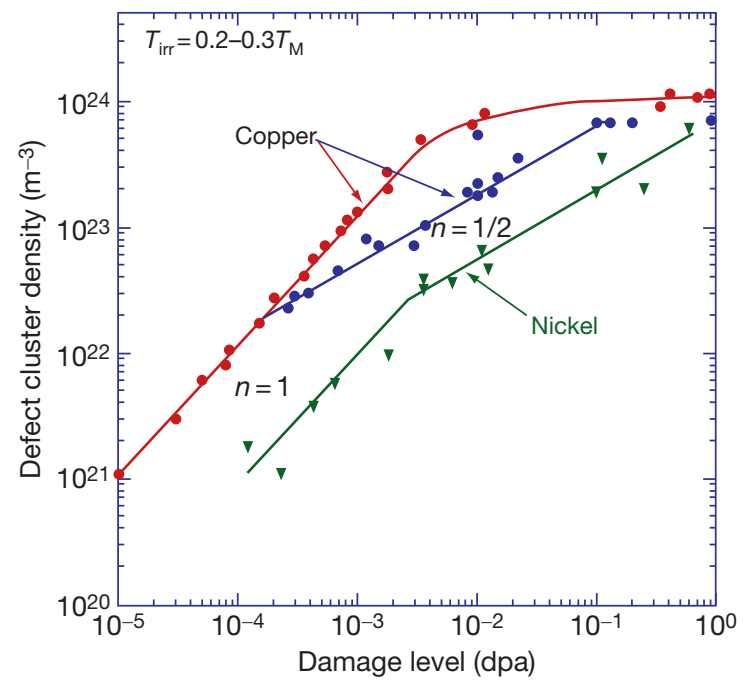

Figure 9 Defect cluster density in neutron-irradiated copper and nickel following fission reactor, $14 \mathrm{MeV}$, and spallation neutron irradiation near room temperature, as measured by TEM. Depending on the purity of the nominally high-purity copper, the defect cluster accumulation at intermediate doses ( 0.001-0.01 dpa) either exhibits a continuation of linear kinetics or switches to a square root accumulation behavior. Based on data reported by Zinkle ${ }^{94}$ and Hashimoto et al. ${ }^{95,96}$

density may approach $10^{24} \mathrm{~m}^{-3}$, which corresponds to a defect cluster spacing of less than $10 \mathrm{~nm}$ and is approximately equal to the maximum diameter of subcascades during the collisional phase in neutronirradiated metals. As with irradiation near recovery Stage II, the critical dose for transition in defect cluster accumulation kinetics is dependent on the overall defect sink strength. With continued irradiation, the loops may unfault and evolve into network dislocations, particularly if external stress is applied. Figure 9 summarizes the dose-dependent defect cluster densities in neutron-irradiated copper and nickel. ${ }^{94-96}$ In both of these materials, the predominant visible defect cluster was the SFT over the entire investigated dose and temperature regime. Depending on the purity of the copper investigated, the transition from linear to square root accumulation behavior may or may not be evident (cf. the differing behavior for $\mathrm{Cu}$ in Figure 9). The visible defect cluster density in irradiated copper reaches a constant saturation value (attributed to displacement cascade overlap with preexisting clusters) for damage levels above $\sim 0.1 \mathrm{dpa}$. The lower visible defect cluster density in $\mathrm{Ni}$ compared to $\mathrm{Cu}$ at doses up to $1 \mathrm{dpa}$ has been attributed to a longer thermal spike lifetime of the $\mathrm{Cu}$ displacement cascades due to inefficient 
coupling between electrons and phonons (thereby promoting more complete vacancy and interstitial clustering within the displacement cascade). ${ }^{97,98}$

Figure 10 compares the defect cluster accumulation behavior for two fcc metals $(\mathrm{Cu}, \mathrm{Ni})$ and two bcc metals $(\mathrm{Fe}, \mathrm{Mo})$ following fission neutron irradiation near room temperature. ${ }^{30,95,96,99-101}$ For all four materials, the increase in visible defect cluster density is initially proportional to dose. The visible defect cluster density is highest in $\mathrm{Cu}$ over the

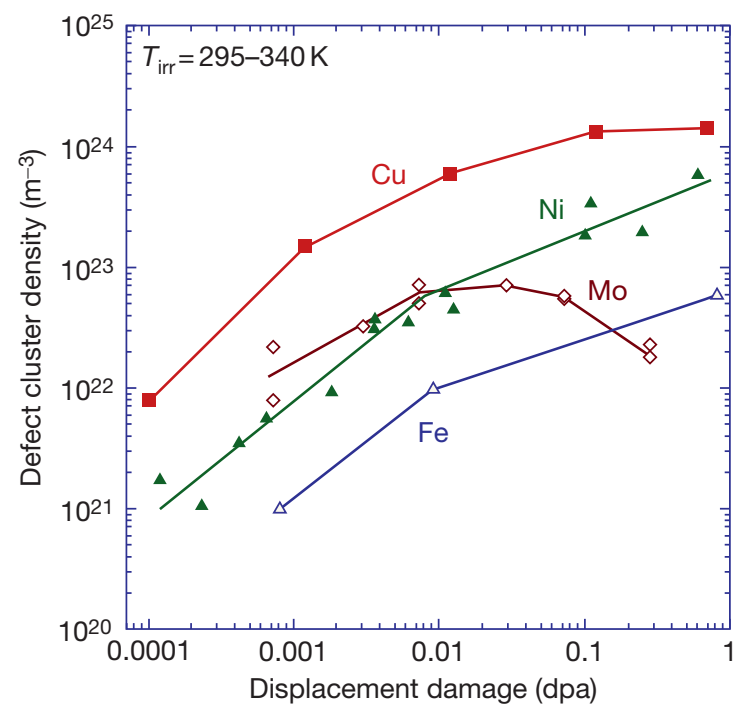

Figure 10 Defect cluster density in copper, nickel, molybdenum, and nickel following fission reactor and 14-MeV neutron irradiation near room temperature, as measured by TEM. Based on data reported by Kiritani ${ }^{30}$, Hashimoto et al. ${ }^{95,96}$, Eldrup et al. ${ }^{99}$, Zinkle and Singh ${ }^{100}$, and Li et al. ${ }^{101}$ investigated damage range of $10^{-4}-1 \mathrm{dpa}$. The irradiated Fe has the lowest visible density at low doses, whereas $\mathrm{Ni}$ and Mo have comparable visible cluster densities. At doses above $\sim 0.01 \mathrm{dpa}$, the visible loop density in Mo decreases due to loop coalescence in connection with the formation of aligned 'rafts' of loops. Partial formation of aligned loop rafts has also been observed in neutron-irradiated $\mathrm{Fe}$ for doses near $0.8 \mathrm{dpa}$, as shown in Figure $11 .^{100}$ The individual loops within the raft aggregations in neutronirradiated Fe exhibited the same Burgers vector. The maximum visible cluster density in the fcc metals is about one order of magnitude higher than in the bcc metals (due in part to loop coalescence associated with raft formation). Positron annihilation spectroscopy analyses suggest that submicroscopic cavities are present in the two irradiated bcc metals, with cavity densities that are about two orders of magnitude higher than the visible loop densities. ${ }^{99-102}$

\subsection{High temperature regime: mobile defects and vacancy loop dissociation ( $T>$ Stage $V$ )}

The typical microstructural features that appear during irradiation at temperatures above recovery Stage $\mathrm{V}$ include dislocation loops (vacancy and interstitial type), network dislocations, and cavities. SFTs are thermally unstable in this temperature regime and therefore only SFTs created in the latter stages of the irradiation exposure are visible during postirradiation examination. ${ }^{94}$ A variety of precipitates may also be nucleated in irradiated alloys. ${ }^{11,103-106}$ Defect cluster accumulation in this temperature regime exhibits
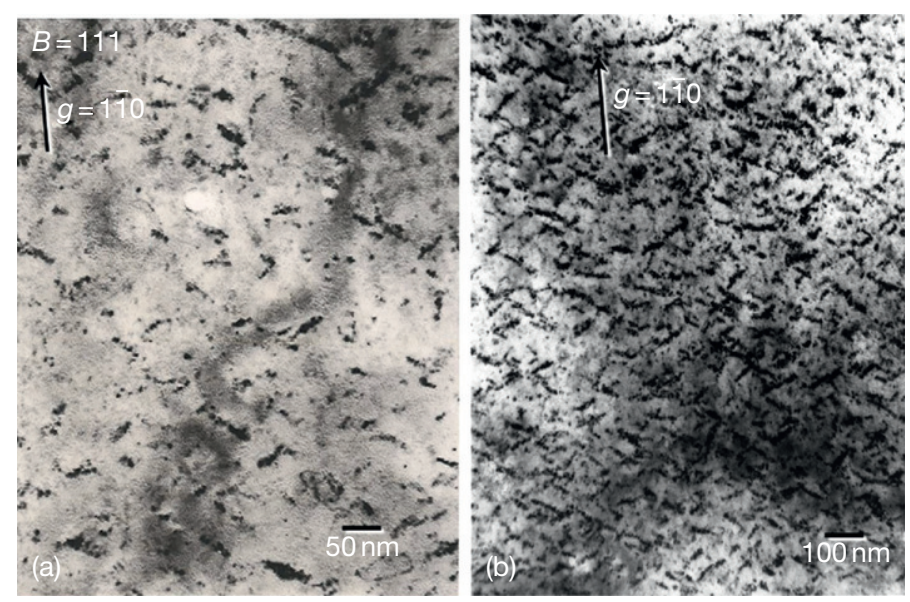

Figure 11 Examples of aligned rafts of dislocation loops in iron following fission neutron irradiation to $0.8 \mathrm{dpa}$ at $\sim 60^{\circ} \mathrm{C}$. The microstructure in thin (a) and thick (b) foil regions are shown. Reproduced from Zinkle, S. J.; Singh, B. N. J. Nucl. Mater. 2006, 351, 269-284. 
several different trends. The visible SIA clusters evolve from a low density of small loops to a saturation density of larger loops after damage levels of $\sim 1-10 \mathrm{dpa}$. Upon continued irradiation, a moderate density of network dislocations is created due to loop unfaulting and coalescence. The dislocation loop and network dislocation density monotonically decrease with increasing temperature above recovery Stage $V_{,}^{20,107}$ whereas the density of precipitates (if present) can either increase or decrease with increasing temperature.

The major microstructural difference from lower temperature irradiations in most materials is the emergence of significant levels of cavity swelling. After an initial transient regime associated with cavity nucleation, a prolonged linear accumulation of vacancies into voids is typically observed. ${ }^{108,109}$ The cavity density monotonically decreases with increasing temperature in this temperature regime. ${ }^{20,107,110}$ Figure $\mathbf{1 2}$ summarizes the densities of voids and helium bubbles (associated with $\mathrm{n}, \alpha$ transmutations) in austenitic stainless steel as a function of fission reactor irradiation temperature for damage rates near $1 \times 10^{-6} \mathrm{dpa} \mathrm{s}^{-1}$. $^{20}$ The bubble and void densities exhibit similar temperature dependences in fission reactor-irradiated austenitic stainless steel, with the bubble density approximately one order of magnitude higher than the void density between 400 and $650^{\circ} \mathrm{C}$. For neutron- irradiated copper and $\mathrm{Cu}-\mathrm{B}$ alloys, the bubble density is similarly observed to be about one order of magnitude larger than the void density for temperatures between 200 and $400{ }^{\circ} \mathrm{C} \cdot{ }^{107,110}$ At higher temperatures, the void density in copper decreases rapidly and becomes several orders of magnitude smaller than the bubble density. The results from several studies suggest that the lower temperature limits for formation of visible voids ${ }^{111-113}$ and helium bubbles ${ }^{53}$ can each be reduced by $100^{\circ} \mathrm{C}$ or more when the damage rate is decreased to $10^{-9}-10^{-8} \mathrm{dpa} \mathrm{s}^{-1}$, due to enhanced thermal annealing of sessile vacancy clusters during the time to achieve a given dose. Dose rate effects are discussed further in Section 1.03.3.7.

The void swelling regime for fcc materials typically extends from 0.35 to $0.6 T_{\mathrm{M}}$, where $T_{\mathrm{M}}$ is the melting temperature, with maximum swelling occurring near $0.4-0.45 T_{\mathrm{M}}$ for typical fission reactor neutron damage rates of $10^{-6} \mathrm{dpa} \mathrm{s}^{-1} \cdot{ }^{92,114}$ Figure 13 summarizes the temperature-dependent void swelling for neutron-irradiated copper. ${ }^{110}$ The results for a neutron-irradiated $\mathrm{Cu}-\mathrm{B}$ alloy, where $\sim 100$ atomic parts per million (appm) He was produced during the $1 \mathrm{dpa}$ irradiation due to thermal neutron transmutation reactions with the $\mathrm{B}$ solute, are also shown in this figure. ${ }^{107}$ For both materials the onset

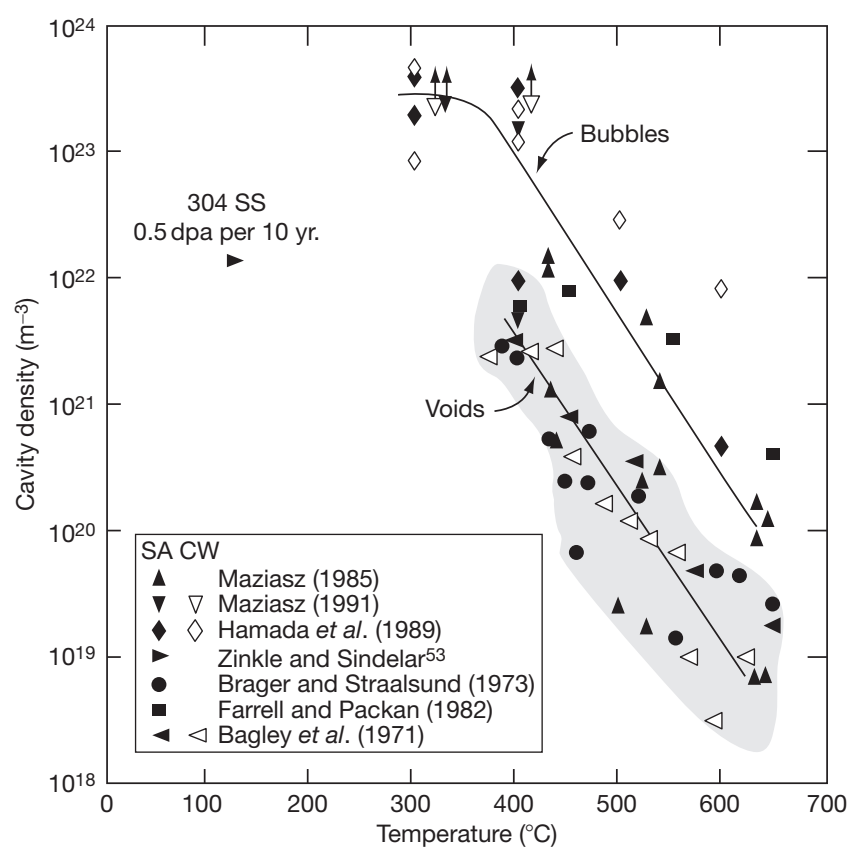

Figure 12 Effect of neutron irradiation temperature on the cavity density observed in austenitic stainless steels for damage rates near $1 \times 10^{-6} \mathrm{dpa} \mathrm{s}^{-1}$ (except the labeled data point at $120^{\circ} \mathrm{C}$ which had a damage rate of $\sim 10^{-9} \mathrm{dpa} \mathrm{s}{ }^{-1}$ ). Reproduced from Zinkle, S. J.; Maziasz, P. J.; Stoller, R. E. J. Nucl. Mater. 1993, 206, 266-286. 


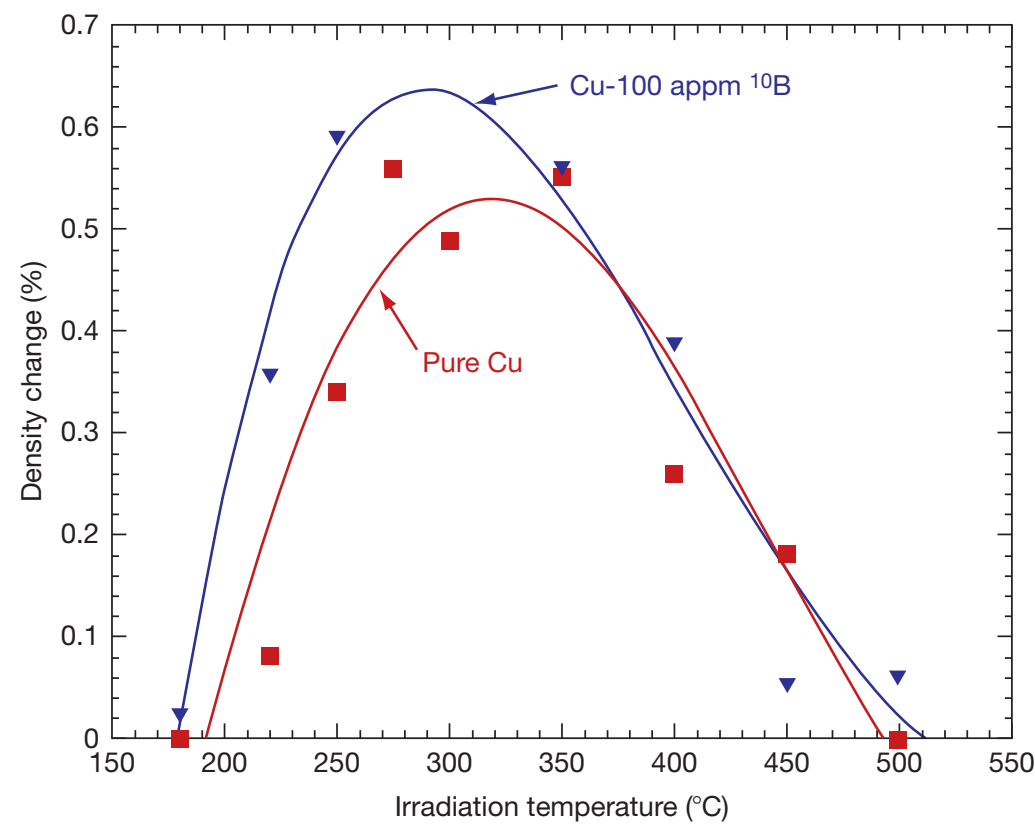

Figure 13 Temperature-dependent void swelling behavior in neutron-irradiated copper and Cu-B alloy after fission neutron irradiation to a dose near 1.1 dpa. Adapted from Zinkle, S. J.; Farrell, K.; Kanazawa, H. J. Nucl. Mater. 1991, 179-181, 994-997; Zinkle, S. J.; Farrell, K. J. Nucl. Mater. 1989, 168, 262-267.

of swelling occurs at temperatures near $180^{\circ} \mathrm{C}$, which corresponds to recovery Stage $\mathrm{V}$ in $\mathrm{Cu}$ for the $2 \times 10^{-7} \mathrm{dpa}^{-1}$ damage rates in this experiment. The swelling in $\mathrm{Cu}$ was negligible for temperatures above $\sim 500^{\circ} \mathrm{C}$, and maximum swelling was observed near $300^{\circ} \mathrm{C}$. The lower temperature limit for swelling in fcc materials is typically controlled by the high point defect sink strength of sessile defect clusters below recovery Stage V. The upper temperature limit is controlled by thermal stability of voids and a reduction in the vacancy supersaturation relative to the equilibrium vacancy concentration.

As noted by Singh and Evans, ${ }^{92}$ the temperature dependence of the void swelling behavior of bcc and fcc metals can be significantly different. In particular, due to the lower amount of in-cascade formation of large sessile vacancy clusters in medium-mass bcc metals compared to fcc metals, the recovery Stage $\mathrm{V}$ is much less pronounced in bcc metals. The presence of a high concentration of mobile vacancies at temperatures below recovery Stage V (and a concomitant reduction in the density of sessile vacancy-type defect cluster sinks) allows void swelling to occur in bcc metals for temperatures above recovery Stage III (onset of long-range vacancy migration). Figure 14 compares the temperature dependence of the void swelling behavior of $\mathrm{Ni}$ (fcc) and $\mathrm{Fe}$ (bcc) after high dose neutron irradiation. ${ }^{115}$ Whereas the peak



Figure 14 Comparison of the temperature-dependent void swelling behavior in $\mathrm{Fe}$ and $\mathrm{Ni}$, based on data reported by Budylkin et al. ${ }^{115}$

swelling after $\sim 50 \mathrm{dpa}$ in neutron-irradiated $\mathrm{Ni}$ occurred near $0.45 T_{\mathrm{M}}$, the peak swelling in Fe occurred at the lowest investigated temperature of $\sim 0.35 T_{\mathrm{M}}$. Several other bcc metals including $\mathrm{Mo}, \mathrm{W}, \mathrm{Nb}$, and Ta exhibit void formation for irradiation temperatures as low as $\sim 0.2 T_{\mathrm{M}}$, which is approaching the upper limit of recovery Stage III. ${ }^{92}$ It is worth noting the peak swelling temperature for neutron-irradiated bcc metals $\mathrm{Mo}$ and $\mathrm{Nb}-1 \mathrm{Zr}$ after exposures of $\sim 50 \mathrm{dpa}$ 
occur near $0.3-0.35 T_{\mathrm{M}},{ }^{116,117}$ which is much lower than the $0.4-0.45 T_{\mathrm{M}}$ peak swelling temperature observed for fcc metals.

\subsection{Very high temperature regime: He cavities ( $T \gg$ Stage $V$ )}

Irradiation at temperatures near or above $0.5 T_{\mathrm{M}}$ typically results in only minor microstructural changes due to the strong influence of thermodynamic equilibrium processes, unless significant amounts of impurity atoms such as helium are introduced by nuclear transmutation reactions or by accelerator implantation. When helium is present, cavities are nucleated in the grain interior and along grain boundaries. The cavity size increases and the density decreases rapidly with increasing temperature. Figure 15 compares the helium cavity density for various implantation and neutron irradiation conditions in austenitic stainless

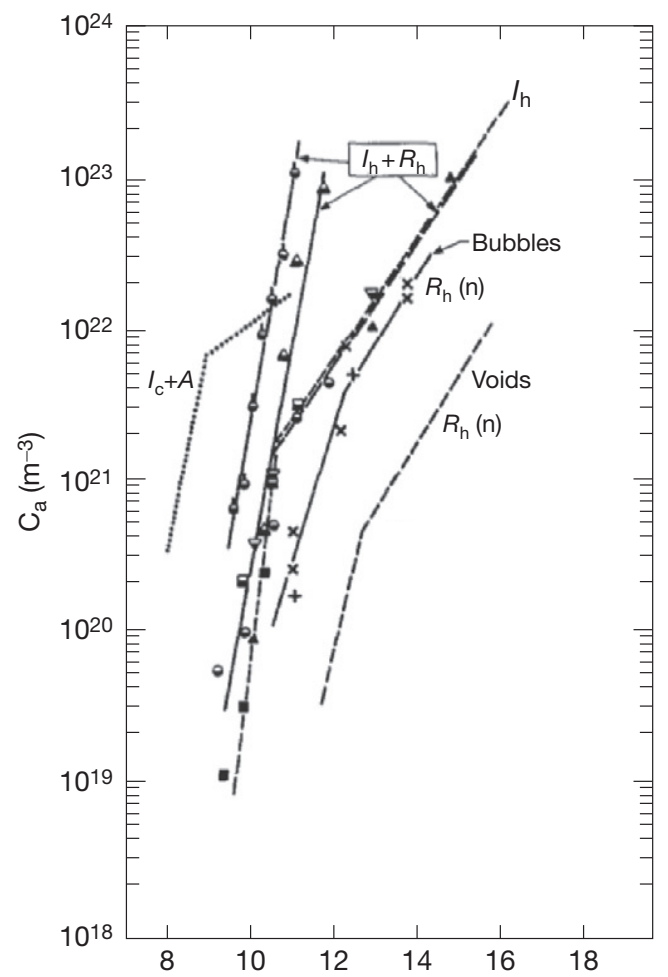

Figure 15 Temperature dependence of observed cavity densities in commercial austenitic steels during $\mathrm{He}$ implantation or neutron irradiation at elevated temperatures ( $I_{\mathrm{h}}$ and $R_{\mathrm{h}}$, respectively). The dashed lines denote the densities of voids during neutron irradiation $\left(R_{h}(n)\right)$ and bubbles during implantation near room temperature followed by high temperature annealing $\left(\mathrm{I}_{\mathrm{c}}+\mathrm{A}\right)$. Adapted from Singh, B. N.; Trinkaus, H. J. Nucl. Mater. 1992, 186, 153-165; Trinkaus, H.; Singh, B. N. J. Nucl. Mater. 2003, 323 (2-3), 229-242. steels as a function of temperature. ${ }^{118,119}$ The temperature dependence of the cavity density is distinguished by two different regimes. At very high temperatures, the cavity density is controlled by gas dissociation mechanisms with a corresponding high activation energy, and at lower temperatures by gas or bubble diffusion kinetics. ${ }^{118}$ The cavity density decreases by nearly two orders of magnitude for every $100 \mathrm{~K}$ increase in irradiation temperature in this very high temperature regime. The helium cavity densities in materials irradiated at low temperatures (near room temperature) and then annealed at high temperature are typically much higher than in materials irradiated at high temperature, due to excessive cavity nucleation that occurs at low temperature. In the absence of applied stress, the helium-filled cavities tend to nucleate rather homogeneously in the grain interiors and along grain boundaries. If the helium generation and displacement damage occurs in the presence of an applied tensile stress, the helium cavities are preferentially nucleated along grain boundaries and may cause grain boundary embrittlement. ${ }^{120}$

\subsubsection{Role of Atomic Weight}

Materials with low atomic weight, such as aluminum, exhibit more spatially diffuse displacement cascades than high atomic weight materials due to the increase in nuclear and electronic stopping power with increasing atomic weight. For example, the calculated average vacancy concentration in Au displacement cascades is about two to three times higher than in $\mathrm{Al}$ cascades for a wide range of PKA energies. ${ }^{57}$ This increased energy density and compactness in the spatial extent of displacement cascades can produce enhanced clustering of point defects within the energetic displacement cascades of high atomic weight materials. Electrical resistivity isochronal annealing studies of fission neutron-irradiated metals have confirmed that the amount of defect recovery during Stage I annealing decreases with increasing atomic weight, ${ }^{79}$ which is an indication of enhanced SIA clustering within the displacement cascades. The importance of atomic weight on defect clustering depends on the material-specific critical energy for subcascade formation compared to the average PKA energy. For example, in the fcc noble metal series $\mathrm{Cu}$, $\mathrm{Ag}, \mathrm{Au}$, the subcascade formation energy increases slightly with mass $(10,13$, and $14 \mathrm{keV}$, respectively), and very little qualitative difference exists in the defect cluster accumulation behavior of these three materials. ${ }^{13,56}$ In general, there is not a universal relation 
between atomic weight and microstructural parameters such as overall defect production, ${ }^{121}$ defect cluster yield, ${ }^{122,123}$ or visible defect cluster size. ${ }^{56}$

\subsubsection{Role of Crystal Structure}

MD simulations ${ }^{23}$ predict the absolute level of defect production is not strongly affected by crystal structure. Conversely, electrical resistivity studies of fission neutron-irradiated metals suggest that the overall defect production is highest in HCP metals, intermediate in bcc metals, and lowest in fcc metals, ${ }^{121}$ which suggests that the anisotropic nature of HCP crystals might inhibit defect recombination within displacement cascades. TEM measurements of defect cluster yield (number of visible cascades per incident ion) in ion-irradiated metals have found that the relatively few visible defect clusters are formed directly in displacement cascades in bcc metals, ${ }^{122}$ whereas cluster formation is relatively efficient in fcc metals and variable behavior is observed for HCP metals. ${ }^{123}$ Faulted dislocation loops are often observed in irradiated fcc and HCP metals, but due to their high stacking fault energies most studies on irradiated bcc metals have only observed perfect loops. ${ }^{8,16,21,47,124}$ Since perfect loops are glissile, this can lead to more efficient sweeping up of radiation defects and accelerate the development of dislocation loop rafts or network dislocation structures in bcc materials. Figure 16 shows examples of the dislocation loop microstructures in bcc, fcc, and HCP metals with similar atomic weight following electron irradiation at temperatures above recovery Stage III. ${ }^{47}$ All of the loops are interstitial type with comparable size for the same irradiation dose. However, significant differences exist in the loop configurations, in particular habit planes and faulted $(\mathrm{Ni}, \mathrm{Zn})$ versus perfect $(\mathrm{Fe})$ loops. One significant aspect of loop formation in HCP materials is that differential loop evolution on basal and prism planes can lead to significant anisotropic growth. ${ }^{125-129}$

In general, defect accumulation in the form of void swelling is significantly lower in bcc materials compared to fcc materials, although there are notable exceptions where very high swelling rates (approaching $3 \%$ per dpa $)^{130,131}$ have been observed in some bcc alloys. Pronounced elastic and point defect diffusion anisotropy ${ }^{128}$ can also suppress void swelling in HCP materials, although high swelling has been observed in some HCP materials such as graphite. ${ }^{132}$ It has long been recognized that ferritic/martensitic steels exhibit significantly lower void swelling than
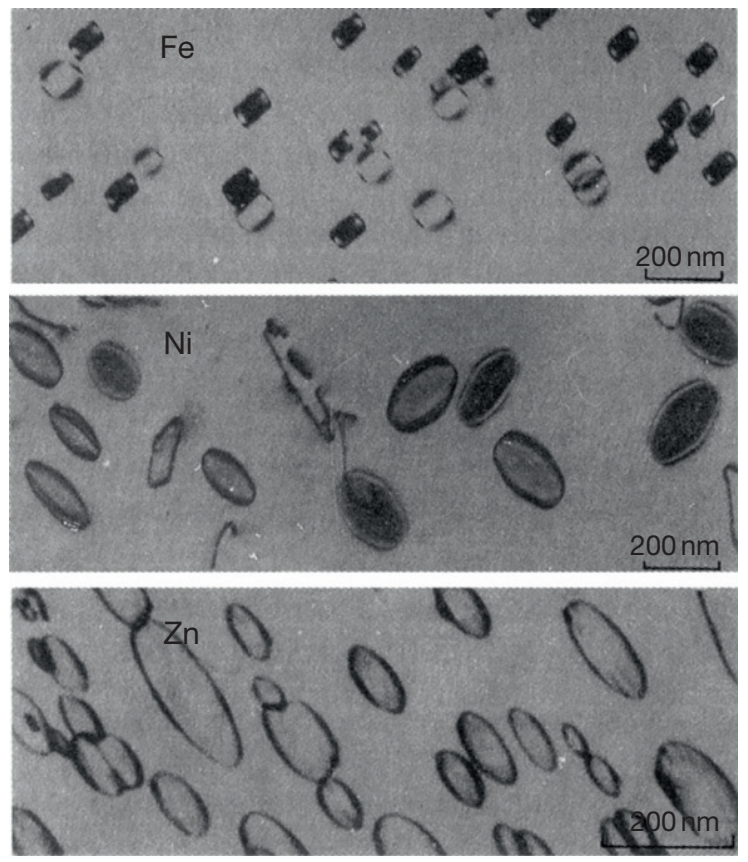

Figure 16 Dislocation loop microstructures in $\mathrm{Fe}, \mathrm{Ni}$, and $\mathrm{Zn}$ following electron irradiation at temperatures above recovery Stage III. The loops in Fe were perfect and located on (100) planes, and the loops in $\mathrm{Ni}$ and $\mathrm{Zn}$ were faulted and located on $\{111\}$ and (0001) planes, respectively.

Reproduced from Kiritani, M. J. Nucl. Mater. 2000, 276(1-3), 41-49.

austenitic stainless steels. ${ }^{109,133,134}$ Figure 17 compares the microstructure of austenitic stainless steel and $9 \% \mathrm{Cr}$ ferritic/martensitic steel after dual beam ion irradiation at $650{ }^{\circ} \mathrm{C}$ to $50 \mathrm{dpa}$ and $260 \mathrm{appm}$ He. ${ }^{135}$ Substantial void formation is evident in the Type 316 austenitic stainless steel, whereas cavity swelling is very limited in the $9 \% \mathrm{Cr}$ ferritic/martensitic steel for the same irradiation conditions. Several mechanisms have been proposed to explain the lower swelling in ferritic/martensitic steel, including lower dislocation bias for SIA absorption, larger critical radii for conversion of helium bubbles to voids, and higher point defect sink strength.

\subsubsection{Role of Atomic Bonding}

Atomic bonding (i.e., metallic, ionic, covalent, and polar covalent) is a potential factor to consider when comparing the microstructural evolution between metals and nonmetals, or between different nonmetallic materials that may have varying amounts of directional covalent or ionic bonds. For example, several authors have proposed an empirical atomic bonding 

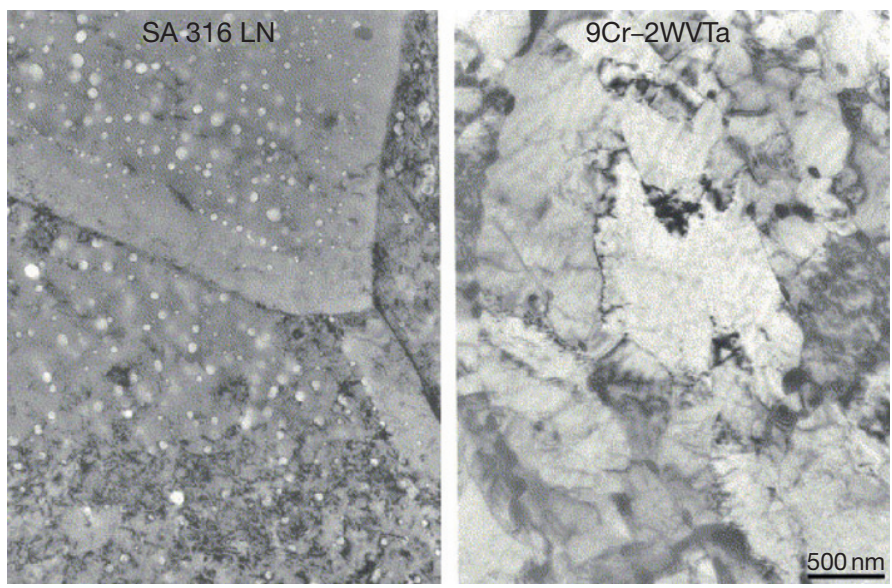

Figure 17 Comparison of the microstructure of Type 316 LN austenitic stainless steel and 9\%Cr-2\%WVTa ferritic/ martensitic steel after dual beam ion irradiation at $650^{\circ} \mathrm{C}$ to 50 dpa and 260 appm He. Reproduced from Kim, I.-S.; Hunn, J. D.; Hashimoto, N.; Larson, D. L.; Maziasz, P. J.; Miyahara, K.; Lee, E. H. J. Nucl. Mater. 2000, 280(3), $264-274$.

criterion to correlate the amorphization susceptibility of nonmetallic materials. ${ }^{136,137}$ Materials with ionicity parameters above 0.5 appear to have enhanced resistance to irradiation-induced amorphization. However, there are numerous materials which do not follow this correlation, ${ }^{86,138,139}$ and a variety of alternative mechanisms have been proposed ${ }^{86-88,138-141}$ to explain resistance to amorphization. Atomic bonding can directly or indirectly influence point defect migration and annihilation mechanisms (e.g., introduction of recombination barriers), and thereby influence the overall microstructural evolution.

\subsubsection{Role of Dose Rate}

The damage accumulation is independent of dose rate at very low temperatures, where point defect migration does not occur. However, at elevated temperatures (above recovery Stage I) the damage rate can have a significant influence on the damage accumulation. Simple elevated temperature kinetic models for defect accumulation ${ }^{72,142-144}$ predict a transition from linear to square root dependence on the irradiation fluence when the radiation-induced defect cluster density becomes comparable to the density of preexisting point defect sinks such as line dislocations, precipitates, and grain boundaries. Similar square root flux dependence is predicted from more comprehensive kinetic rate theory models ${ }^{6,70,71,145}$ for irradiation temperatures between recovery Stage II and IV. Electron microscopy analyses of electron ${ }^{5}$ and neutron ${ }^{146}$ irradiation experiments performed above recovery Stage I have reported defect cluster densities that exhibit square root dependence on irradiation flux or fluence.



Figure 18 Effect of irradiation flux on the density of interstitial dislocation loops in several fcc and bcc metals during electron irradiation near room temperature or at cryogenic temperature (above recovery Stage I).

Reproduced from Kiritani, M. In Fundamental Aspects of Radiation Damage in Metals, CONF-751006-P2; Robinson, M. T.; Young, F. W., Jr., Eds. National Tech. Inform. Service: Springfield, VA, 1975; Vol. II, pp 695-714.

Figure 18 summarizes the square root dose rate dependence for dislocation loop densities at intermediate temperatures in several electron-irradiated pure metals. $^{5}$

Similarly, the predicted critical dose to achieve amorphization is independent of dose rate below 


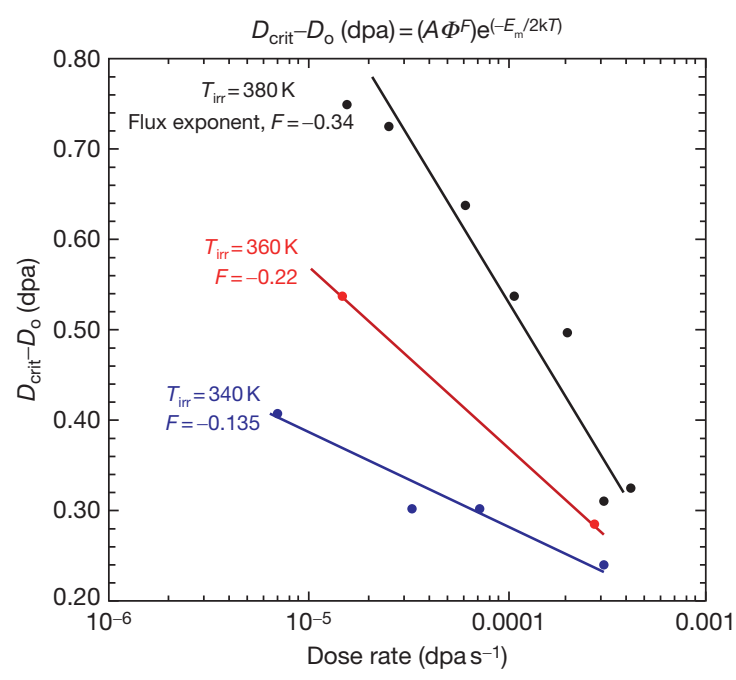

Figure 19 Effect of dose rate $(\Phi)$ on the critical dose $\left(D_{\text {crit }}\right)$ to induce complete amorphization in $6 \mathrm{H}-\mathrm{SiC}$ single crystals during $2 \mathrm{MeV} \mathrm{Si}$ ion irradiation. The dose $D_{0}$ corresponds to the amorphization dose at very low temperatures, where all defects are immobile. The equation at the top of the figure is the prediction from a model (ref. 147) for the dose dependence of amorphization on dose rate, point defect migration energy $\left(E_{m}\right)$ and irradiation temperature $(T)$. The parameter $\mathrm{F}$ describes the dose rate power law dependence and $\mathrm{k}$ is Boltzmann's constant. Based on data reported by Snead et al. ${ }^{148}$

recovery Stage I and depends on the inverse square root of dose rate for temperatures above recovery Stage I. $^{147}$ Experimental studies have confirmed that the threshold dose to achieve amorphization in ion-irradiated $\mathrm{SiC}$ is nearly independent of dose rate below $\sim 350 \mathrm{~K}$ (corresponding to recovery Stage I) and approaches an inverse square root flux dependence for irradiation temperatures above $380 \mathrm{~K}$, as shown in Figure 19. ${ }^{148}$

In the void swelling ${ }^{149-151}$ and high temperature helium embrittlement ${ }^{119,152,153}$ regimes, damage rate effects are very important considerations due to the competition between defect production and thermal annealing processes. Experimental studies using ion irradiation $\left(\sim 10^{-3} \mathrm{dpa} \mathrm{s}^{-1}\right)$ and neutron irradiation $\left(\sim 10^{-6}\right.$ dpa s$\left.^{-1}\right)$ damage rates have observed that the peak void swelling regime is typically shifted to higher temperatures by about $100-150{ }^{\circ} \mathrm{C}$ for the high-dose rate irradiations compared to test reactor neutron irradiation conditions. ${ }^{14,154-158}$ Similarly, the minimum and maximum temperature for measureable void swelling increase with increasing dose rate. For example, recent low dose rate neutron irradiation studies $^{111-113}$ performed near $10^{-9}-10^{-8} \mathrm{dpa} \mathrm{s}^{-1}$ have observed void swelling in austenitic stainless steel at temperatures as low as $280-300^{\circ} \mathrm{C}$, which is significantly lower than the $\sim 400^{\circ} \mathrm{C}$ lower limit for void swelling observed during fission reactor irradiations near $10^{-6} \mathrm{dpa} \mathrm{s}^{-1}$ (cf. Figure 12).

\subsubsection{Role of lonizing Radiation}

Due to relatively large concentrations of conduction electrons, materials with metallic bonding typically do not exhibit sensitivity to ionizing radiation. On the other hand, semiconductor and insulating materials can be strongly affected by ionizing radiation by various mechanisms that lead to either enhanced or suppressed defect accumulation. ${ }^{159}$ Some materials such as alkali halides, quartz, and organic materials, are susceptible to displacement damage from radiolysis reactions. ${ }^{65,160-163}$ In materials that are not susceptible to radiolysis, significant effects from ionizing radiation can still occur via modifications in point defect migration behavior. Substantial reductions in point defect migration energies due to ionization effects have been predicted, and significant microstructural changes attributed to ionization effects have been observed in several semiconductors and inorganic insulator materials. ${ }^{18,159,164-169}$ The effect of ionizing radiation can be particularly strong for electron or light ion beam irradiations of certain ceramic materials since the amount of ionization per unit displacement damage is high for these irradiation species; the ionization effect per dpa is typically less pronounced for heavy ion, neutron, or dual ion beam irradiation. Figure 20 summarizes the effect of variations in the ratio of ionizing to displacive radiation (achieved by varying the ion beam mass) on the dislocation loops density and size in several oxide ceramics. ${ }^{94,169,170}$ The loop density decreases rapidly when the ratio of ionizing to displacive radiation (depicted in Figure 20 as electron-hole pairs per dpa) exceeds a materialdependent critical value, and the corresponding loop size simultaneously increases rapidly.

Numerous microstructural changes emerge in materials irradiated with so-called swift heavy ions that produce localized intense energy deposition in their ion tracks. Defect production along the ion tracks is observed above a material-dependent threshold value for the electronic stopping power with typical values of $1-50 \mathrm{keV} \mathrm{nm}^{-1}$. $^{159,171-175}$ The microstructural changes are manifested in several ways, including dislocation loop punching, ${ }^{176}$ creation of amorphous tracks with typical diameters of a few $\mathrm{nm},{ }^{159,173,174,177-180}$ atomic disordering, ${ }^{176,181,182}$ crystalline phase transformations, ${ }^{171}$ destruction of preexisting small dislocation 

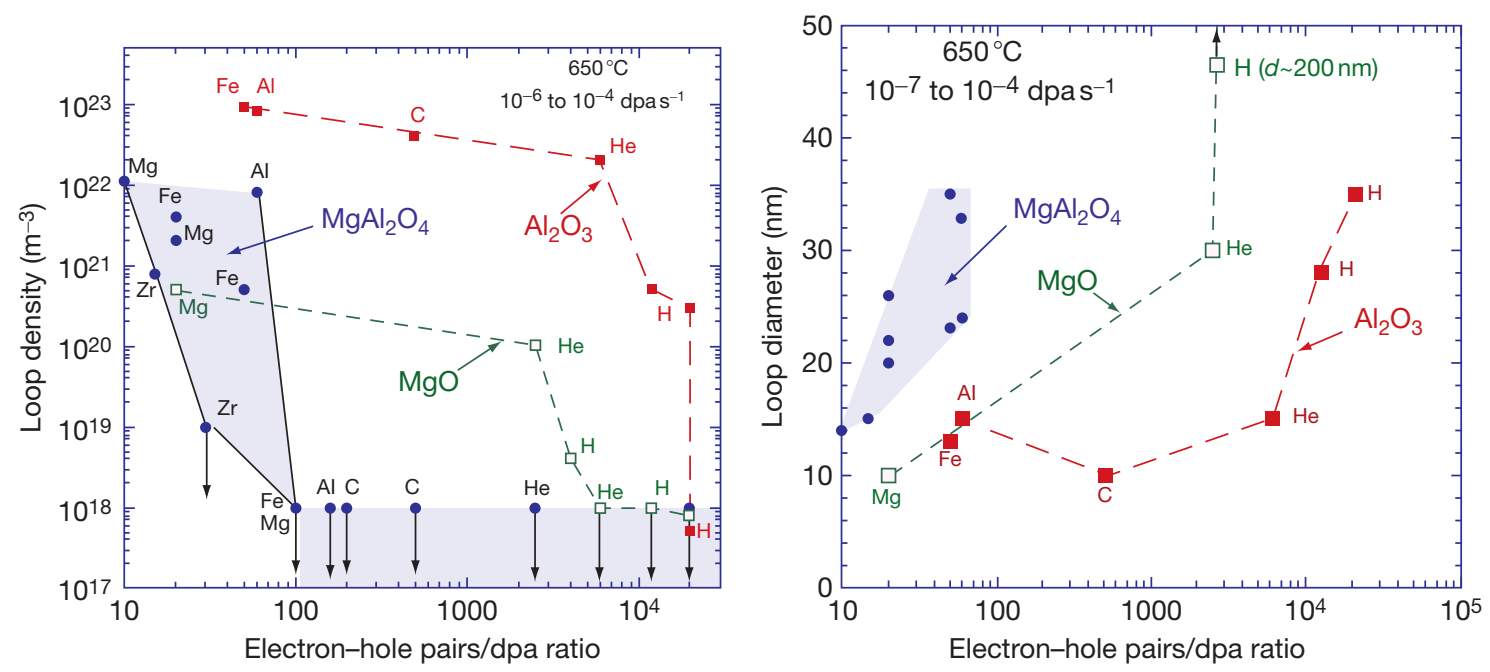

Figure 20 Effect of variations in ionizing to displacive radiation on the dislocation loop density and size in ion-irradiated $\mathrm{MgO}, \mathrm{Al}_{2} \mathrm{O}_{3}$, and $\mathrm{MgAl}_{2} \mathrm{O}_{4}$. Adapted from Zinkle, S. J. Radiat. Eff. Defects Solids 1999, 148, 447-477; Zinkle, S. J. J. Nucl. Mater. 1995, 219, 113-127; Zinkle, S. J. In Microstructure Evolution During Irradiation; Robertson, I. M., Was, G. S., Hobbs, L. W., Diaz de la Rubia, T., Eds. Materials Research Society: Pittsburgh, PA, 1997; Vol. 439, pp 667-678.
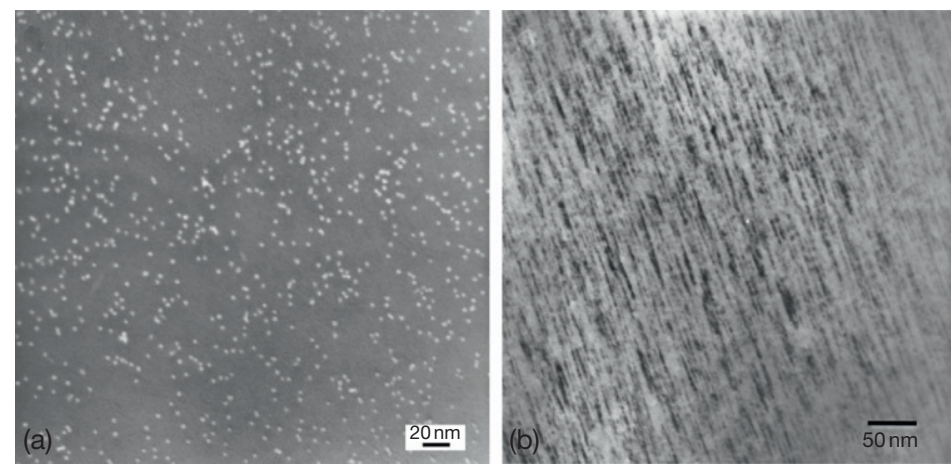

Figure 21 Plan view microstructure of disordered ion tracks in $\mathrm{MgAl}_{2} \mathrm{O}_{4}$ irradiated $430 \mathrm{MeV} \mathrm{Kr}$ ions at room temperature to a fluence of $6 \times 10^{15}$ ions per square meter (isolated ion track regime) under (a) weak dynamical bright field and (b) $g=\langle 222\rangle$ centered dark field imaging conditions (tilted $10^{\circ}$ to facilitate viewing of the longitudinal aspects of the ion tracks). High-resolution TEM and diffraction analyses indicate disordering of octahedral cations (but no amorphization) within the individual ion tracks. Adapted from Zinkle, S. J.; Skuratov, V. A. Nucl. Instrum. Methods B 1998, 141(1-4), 737-746; Zinkle, S. J.; Matzke, H.; Skuratov, V. A. In Microstructural Processes During Irradiation; Zinkle, S. J., Lucas, G. E., Ewing, R. C., Williams, J. S., Eds. Materials Research Society: Warrendale, PA, 1999; Vol. 540, pp $299-304$.

loops, ${ }^{176}$ and formation of nanoscale hillocks and surrounding valleys ${ }^{183,184}$ at free surfaces. Annealing of point defects occurs for irradiation conditions below the material-dependent threshold electronic stopping power for track creation, ${ }^{159,180,185,186}$ whereas defect production occurs above the stopping power threshold. ${ }^{159,171,173,175,178,180,183,185,186}$ The swift heavy ion annealing and defect production phenomena are observed in both metals and alloys ${ }^{171,175,183,185,186}$ as well as nonmetals. ${ }^{159,172,173,178-180,187-190}$ Defect production by swift heavy ions is of importance for understanding the radiation resistance of current and potential fission reactor fuel systems, including the mechanisms responsible for the finely polygonized rim effect ${ }^{188,191}$ in $\mathrm{UO}_{2}$ and radiation stability of inert matrix fuel forms. ${ }^{182,189,191}$ The swift heavy ion defect production mechanism is generally attributed to thermal spike ${ }^{178,192}$ and self-trapped exciton ${ }^{187}$ effects. Figure 21 shows examples of the plan view (i.e. along the direction of the ion beam) microstructure of disordered ion tracks in $\mathrm{MgAl}_{2} \mathrm{O}_{4}$ irradiated with swift heavy ions. ${ }^{176,182}$ 


\subsubsection{Role of Solute Segregation and Precipitation}

Solute atoms of importance include elements originally added to the material during fabrication and species produced by nuclear transmutation reactions (e.g., $\mathrm{He}$ and $\mathrm{H}$, and a range of other elements). Solute atoms may exhibit preferential coupling with point defects created during irradiation, leading to either enhancement or depletion of solutes at point defect sink structures such as dislocations, grain boundaries, preexisting precipitates, and voids. ${ }^{193-198}$ The solute-defect coupling can modify the kinetics for point defect diffusion, and the resultant solute enrichment or depletion may sufficiently modify the local composition to induce the formation of new phases. There are three general categories of precipitation associated with radiation-induced segregation processes ${ }^{103,199}$ : radiation-induced (phases that form due to irradiation-induced nonequilibrium solute segregation and dissolve during postirradiation annealing), radiation-enhanced (precipitate formation accelerated or occurring at lower temperatures due to irradiation, but are thermally stable after formation), and radiation-modified (different chemical composition of precipitates compared to thermodynamically stable composition). In some materials, radiation-retarded precipitation (phase formation shifted to higher temperatures or longer exposure times) has been reported. ${ }^{200}$

A phenomenon that is uniquely associated with ion irradiation is the potential for the ions from the irradiating beam to modify the microstructural evolution by perturbing the relative balance of SIAs compared to vacancies flowing to defect sinks. The injected ions act as a source of additional interstitial atoms and can significantly suppress void nucleation and growth. ${ }^{149,154,201,202}$ The peak concentration of the injected ions occurs near the displacement damage peak for ion irradiation, and therefore considerable care must be exercised when evaluating the void swelling data obtained near the peak damage region in ion-irradiated materials. ${ }^{154,201,202}$ Figure 22 shows an example of the dramatic changes in microstructure that can occur in the injected ion region. ${ }^{203}$ In this example, void formation in ion-irradiated nickel at $400{ }^{\circ} \mathrm{C}$ is completely suppressed in the regions with the injected interstitials and the void microstructure is replaced with an aligned array of small interstitialtype dislocation loops.

Numerous studies have observed that the precipitation behavior during irradiation can strongly influence microstructural evolution, for example, the swelling behavior of austenitic stainless steels. ${ }^{103,106,204-206}$

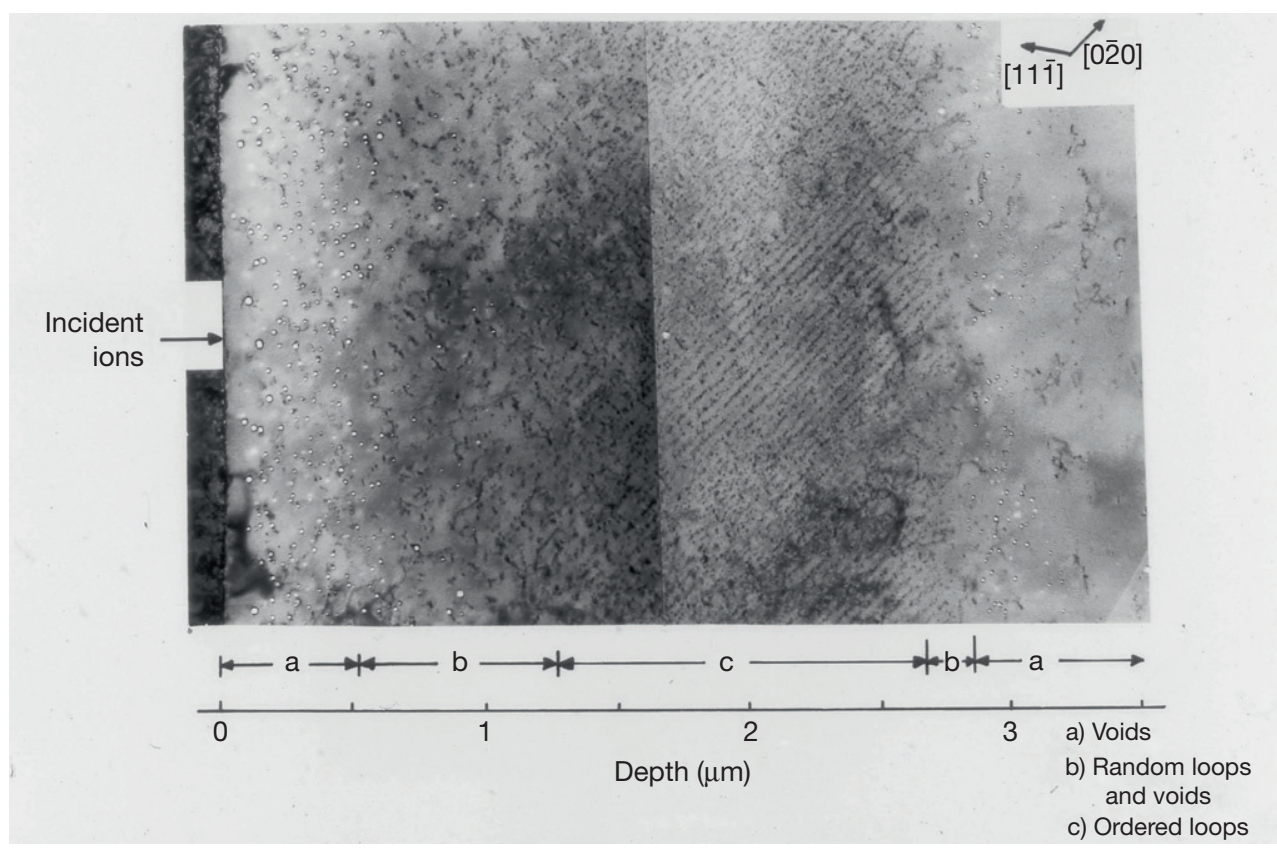

Figure 22 Cross-section TEM microstructure of nickel irradiated at $400^{\circ} \mathrm{C}$ with $14 \mathrm{MeV}$ Cu ions to a fluence of $5 \times 10^{20}$ ions $\mathrm{m}^{-2}$ which produced a peak damage level of about $55 \mathrm{dpa}$ at a depth near $2 \mu \mathrm{m}$. Void formation is completely suppressed in the injected interstitial regime $(\sim 1.3-2.8 \mu \mathrm{m})$ and the void microstructure is replaced with an array of small interstitial-type dislocation loops aligned along $\{100\}$ planes. Reproduced from Whitley, J. B. Depth dependent damage in heavy ion irradiated nickel. University of Wisconsin, Madison, 1978. 




Figure 23 Comparison of the cavity microstructures for a pure $\mathrm{Fe}-13 \mathrm{Cr}-15 \mathrm{Ni}$ austenitic alloy (left panel) and the same alloy with $\mathrm{P}, \mathrm{Si}, \mathrm{Ti}$, and $\mathrm{C}$ additions that produced dense radiation-induced phosphide precipitation (center and right panels) following dual beam $\mathrm{Ni}+\mathrm{He}$ irradiation at $675^{\circ} \mathrm{C}$. The irradiation conditions were $0.4 \mathrm{dpa}$ and 0.2 appm He for the left panel (70 dpa and 35 appm for the inset figure), and $109 \mathrm{dpa}$ and $2000 \mathrm{appm}$ He for the other two figures. Reproduced from Mansur, L. K.; Lee, E. H. J. Nucl. Mater. 1991, 179-181, 105-110.

In extreme cases, large-scale phase transformations can occur such as the $\gamma$ (austenite, fcc) to $\alpha$ (ferritic, bcc) transformation in austenitic stainless steel following high dose neutron irradiation. ${ }^{106,207}$ Depending on the type of precipitation, either enhanced or suppressed swelling can occur. Void swelling enhancement has generally been attributed to a point defect collector mechanism and typically occurs for moderate densities of relative coarse precipitates such as $G$ phase in austenitic stainless steels, whereas void swelling suppression is generally observed for high densities of finely dispersed precipitates and is usually attributed to high sink strength effects. ${ }^{103,151,208}$ Figure 22 shows an example of the strong void swelling suppression associated with formation of radiation-induced $\mathrm{Si}$ - and $\mathrm{Ti}$-rich phosphide precipitates compared to a simple $\mathrm{Fe}-\mathrm{Cr}-\mathrm{Ni}$ ternary austenitic alloy. ${ }^{208}$ Similarly, the $\mathrm{He} / \mathrm{dpa}$ ratio can influence the types and magnitude of point defect clusters and precipitation due to modifications in the point defect evolution under irradiation (Figure 23). ${ }^{106}$

\subsubsection{Overview of Key Radiation- Induced Property Degradation Phenomena}

There are eight major property changes that may occur in irradiated materials due to a variety of microstructural changes. Listed in order of increasing temperature where the effects are typically dominant, these phenomena are radiation-induced amorphization, radiation hardening (often accompanied by loss of tensile elongation and reduction in fracture toughness), decrease in thermal and electrical conductivity, mechanical property or corrosion degradation due to radiation-induced segregation and precipitation, dimensional instabilities due to three distinct phenomena (anisotropic irradiation growth, irradiation creep, void swelling), and high temperature embrittlement of grain boundaries due to helium accumulation. The microstructural origins associated with these eight degradation processes are summarized in the following sections, and more detailed descriptions of the property degradations in metals and nonmetals are given in accompanying chapters in this Comprehensive. The radiation doses at which these phenomena emerge to become of practical engineering significance are generally dependent on irradiation temperature, PKA energy, and material.

\subsubsection{Radiation-Induced Amorphization}

At very low temperatures where motion of SIAs or SIA clusters is limited, a crystalline to amorphous phase transition can be induced. The phase transition usually produces large swelling (5-30\%) and decreases in elastic moduli. ${ }^{15,91,182,209}$ This phase transition typically occurs for damage levels of $\sim 0.1-1$ dpa at low temperatures and has been attributed to several mechanisms including direct amorphization within collision cascades, and an increase in 

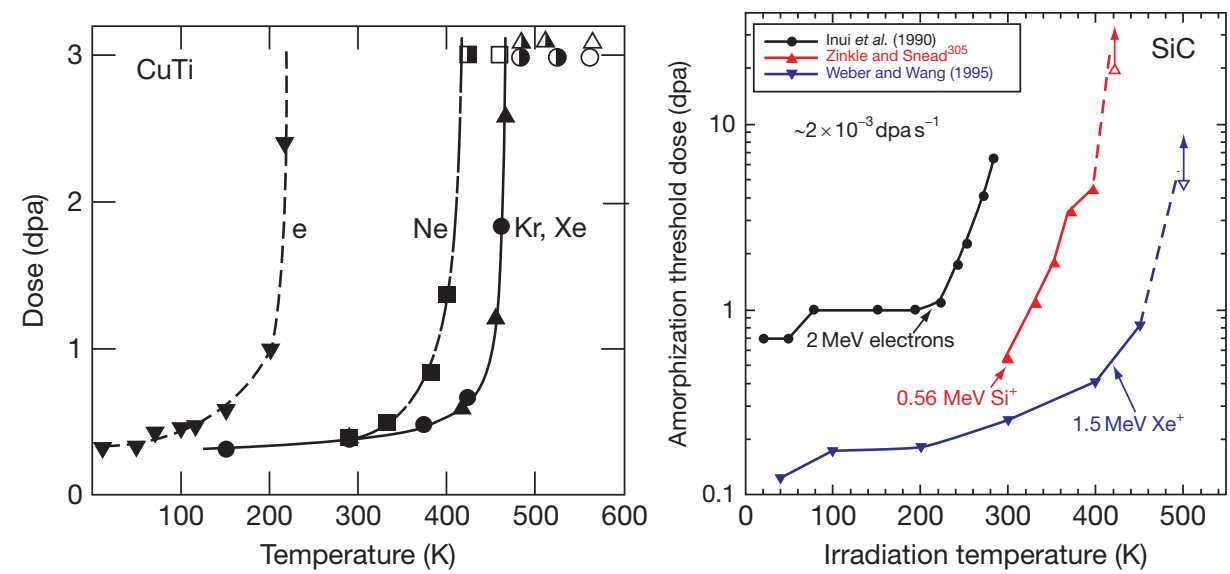

Figure 24 Effect of irradiating particle on the temperature-dependent dose for amorphization in irradiated CuTi ${ }^{214}$ and SiC. ${ }^{139}$ In both plots, filled symbols denote complete amorphization and open symbols denote amorphization did not occur.

the crystalline free energy due to point defect accumulation and disordering processes. $86,147,210-213$ The dose dependence for accumulation of the amorphous volume fraction is significantly different for the direct impact mechanism compared to point defect accumulation or multiple overlap mechanisms. ${ }^{213}$ As the irradiation temperature is raised to values where long range SIA and SIA cluster migration occurs, point defect diffusion to reduce the increase in free energy occurs and the dose to induce amorphization typically increases rapidly with increasing temperature until a temperature is reached where it is not possible to induce amorphization. In many cases, the critical temperature for amorphization increases with increasing PKA energy. Figure 24 compares the effect of PKA energy on the temperaturedependent dose for complete amorphization for an intermetallic alloy ${ }^{214}$ and a ceramic ${ }^{139}$ material. In both materials, for all types of irradiating particles, the critical dose for amorphization increases rapidly when the irradiation temperature exceeds a critical value. The critical temperature for amorphization is significantly higher for heavy ion irradiation conditions compared to electron irradiation conditions.

\subsubsection{Radiation-Induced Hardening}

Irradiation of metals and alloys at temperatures below recovery Stage $\mathrm{V}$ typically produces pronounced radiation hardening, as discussed in Chapter 1.04, Effect of Radiation on Strength and Ductility of Metals and Alloys. The matrix hardening is typically accompanied by reduction in tensile elongation and in many cases lower fracture toughness. ${ }^{215-222}$ The uniform elongation measured in tensile tests for

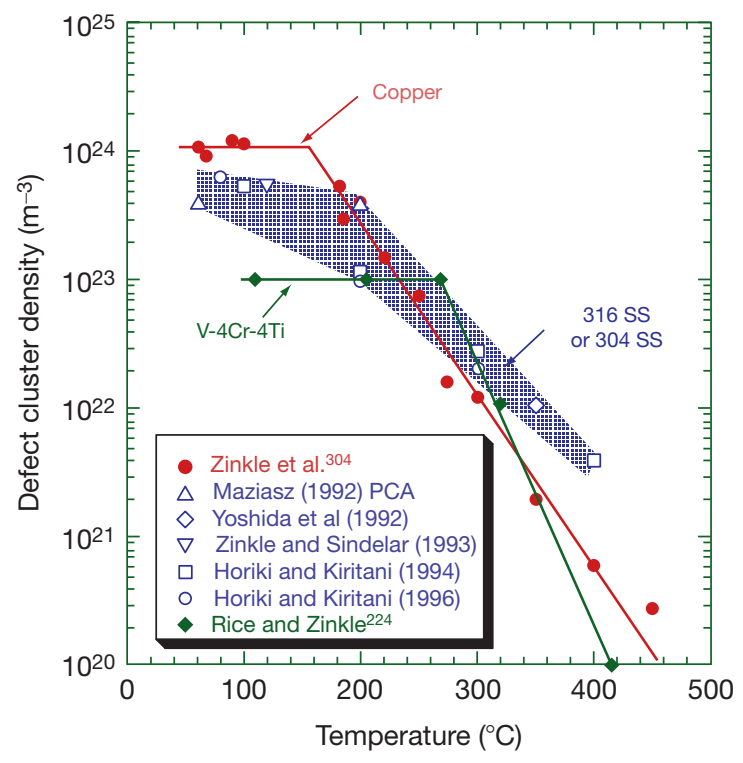

Figure 25 Comparison of the temperature-dependent defect cluster densities in neutron-irradiated $\mathrm{Cu}$, austenitic stainless steel, and $\mathrm{V}-4 \mathrm{Cr}-4 \mathrm{Ti}$. Based on data reported by Rice and Zinkle ${ }^{224}$ and Rowcliffe et al. ${ }^{225}$

metals and alloys irradiated in this temperature regime usually decreases to $<1 \%$ for damage levels above $0.1-1 \mathrm{dpa}$, which may require use of more conservative engineering design rules for the allowable stress of structural materials. ${ }^{223}$ The hardening is largely due to the creation of high densities of sessile defect clusters, which act as obstacles to dislocation motion in the matrix. The defect cluster densities decrease rapidly with increasing temperature above recovery Stage V. Figure 25 compares the temperature-dependent defect cluster densities 224,225 
observed in neutron-irradiated $\mathrm{Cu}$, austenitic stainless steel, and $\mathrm{V}-4 \mathrm{Cr}-4 \mathrm{Ti}$. Stage $\mathrm{V}$ annealing of defect clusters is evident for temperatures above $\sim 150, \sim 200$, and $\sim 275^{\circ} \mathrm{C}$ for $\mathrm{Cu}$, stainless steel, and $\mathrm{V}-4 \mathrm{Cr}-4 \mathrm{Ti}$, respectively. The mechanical properties in irradiated nonmetals at temperatures below recovery Stage $\mathrm{V}$ exhibit variable behavior, with observations of increased hardness, ${ }^{226,227}$ unchanged strength, ${ }^{228}$ and decreased hardness or flexural strength. ${ }^{229-232}$

\subsubsection{Thermal and Electrical Conductivity Degradation}

Thermal and electrical conductivity degradation can occur over a wide range of irradiation temperatures. For pure metals, there are two primary contributions: electron scattering from point defects (and associated defect clusters) and nuclear transmutation solute atoms. The conductivity degradation associated with radiation defects usually amounts to less than $\sim 1 \%$ change except in the case of high void swelling conditions. ${ }^{233-236}$ Conversely, the conductivity degradation associated with neutron-induced transmutation products tends to monotonically increase with increasing dose and typically becomes larger than the radiation defect contribution for doses above $\sim 1$ dpa. Thermal conductivity degradation much greater than $10 \%$ can occur in high-conductivity metals and ceramics. ${ }^{235,237}$ The conductivity degradation in irradiated alloys can be complex due to shortrange ordering and precipitation phenomena, ${ }^{238}$ with the possibility for either increased or decreased conductivity compared to the unirradiated condition. For nonmetallic irradiated materials, the electrical conductivity during irradiation typically experiences a transient increase due to excitation of valence electrons into the valence band by ionizing radiation. ${ }^{239-243}$ The thermal conductivity of irradiated nonmetals is typically degraded by displacement damage due to phonon scattering by point defects and defect clusters. ${ }^{237,243-246}$

\subsubsection{Radiation-Induced Segregation and Precipitation}

At intermediate temperatures where SIAs and vacancies are mobile, significant solute segregation to point defect sinks can occur. This can lead to precipitation of new phases due to the local enrichment or depletion of solute. These radiation-induced or -enhanced precipitation reactions typically become predominant phenomena in irradiated ferritic and austenitic steels at elevated temperatures for doses above about $10 \mathrm{dpa},{ }^{11,20,104,106,200,204}$ and in irradiated reactor pressure vessel steels at low dose rates for damage levels above 0.001-0.01 dpa. ${ }^{247,248}$ Some general aspects of radiation-induced and -enhanced solute segregation and precipitation were described previously in Section 1.03.3.9. The solute segregation and precipitation associated with irradiation can lead to several deleterious effects including property degradation due to grain boundary or matrix embrittlement ${ }^{24,247,249-252}$ and enhanced susceptibility for localized corrosion or stress corrosion cracking. ${ }^{253-256}$ Solute segregation and precipitation can lead to either enhanced or suppressed void swelling behavior. ${ }^{149,257,258}$ For austenitic stainless steel, undesirable precipitate phases that generally are associated with high void swelling include the radiation-induced phases $\mathrm{M}_{6} \mathrm{Ni}_{16} \mathrm{Si}_{7}(\mathrm{G}), \mathrm{Ni}_{3} \mathrm{Si}\left(\gamma^{\prime}\right)$, $\mathrm{MP}, \mathrm{M}_{2} \mathrm{P}$, and $\mathrm{M}_{3} \mathrm{P}$, and the radiation-modified phases $\mathrm{M}_{6} \mathrm{C}$, Laves, and $\mathrm{M}_{2} \mathrm{P}^{200}$ The undesirable radiation-induced and -modified phases generally are associated with undersized misfits with the lattice, which tends to preferentially attract SIAs and thereby enhance the interstitial bias effect. Figure 26 shows an example of enlarged cavity formation in association with $G$ phase precipitates in neutronirradiated austenitic stainless steel. ${ }^{106}$ Potentially desirable radiation-enhanced and -modified phases (when present in the form of finely dispersed precipitates) include $\mathrm{M}_{6} \mathrm{C}$, Laves, $\mathrm{M}_{23} \mathrm{C}_{6}, \mathrm{MC}, \sigma$, and $\chi$. $^{200}$

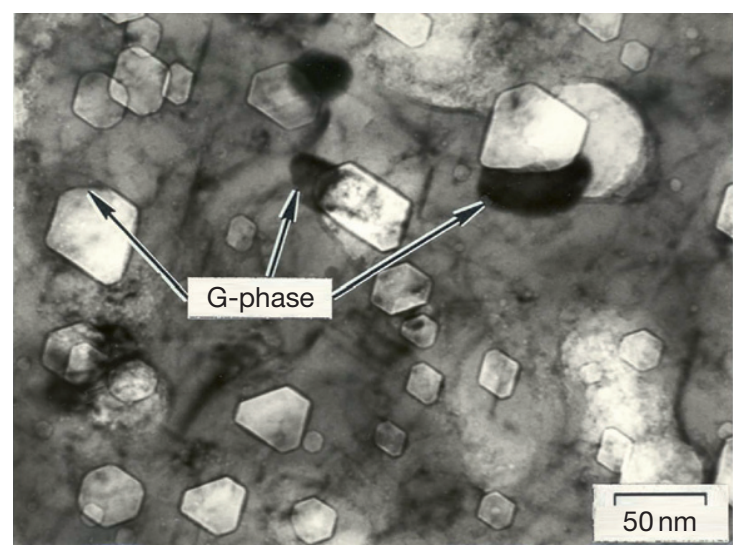

Figure 26 Enlarged cavity formation in association with $\mathrm{G}$ phase $\left(\mathrm{Mn}_{6} \mathrm{Ni}_{16} \mathrm{Si}_{7}\right)$ precipitates in Ti-modified 'prime candidate alloy' austenitic stainless steel following mixed-spectrum fission reactor irradiation at $500^{\circ} \mathrm{C}$ to 11 dpa that generated 200 appm He. Reproduced from Maziasz, P. J. J. Nucl. Mater. 1989, 169, 95-115. 


\subsubsection{Dimensional Instabilities: Irradiation Growth, Creep, and Swelling}

Irradiation growth (due to anisotropic nucleation and growth of dislocation loops on different habit planes) can be of significant practical concern at intermediate temperatures in anisotropic materials such as $\mathrm{Zr}$ alloys, $\mathrm{Be}, \mathrm{BeO}, \mathrm{Al}_{2} \mathrm{O}_{3}$, uranium, and graphite. $40,126,259-261$ Anisotropic growth in individual grains in polycrystalline materials can produce large grain boundary stresses, leading to loss of strength and grain boundary fracture in some materials. Figure 27 shows the large anisotropy in measured lattice parameter change in the basal and prism planes for $\mathrm{BeO}$ irradiated near room temperature. ${ }^{262}$ For neutron fluences above $2 \times 10^{20} \mathrm{~cm}^{-2}(\sim 0.2 \mathrm{dpa})$ with a $c$-axis expansion $>0.5 \%$ and an $a$-axis expansion near $0.1 \%$, a rapid decrease in flexural strength was observed. ${ }^{262,263}$ In materials with highly textured grains, unacceptable anisotropic growth at the macroscopic level can occur. One engineering solution is to use processing techniques to produce randomly aligned, small grain-sized materials.

Irradiation creep occurs in the presence of applied stress, due to biased absorption of point defects at cavities and along specific dislocation orientations relative to the applied stress. ${ }^{264}$ Irradiation creep produces dimensional expansion that acts in addition to normal thermal creep mechanisms and is most

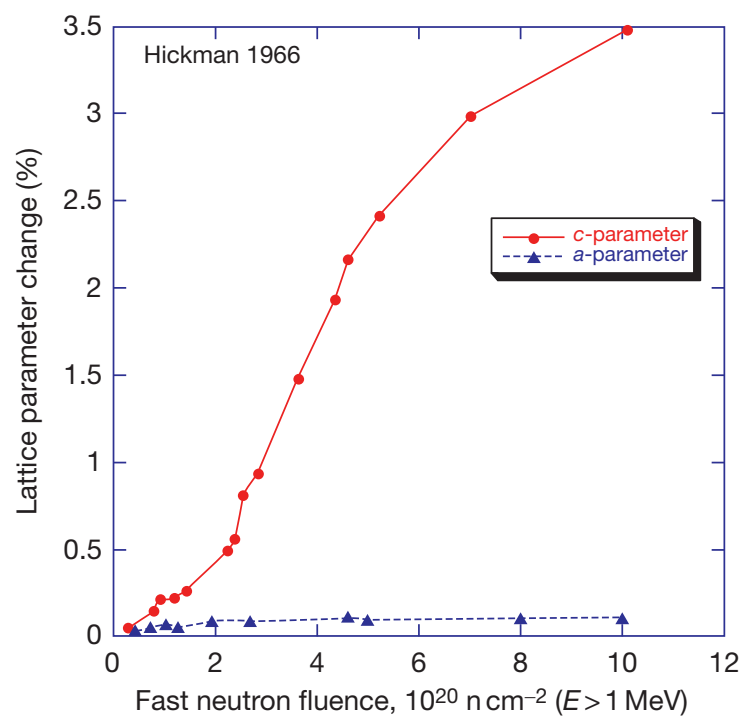

Figure 27 Effect of fission neutron irradiation near $75^{\circ} \mathrm{C}$ on the measured lattice parameter changes for $\mathrm{BeO}$.

Adapted from Hickman, B. S. In Studies in Radiation Effects, Series A: Physical and Chemical; Dienes, G. J., Ed. Gordon and Breach: New York, 1966; Vol. 1, pp 72-158. prominent at temperatures from recovery Stage III up to temperatures where thermal creep deformation becomes rapid (typically above $0.5 T_{\mathrm{M}}$ ). The magnitude of steady-state irradiation creep is proportional to the applied stress level and dose, and consists of a creep compliance term and a void swelling term. The magnitude of typical irradiation creep compliance coefficients ${ }^{260,265,266}$ for fcc and bcc metals is $0.5-1 \times 10^{-12} \mathrm{~Pa}^{-1} \mathrm{dpa}^{-1}$. The irradiation creep compliance for ferritic/martensitic steels appears to be about one-half of that for austenitic steels. ${ }^{109}$ Accelerated irradiation creep due to differential absorption of point defects at low temperatures (e.g. below recovery Stage V) or at low doses can produce creep deformation rates that are up to 10-100 times larger than the steady-state irradiation creep rates. ${ }^{267,268}$

Volumetric swelling from void formation occurs at temperatures above recovery Stage $\mathrm{V}$ in fcc and HCP materials (and above Stage III for bcc materials), and typically exhibits a linear increase with dose after an initial transient regime. As summarized in Figure 28 the dose-dependent swelling in fast fission reactor-irradiated austenitic stainless steel progresses

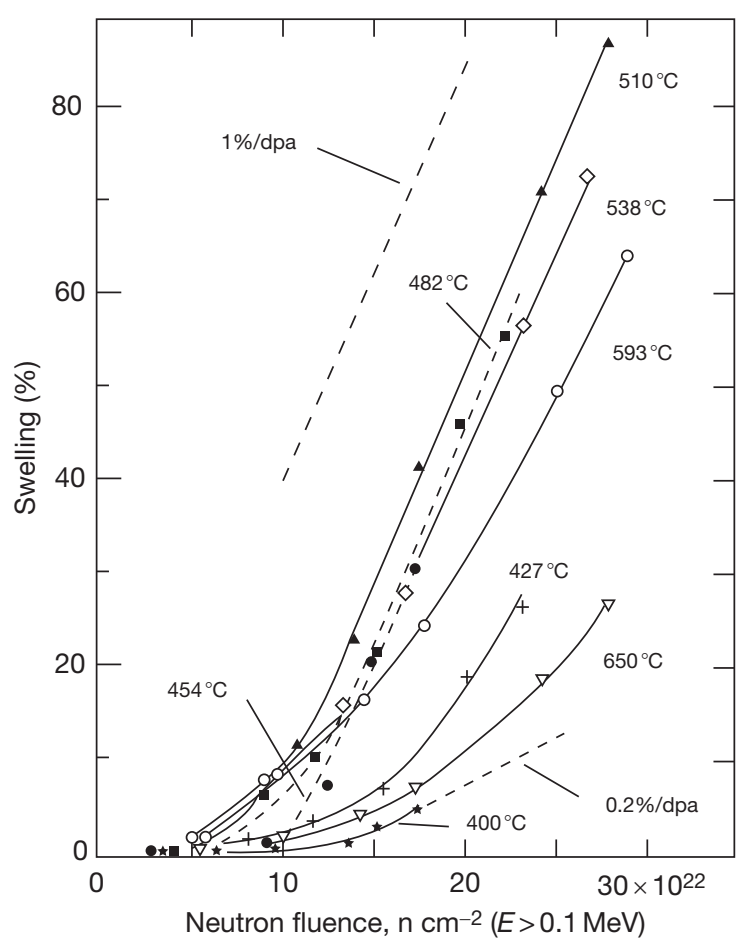

Figure 28 Summary of dose-dependent swelling behavior in $20 \%$ cold-worked Type 316 austenitic stainless steel due to fast fission reactor irradiation. Reproduced from Garner, F. A.; Toloczko, M. B.; Sencer, B. H. J. Nucl. Mater. 2000, 276, 123-142. 
at a swelling rate of $\sim 1 \% / \mathrm{dpa}$ without evidence for saturation up to swelling levels approaching $100 \% .{ }^{109}$ Similar high swelling levels without evidence of saturation have been observed in pure copper ${ }^{108}$ and some simple bcc alloys. ${ }^{131}$ Volumetric swelling levels in structural materials in excess of $\sim 5 \%$ are difficult to accommodate by engineering design, ${ }^{269}$ and additional embrittlement mechanisms may appear in austenitic stainless steel for swelling levels above 10\% including void channeling and loss of ductility. ${ }^{270,271}$ Therefore, there is strong motivation to design structural materials that are resistant to void swelling by introducing a high matrix density of point defect sinks or other techniques. In general, the amount of void swelling is lower in bcc materials compared to fcc materials. ${ }^{50,92,109}$ For example, the observed void swelling in many ferritic/martensitic steels is $<2 \%$ after fission neutron damage levels of $50 \mathrm{dpa}$ or higher, whereas the void swelling in simple austenitic stainless steels may be $30 \%$ or higher. ${ }^{109}$ The superior swelling resistance in ferritic/martensitic steels is largely due to a higher transient dose before onset of steady-state swelling, along with a lower steady-state swelling rate. For many HCP materials, the amount of void swelling is relatively small compared to fcc materials due to anisotropic point defect migration that tends to promote defect recombination. ${ }^{128}$ However, the potential for anisotropic swelling associated with cavity formation in HCP materials may induce large stresses and potential cracking at grain boundaries. ${ }^{263,272,273}$ Figure 29 shows an example of aligned cavity formation and grain boundary separation in $\mathrm{Al}_{2} \mathrm{O}_{3}$ following fast fission reactor irradiation. ${ }^{272}$

\subsubsection{High Temperature Embrittlement}

High temperature helium embrittlement occurs at elevated temperatures (typically near or above $0.5 T_{\mathrm{M}}$ ) when sufficient levels of helium are produced by nuclear transmutation reactions and mechanical stress is applied during irradiation. Intergranular fracture is induced by the transformation of grain boundary bubbles to voids, leading to breakaway growth, cavity coalescence, and rupture in the presence of mechanical stress. ${ }^{120,152,153,274-277}$ The application of tensile stress during high temperature irradiation induces migration of the helium to the grain boundaries, where large cavities can be formed. ${ }^{120}$ In the absence of applied stress, the helium bubbles are distributed throughout the material. The observed tensile ductility due to helium embrittlement decreases with decreasing strain rate ${ }^{120,278}$ and decreasing

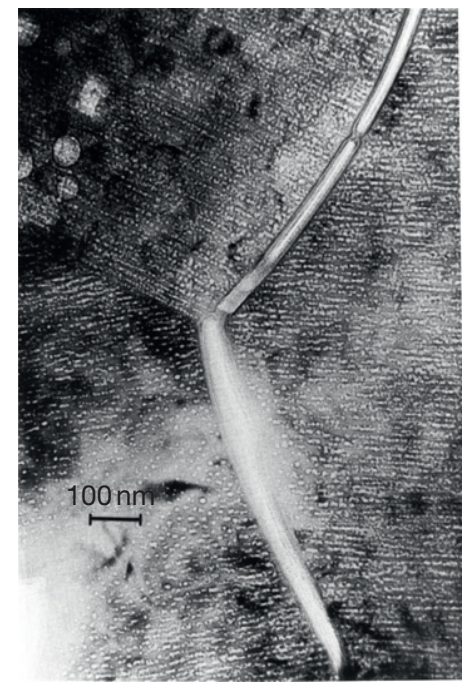

Figure 29 Aligned cavity formation and grain boundary separation in $\mathrm{Al}_{2} \mathrm{O}_{3}$ following fast fission reactor irradiation to $12 \mathrm{dpa}$ at $1100 \mathrm{~K}$. Reproduced from Clinard, F. W., Jr.; Hurley, G. F.; Hobbs, L. W. J. Nucl. Mater. 1982, 108-109, 655-670.

stress $^{120}$ (opposite of the behavior observed in many unirradiated metals and alloys), pointing out the importance of exposure time at elevated temperature on helium embrittlement. Figure 30 shows examples of the grain boundary microstructures of an $\mathrm{Fe}-\mathrm{Cr}-\mathrm{Ni}$ ternary alloy preimplanted with $160 \mathrm{appm}$ He during annealing at $750^{\circ} \mathrm{C}$ with and without applied tensile stress. ${ }^{279}$ Cavity formation along the grain boundary is very limited in the absence of applied stress for annealing times up to $60 \mathrm{~h}$, whereas pronounced grain boundary cavity swelling occurs for annealing times as short as $8 \mathrm{~h}$ when $\sim 20 \mathrm{MPa}$ stress is applied. Evidence for high temperature helium embrittlement has been observed during tensile and creep testing of austenitic stainless steel at temperatures above $550^{\circ} \mathrm{C}$ $\left(\sim 0.45-0.5 T_{\mathrm{M}}\right)$ when the helium concentration exceeds $\sim 30$ appm. ${ }^{255,265,277,280,281}$ Austenitic stainless steels containing fine dispersions of precipitates exhibit better resistance to helium embrittlement than simple $\mathrm{Fe}-\mathrm{Cr}-\mathrm{Ni}$ alloys, and microstructural investigations suggest that helium trapping at grain interior locations (thereby impeding the flow of helium to grain boundaries) is an important factor. ${ }^{152,277,282-284}$ It has been observed that ferritic/martensitic steels exhibit better resistance to grain boundary helium cavity formation and growth compared to austenitic stainless steels. ${ }^{274,285-287}$ This has been attributed to several potential factors, including efficient trapping 


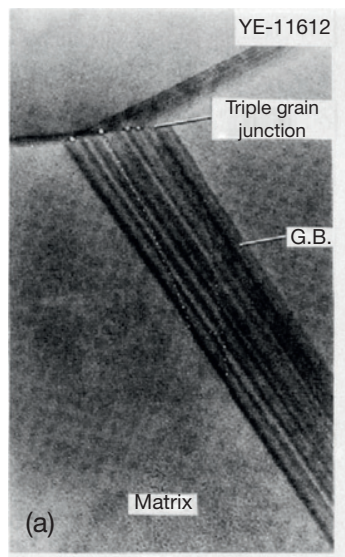

$8 \mathrm{~h}$

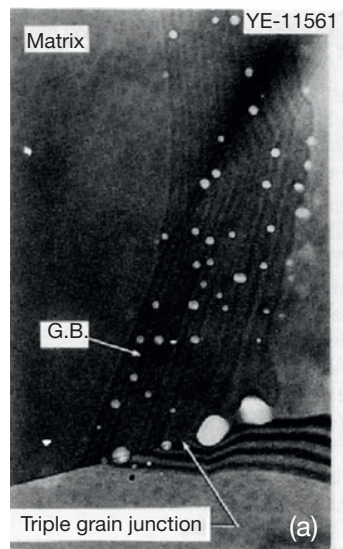

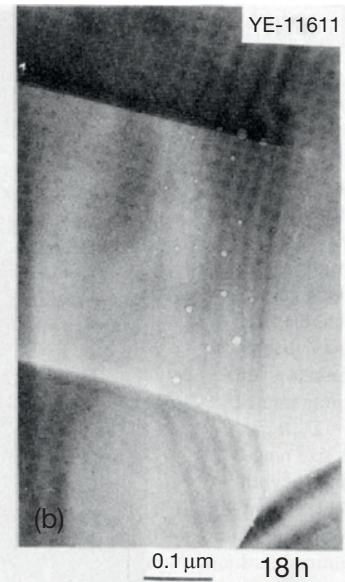

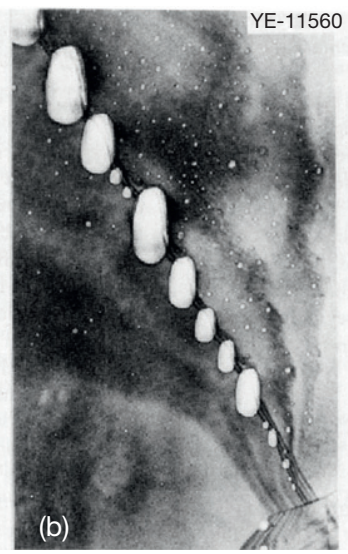

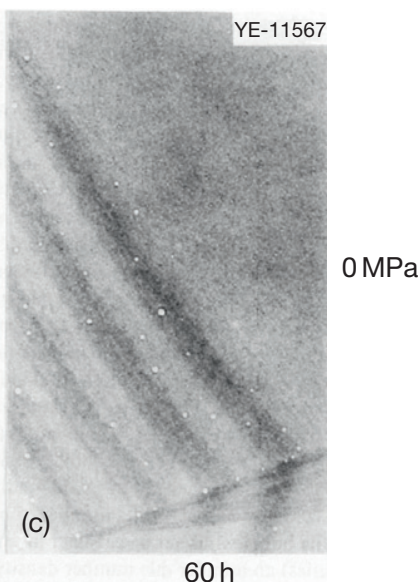

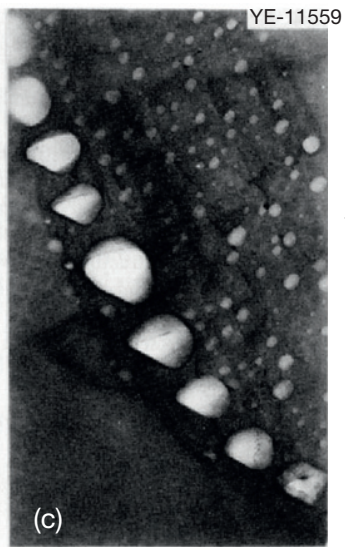

Figure 30 Effect of exposure time and applied stress during annealing at $750^{\circ} \mathrm{C}$ on the formation of grain boundary cavities in Fe-17Cr-17Ni austenitic alloy preimplanted with 160 appm helium. Reproduced from Braski, D. N.; Schroeder, H.; Ullmaier, H. J. Nucl. Mater. 1979, 83, 265-277.

of helium in the ferritic steel grain interior by precipitates and other features, a potentially larger critical radius for conversion of helium bubbles to voids in ferritic steel, and lower matrix strength for ferritic steel compared to austenitic steel. ${ }^{119,274,286,288}$ The helium bubble densities observed in model $\mathrm{Fe}-\mathrm{Cr}$ ferritic alloys and commercial ferritic steels following high temperature implantation are comparable to that observed in austenitic steels. ${ }^{118}$ Relatively good resistance to helium embrittlement compared to austenitic stainless steel has been observed in other bcc metals such as $\mathrm{Nb}$ and $\mathrm{Nb}-1 \mathrm{Zr}$ (no severe embrittlement observed for He concentrations up to 100-500 appm), ${ }^{289-291}$ whereas simple fcc metals such as pure copper are readily susceptible to helium embrittlement even at relatively high (tensile) strain rates at temperatures near $0.5 T_{\mathrm{M}}$ for He concentrations of 100-330 appm. ${ }^{292,293}$

\subsubsection{Examples of Radiation- Induced Microstructural Changes}

\subsubsection{Dislocation Loop Formation}

A common feature in many irradiated metals and nonmetals at temperatures between recovery Stage III and Stage V is dislocation loop formation (either perfect or faulted), with typical loop diameters ranging from $\sim 2$ to $\sim 100 \mathrm{~nm}$. Both vacancy (intrinsic) and interstitial (extrinsic) loops are frequently observed in irradiated materials. The dislocation loop shape is frequently circular (in order to minimize dislocation line length), but rhombus, square, hexagonal, or other shapes have been observed in some materials due to elastic energy considerations. ${ }^{21}$ Figure 31 shows an example of circular faulted interstitial-type dislocation loop formation in $\mathrm{MgAl}_{2} \mathrm{O}_{4}$ due to ion irradiation at $650{ }^{\circ} \mathrm{C}$. The parallel fringes visible in the loop 


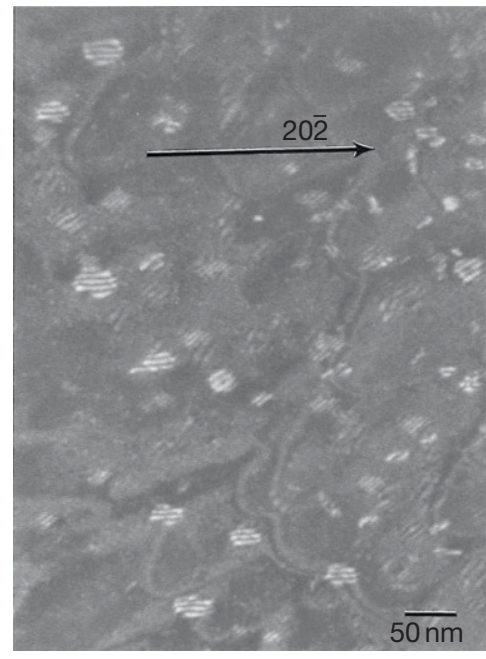

Figure 31 Faulted interstitial-type dislocation loop formation in $\mathrm{MgAl}_{2} \mathrm{O}_{4}$ irradiated with $2 \mathrm{MeV} \mathrm{Al}^{+}$ions at $650^{\circ} \mathrm{C}$ to $14 \mathrm{dpa}$. The image was taken with a beam direction near [101] using weak beam dark field $(g, 6 g)$, $g=20 \overline{2}$ diffraction imaging conditions (data from S. J. Zinkle, unpublished research).

interiors are a signature of the stacking fault and are visible in TEM by selecting the appropriate diffraction imaging conditions. Faulted loop formation is energetically unfavorable in most bcc materials due to their high stacking fault energies, although there is some evidence for formation of small faulted loops in some cases. ${ }^{224}$ Experimental studies using energetic ion beams at cryogenic temperatures (where long range point defect migration does not occur) have obtained convincing evidence for direct formation of visible defect clusters directly within displacement cascades above a threshold energy value. $^{294}$ Dislocation loop formation is usually randomly distributed on the relevant habit planes, with no pronounced spatial correlation. In some cases where mechanical or radiation-induced stresses are present, significant anisotropy occurs regarding the habit planes for loop formation. ${ }^{295,296}$ Within a limited temperature and damage rate regime, the dislocation loop microstructure in some materials also exhibits a tendency to self-organize into aligned walls. ${ }^{297-299}$ Figure 32 shows an example of well-developed defect cluster patterning in pure copper following proton irradiation to $2 \mathrm{dpa} .{ }^{298}$ The defect clusters within the walls consist of SFTs and small dislocation loops.

\subsubsection{Network Dislocation Formation}

Network dislocation structures are routinely observed in metals $s^{5,8,200}$ and ceramics ${ }^{300,301}$ irradiated at

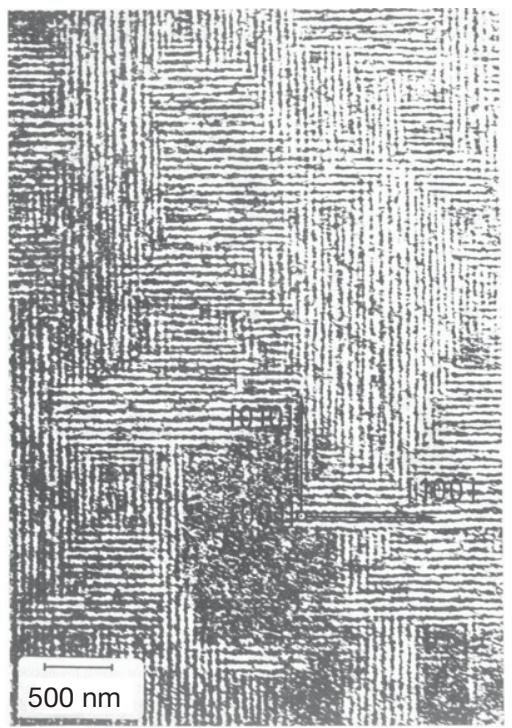

Figure 32 Defect cluster patterning into aligned $\{001\}$ walls in single crystal copper irradiated with protons at $100^{\circ} \mathrm{C}$ to $2 \mathrm{dpa}$. Reproduced from Jäger, W.;

Trinkaus, H. J. Nucl. Mater. 1993, 205, 394-410.

temperatures above recovery Stage I to temperatures in excess of recovery Stage V. During prolonged irradiation, the microstructural evolution typically involves formation and growth of faulted dislocation loops, loop unfaulting to create perfect dislocation loops, and then loop interaction/impingement to form network dislocation structures. The network dislocations are typically randomly distributed and are often heavily jogged as opposed to the relatively straight dislocations found in unirradiated metals. Figure 33 shows a typical network dislocation microstructure for irradiated copper. ${ }^{302}$ The quantitative value of the dislocation density can vary significantly among different materials within the same crystal structure. For example, typical network dislocation densities in irradiated metals at temperatures between recovery Stages III and V range from $\sim 0.01$ to $-0.1 \times 10^{14} \mathrm{~m}^{-2}$ for $\mathrm{Cu}^{302-304}$ to $\sim 1-10 \times 10^{14} \mathrm{~m}^{-2}$ for pure $\mathrm{Ni}^{304}$ and austenitic stainless steel. ${ }^{20}$

\subsubsection{Stacking Fault Tetrahedra}

Irradiation of fcc metals under energetic displacement cascade conditions induces the formation of stacking fault tetrahedra. Figure 34 shows an example of the formation of small dislocation loops and SFTs (triangle-shaped projected images) in copper due to irradiation with $750 \mathrm{MeV}$ protons $(2.5 \mathrm{MeV}$ average PKA energy) at $\sim 90^{\circ} \mathrm{C}$ to $\sim 0.7 \mathrm{dpa}^{302}$ 


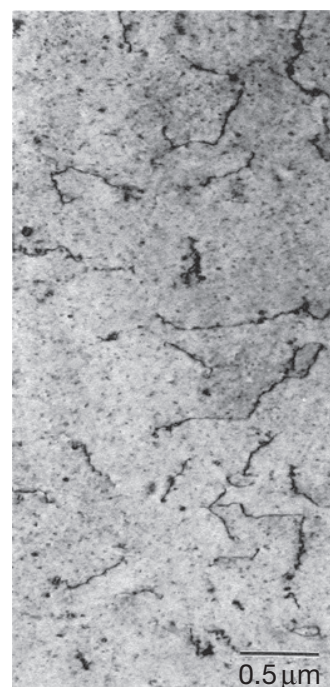

Figure 33 Dislocation microstructure of pure copper following irradiation with $750 \mathrm{MeV}$ protons at $\sim 200^{\circ} \mathrm{C}$ to $\sim 2$ dpa. Reproduced from Zinkle, S. J.; Horsewell, A.;

Singh, B. N.; Sommer, W. F. J. Nucl. Mater. 1994, 212-215, 132-138.

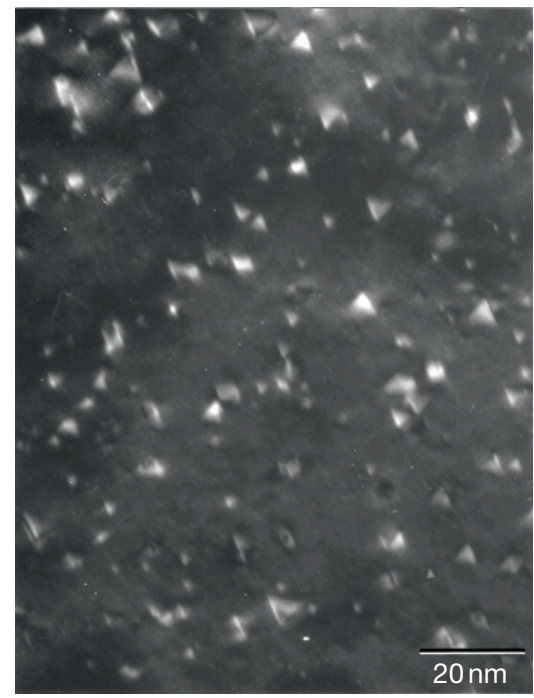

Figure 34 Weak beam dark field $(g, 4 g), g=002$ microstructure of pure copper following irradiation with $750 \mathrm{MeV}$ protons at $\sim 90^{\circ} \mathrm{C}$ to $\sim 0.7 \mathrm{dpa}$. The TEM figure is based on irradiated specimens described in Zinkle et al. ${ }^{302}$ The SFTs are visible as small triangle-shaped defects since the electron beam direction was near [110] (data from S. J. Zinkle, unpublished research).

The SFTs are thermally stable up to recovery Stage V. SFTs have been observed in numerous irradiated fcc metals, including aluminum, ${ }^{305}$ copper, ${ }^{12,53,146,302,306,307}$ nickel, ${ }^{304,307-309}$ silver, ${ }^{306,307}$ gold, ${ }^{307,310,311}$ palladium, ${ }^{310,312}$ and austenitic stainless steels. ${ }^{53,96,307,312,313}$ Evidence from thin film and low-dose irradiation studies using ion beams or other energetic displacement cascade conditions suggests that SFTs can be formed directly in displacement cascades when the PKA energy exceeds a threshold value of $\sim 5-10 \mathrm{keV}$, in agreement with molecular dynamics simulations. ${ }^{26,29}$ There are also several observations of SFT formation in some fcc metals due to point defect nucleation and growth during electron irradiation. ${ }^{299,305}$ The results from irradiations performed under energetic displacement cascade conditions at temperatures near recovery Stage I suggest that SFTs are not visible, perhaps due to insufficient rearrangement of the vacancy-rich core within the rapidly quenched displacement cascade. ${ }^{74,305}$

\subsubsection{Dislocation Channeling and Flow Localization}

Mechanical deformation of metals and alloys after irradiation at temperatures below recovery Stage V produces deformation microstructures that typically evolve from predominantly dislocation cell microstructures in the unirradiated and low-dose irradiated conditions to a variety of localized deformation microstructures above a threshold damage level including twinning, planar dislocation deformation, and formation of dislocation channels. ${ }^{314-316}$ Formation of cleared dislocation channels has been suggested to be the cause of low uniform elongations observed in tensile tests of metals and alloys irradiated at temperatures below recovery Stage $V^{221,317}$ and dislocation channeling is frequently observed following deformation of irradiated materials that exhibit low uniform elongation. . $^{5,96,100,312,316,318-321}$ An alternative mechanism for the low uniform elongations in irradiated materials, based on a material-specific threshold stress for plastic instability, has also been proposed. ${ }^{216,322-324}$ The spacing between dislocation channels is typically on the order of $1 \mu \mathrm{m}$, and the width of the individual channels ranges from $\sim 20$ to $200 \mathrm{~nm}$. Localized deformation visible as surface slip steps in irradiated copper following tensile straining has been directly correlated with cleared dislocation channels. ${ }^{325}$ The matrix regions between the cleared channels do not exhibit evidence of substantial dislocation activity, suggesting that all of the dislocation motion associated with deformation is restricted to the dislocation channel regions. Figure 35 shows an example of cleared dislocation channels observed in austenitic stainless steel following fission neutron 


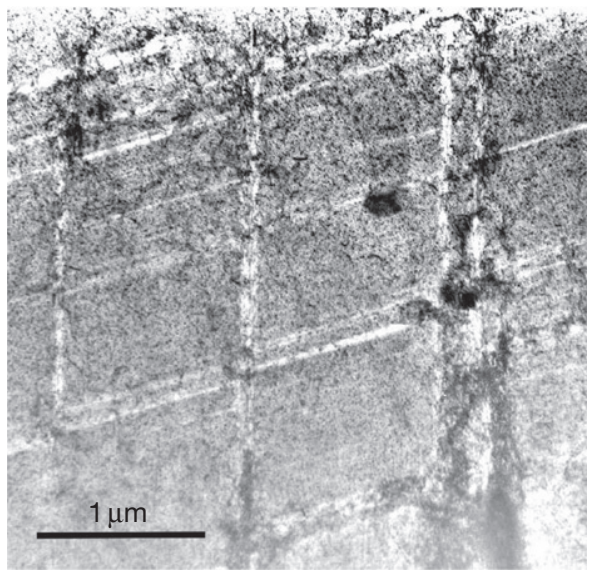

Figure 35 Cleared dislocation channels observed in Type 316 austenitic stainless steel following fission neutron irradiation to $0.78 \mathrm{dpa}$ near $80^{\circ} \mathrm{C}$ and subsequent uniaxial tensile deformation to $32 \%$ strain. The electron beam direction was near [110]. Reproduced from Byun, T. S.; Hashimoto, N.; Farrell, K.; Lee, E. H. J. Nucl. Mater. 2006, 349, 251-264.

irradiation to $0.78 \mathrm{dpa}$ near $80^{\circ} \mathrm{C}$ and subsequent uniaxial tensile deformation to $32 \%$ strain. $^{326}$

The mechanisms responsible for annihilation of SFTs by gliding dislocations within the dislocation channel include stress-induced collapse to triangle loops, multiple shear, partial annihilation with a remnant apex, collapse to a triangle loop or complete annihilation with multiple super jogs, and complete annihilation by screw dislocations followed by cross slip. $^{327-329}$ Computer simulations of dislocation loop interactions with gliding dislocations suggest multiple potential mechanisms that could lead to defectcleared dislocation channels, including absorption, unfaulting, and shear of the loops. ${ }^{330-333}$ Detailed experimental confirmation of these annihilation mechanisms is still needed.

\subsubsection{Crystalline to Amorphous Phase Transitions}

Radiation-induced amorphization can proceed by several different mechanisms, including direct impact amorphization and gradual accumulation of lattice defects and chemical disorder that eventually causes destabilization of the crystalline matrix. ${ }^{213}$ Figure 36 shows an example of the microstructure near the crystalline to amorphous transition dose in ion-irradiated $\mathrm{SiC}$, where the amorphization is induced by gradual buildup of radiation defects. ${ }^{209}$

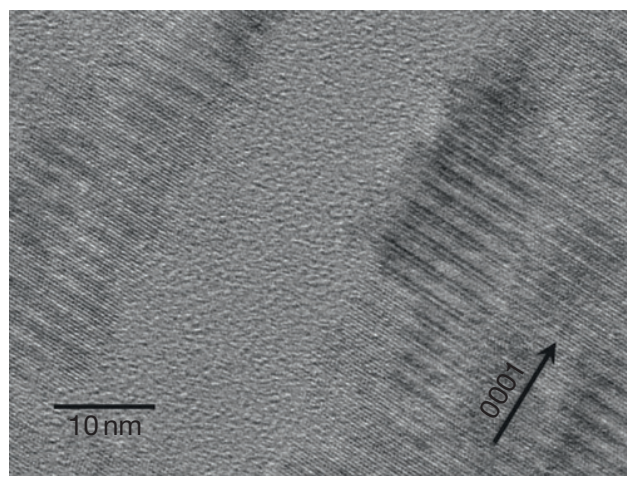

Figure 36 High-resolution transmission electron microscopy image of single crystal $6 \mathrm{H}-\mathrm{SiC}$ following $0.56 \mathrm{MeV} \mathrm{Si}$ ion irradiation at $60^{\circ} \mathrm{C}$ to a damage level of $\sim 2.6$ dpa. Reproduced from Snead, L. L.; Zinkle, S. J.; Hay, J. C.; Osborne, M. C. Nucl. Instrum. Methods B 1998, 141, 123-132.

At intermediate doses, amorphous islands gradually emerge from the initially crystalline matrix in $\mathrm{SiC}$ irradiated at low temperatures. Direct amorphization within individual displacement cascades has been observed in several intermetallic, ${ }^{334}$ semiconductor, ${ }^{12,335}$ and ceramic insulator ${ }^{15,336,337}$ materials. In many other materials, extensive chemical disordering from displacement cascades or point defects precedes amorphization. ${ }^{3,76,87}$ The chemical disordering can be monitored either on the nanoscale dimensions (e.g., due to individual displacement cascades) by techniques such as transmission electron microscopy, ${ }^{12,338}$ or an integrated average value by various techniques including X-ray diffraction, TEM, and Rutherford backscattering spectrometry. ${ }^{76,339}$ As previously noted in Section 1.03.3.8, the intense ionization associated with swift heavy irradiation can lead to amorphization either directly within ion tracks, or by a cumulative process involving chemical disordering before amorphization due to multiple overlapping ion tracks.

\subsubsection{Radiation-Induced Precipitation}

As previously outlined in Sections 1.03.3.9 and 1.03.4, phase changes associated with irradiation can be manifested in a variety of geometries, including randomly distributed matrix or grain boundary precipitates, continuous grain boundary films, precipitatefree zones near grain boundaries or other point defect sinks, spatially ordered arrays of precipitates, large-scale $(>100 \mathrm{~nm})$ phase transformations, and 


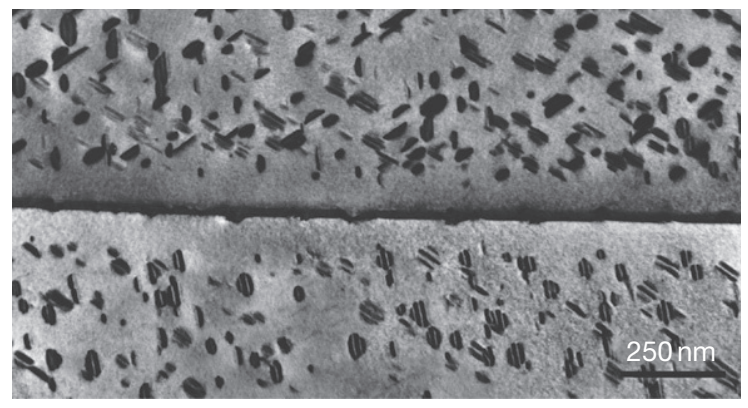

Figure 37 Radiation-induced precipitates on $\{001\}$ habit planes observed next to a grain boundary in $\mathrm{V}-4 \mathrm{Cr}-4 \mathrm{Ti}$ following neutron irradiation to $0.1 \mathrm{dpa}$ at $505^{\circ} \mathrm{C}$. The fringe contrast in the precipitate interior is due to the $a / 3\langle 001\rangle$ displacement vector of the precipitates relative to the vanadium alloy matrix. The beam direction was $\{111\}$ and the diffraction vector was $g=01 \overline{1}$. Reproduced from Rice, P. M.; Zinkle, S. J. J. Nucl. Mater. 1998, 258-263, 1414-1419.

dissolution or growth of thermally stable precipitates. Preferential coupling of solute atoms to point defect fluxes can lead to modifications in the chemistry of precipitates as well as nucleation of phases that would not be stable under thermal equilibrium conditions. Figure 37 shows an example of radiation-induced platelet precipitates observed in the grain interiors of $\mathrm{V}-4 \mathrm{Cr}-4 \mathrm{Ti}$ following neutron irradiation to $0.1 \mathrm{dpa}$ at $505{ }^{\circ} \mathrm{C} .{ }^{224} \mathrm{~A}$ precipitate-free zone is observed adjacent to the grain boundary in this figure.

\subsubsection{Cavity Formation}

Several different cavity geometries are created in irradiated materials. For helium-filled bubbles, the cavity shape is typically spherical. For voids, faceted cavities with faces corresponding to low-index crystallographic planes are often created, e.g. truncated $\{111\}$ octahedra or $\{001\}$ cubes in fcc materials, truncated $\{110\}$ dodecahedra or $\{001\}$ cubes in bcc materials, and more complex shapes in HCP materials, ${ }^{21,22,340-342}$ although nearly spherical shapes are also sometimes observed for voids. When helium is generated during irradiation (due to neutroninduced transmutation reactions, etc.), a bimodal cavity distribution is usually observed with the small cavities corresponding to helium-filled bubbles and the large cavities corresponding to underpressurized voids. The critical radius transition between bubbles and voids is determined by a balance between dislocation bias-induced vacancy influx and pressure-modified thermal emission of vacancies. ${ }^{120,151,208,274,343}$ Figure 38

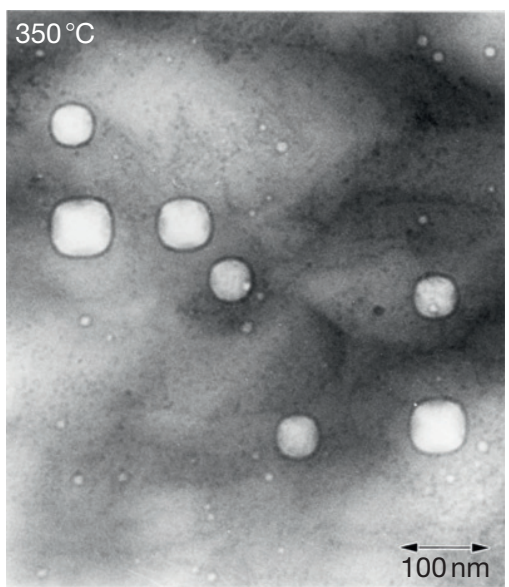

Figure 38 Voids and small helium-filled bubbles in a copper-boron alloy following fission neutron irradiation to $1.2 \mathrm{dpa}$ at $350^{\circ} \mathrm{C}$. Reproduced from Zinkle, S. J.; Farrell, K.; Kanazawa, H. J. Nucl. Mater. 1991, 179-181, 994-997.

shows an example of large faceted voids and small helium-filled spherical bubbles in a neutronirradiated copper-boron alloy. ${ }^{107}$ The visible cavity density usually increases rapidly at low doses, and approaches a constant value for damage levels above $\sim 1-50 \mathrm{dpa}$. The void size tends to increase continuously with increasing dose.

Well-developed periodic void lattices have been observed in several irradiated materials. ${ }^{297,344,345}$ Void lattice formation has most frequently been observed in bcc materials, but periodically aligned void structures have also been observed in $\mathrm{HCP}^{272,346,347}$ and fcc $^{303,348-351}$ materials. Aligned voids have been observed in both metals and ceramic insulators. The aligned cavities in HCP materials are usually manifested as one- or two-dimensional arrays perpendicular or parallel to the basal plane, respectively. ${ }^{297,346}$ The void lattices in bcc and fcc materials adopts the same three-dimensional crystallographic symmetry as the host lattice. ${ }^{297}$ The swelling levels in bcc metals with well-developed void lattices are typically a few percent, which has led to hypotheses that void lattice formation may coincide with a cessation in steadystate swelling. ${ }^{117,352}$ The saturation in void swelling is associated with achieving a constant average void size. Figure 39 shows an example of a well-developed bcc void lattice in ion-irradiated $\mathrm{Nb}-1 \mathrm{Zr}^{353}$ In the study by Loomis et al. it was reported that void lattice formation did not occur unless a threshold level of oxygen was present (60-2700 appm oxygen, depending on the irradiated material). 


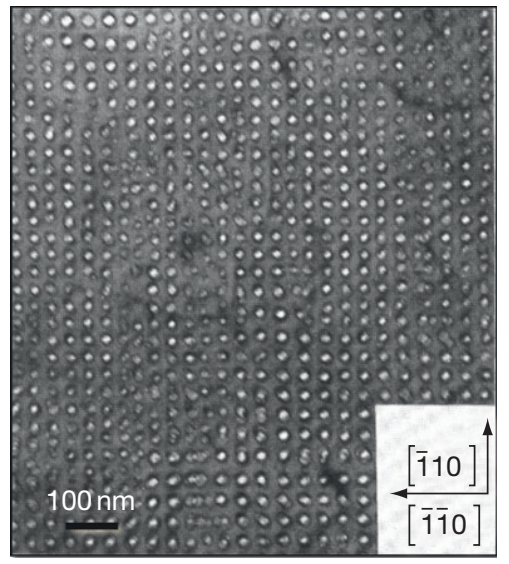

Figure 39 Void lattice formation in $\mathrm{Nb}-1 \mathrm{Zr}$ containing 2700 appm oxygen following irradiation with $3.1 \mathrm{MeV} \mathrm{V}^{+}$ ions to $50 \mathrm{dpa}$ at $780^{\circ} \mathrm{C}$. Reproduced from Loomis, B. A.; Gerber, S. B.; Taylor, A. J. Nucl. Mater. 1977, 68, 19-31.

\subsubsection{Summary}

Radiation-induced microstructural modifications can create large changes in the physical and mechanical properties of materials, as detailed in accompanying chapters in this book. The two most important extrinsic variables that influence microstructural evolution under irradiation are the radiation damage level and temperature. Many similarities are observed for diverse materials and irradiation spectra if the comparisons are performed at comparable damage levels and defect mobility regimes (defect recovery stages). The PKA energy often exerts a significant influence on the microstructural evolution, in particular by inducing direct cascade amorphization or creation of defect clusters within displacement cascades when the PKA energy exceeds a threshold energy value. Numerous other parameters such as dose rate, crystal structure, and atomic weight typically exert less pronounced influence on microstructural evolution, although very large qualitative and quantitative effects can be observed under some circumstances.

\section{Acknowledgments}

Much of the author's work discussed in this chapter was sponsored by the U.S. Department of Energy, Office of Fusion Energy Sciences.

\section{References}

1. Zinkle, S. J.; Ice, G. E.; Miller, M. K.; Pennycook, S. J.; Wang, X.-L. J. Nucl. Mater. 2009, 386-388, 8-14.
2. Zhang, Y.; Weber, W. J.; Jiang, W.; Hallen, A.; Possnert, G. J. Appl. Phys. 2002, 91(10), 6388-6395.

3. Kinoshita, C. J. Electron Microsc. 1985, 34(4), 299-310.

4. Kinoshita, C. J. Nucl. Mater. 1992, 191-194, 67-74.

5. Kiritani, M. In Fundamental Aspects of Radiation Damage in Metals, CONF-751006-P2, Robinson, M. T., Young, F. W., Jr., Eds. National Tech. Inform. Service: Springfield, VA, 1975; Vol. II, pp 695-714.

6. Kiritani, M.; Yoshida, N.; Takata, H.; Maehara, Y. J. Phys. Soc. Jpn. 1975, 38(6), 1677-1686.

7. English, C. A. J. Nucl. Mater. 1982, 108-109, 104-123.

8. Eyre, B. L. J. Phys. F 1973, 3(2), 422-470.

9. Eyre, B. L. In Fundamental Aspects of Radiation Damage in Metals, CONF-751006-P2, Robinson, M. T., Young, F. W., Jr., Eds. National Tech. Inform. Service: Springfield, VA, 1975; Vol. II, pp 729-763.

10. Farrell, K. Radiat. Effects 1980, 53, 175-194.

11. Gelles, D. S. In Reduced Activation Materials for Fusion Reactors, Klueh, R. L., Gelles, D. S., Okada, M., Packan, N. H., Eds. American Society for Testing and Materials: Philadelphia, PA, 1990; pp 113-129.

12. Kiritani, M. J. Nucl. Mater. 1986, 137, 261-278.

13. Kiritani, M., Recoil energy effects and defect processes in neutron irradiated metals. J. Nucl. Mater. 1988, 155-157, 113-120.

14. Kiritani, M., Defect interaction processes controlling the accumulation of defects produced by high energy recoils. J. Nucl. Mater. 1997, 251, 237-251.

15. Weber, W. J.; Ewing, R. C.; Catlow, C. R. A.; et al. J. Mater. Res. 1998, 13(6), 1434-1484.

16. Wilkens, M. In Vacancies and Interstitials in Metals: Seeger, A., Schumacher, D., Schilling, W., Diehl, J., Eds. North-Holland: Amsterdam, 1970; pp 485-529.

17. Zinkle, S. J. Nucl. Instrum. Methods B 1994, 91, 234-246.

18. Zinkle, S. J.; Kinoshita, C. J. Nucl. Mater. 1997, 251, 200-217.

19. Zinkle, S. J.; Matsukawa, Y. J. Nucl. Mater. 2004, 329-333, 88-96.

20. Zinkle, S. J.; Maziasz, P. J.; Stoller, R. E. J. Nucl. Mater. 1993, 206, 266-286.

21. Smallman, R. E.; Westmacott, K. H. Mater. Sci. Eng. 1972, 9(5), 249-272.

22. Zinkle, S. J.; Seitzman, L. E.; Wolfer, W. G. Philos. Mag. A 1987, 55(1), 111-125.

23. Bacon, D. J.; Gao, F.; Osetsky, Y. N. J. Nucl. Mater. 2000, 276, 1-12.

24. Silcox, J.; Hirsch, P. B. Philos. Mag. 1959, 4, 72-89.

25. Matsukawa, Y.; Zinkle, S. J. Science 2007, 318, 959-962.

26. Osetsky, Y. N.; Bacon, D. J. Nucl. Instrum. Methods $B$ 2001, 180, 85-90.

27. Osetsky, Y. N.; Serra, A.; Victoria, M.; Golubov, S. I.; Priego, V. Philos. Mag. A 1999, 79, 2285-2311.

28. Osetsky, Y. N.; Stoller, R. E.; Matsukawa, Y. J. Nucl. Mater. 2004, 329-333, 1228-1232.

29. Nordlund, K.; Gao, F. Appl. Phys. Lett. 1999, 74(18), 2720-2722.

30. Kiritani, M. Mater. Sci. Forum 1987, 15-18, 1023-1046.

31. Kiritani, M. Mater. Chem. Phys. 1997, 50, 133-138.

32. Sekimura, N.; Kanzaki, Y.; Okada, S. R.; Masuda, T.; Ishino, S. J. Nucl. Mater. 1994, 212-215, 160-163.

33. Zinkle, S. J.; Wolfer, W. G.; Kulcinski, G. L.; Seitzman, L. E. Philos. Mag. A 1987, 55(1), 127-140.

34. Norgett, M. J.; Robinson, M. T.; Torrens, I. M. Nucl. Eng Des. 1975, 33, 50-54.

35. Oen, O. S. Cross Sections for Atomic Displacements in Solids by Fast Electrons; ORNL-4897; Oak Ridge National Lab: Oak Ridge, TN, 1973; p 204.

36. Doran, D. G.; Graves, N. J. Displacement Cross Sections and PKA Spectra: Tables and Applications; HEDL-TME 
76-70, Hanford Engineering Development Laboratory: Richland, WA, 1976.

37. Ziegler, J. F.; Biersak, J. P.; Littmark, U. The Stopping and Range of lons in Solids; Pergamon: New York, 1985.

38. Zinkle, S. J.; Singh, B. N. J. Nucl. Mater. 1993, 199, 173-191.

39. Averback, R. S.; Diaz de la Rubia, T. Solid State Phys. 1998, 51, 281-402.

40. Schilling, W.; Ullmaier, H. In Nuclear Materials, Part 2, Frost, B. R. T., Ed. VCH: Weinheim, Germany, 1992; Vol. 10B, pp 179-241.

41. Yasunaga, K.; Yasuda, K.; Matsumura, S.; Sonoda, T. Nucl. Instrum. Methods Phys. Res. B 2008, 266(12-13), 2877-2881.

42. Averback, R. S. J. Nucl. Mater. 1994, 216, 49-62.

43. Diaz de la Rubia, T.; Soneda, N.; Caturla, M. J.; Alonso, E. A. J. Nucl. Mater. 1997, 251, 13-33.

44. Phythian, W. J.; Stoller, R. E.; Foreman, A. J. E.; Calder, A. F.; Bacon, D. J. J. Nucl. Mater. 1995, 223, 245-261.

45. Stoller, R. E. J. Nucl. Mater. 2000, 276, 22-32.

46. Diaz de la Rubia, T.; Phythian, W. J. J. Nucl. Mater. 1992, 191-194, 108-115.

47. Kiritani, M. J. Nucl. Mater. 2000, 276(1-3), 41-49.

48. Muroga, T.; Kitajima, K.; Ishino, S. J. Nucl. Mater. 1985, 133-134, 378-382.

49. Barashev, A. V.; Golubov, S. I. Philos. Mag. 2009, 89(31), 2833-2860.

50. Golubov, S. I.; Singh, B. N.; Trinkaus, H. J. Nucl. Mater. 2000, 276, 78-89.

51. Trinkaus, H.; Heinisch, H. L.; Barashev, A. V.; Golubov, S. I.; Singh, B. N. Phys. Rev. B 2002, 66(6), 060105.

52. Trinkaus, H.; Singh, B. N.; Golubov, S. I. J. Nucl. Mater. 2000, 283-287, 89-98.

53. Zinkle, S. J.; Sindelar, R. L. J. Nucl. Mater. 1988 155-157, 1196-1200.

54. Kiritani, M. Ultramicroscopy 1991, 39(1-4), 180-186.

55. Kiritani, M.; Takata, H. J. Nucl. Mater. 1978, 69-70, 277-309.

56. Kiritani, M. J. Nucl. Mater. 1994, 216, 220-264.

57. Heinisch, H. L.; Singh, B. N. Philos. Mag. A 1993, 67(2), 407-424.

58. Stoller, R. E., Oak Ridge National Lab, private communication, 2010.

59. Stoller, R. E.; Greenwood, L. R. J. Nucl. Mater. 1999, 271-272, 57-62.

60. Zinkle, S. J.; Victoria, M.; Abe, K. J. Nucl. Mater. 2002 307-311, 31-42.

61. Corbett, J. W. Electron Radiation Damage in Semiconductors and Metals. Academic Press: New York, 1966; p 410.

62. Dienes, G. J.; Vineyard, G. H. Radiation Effects in Solids; Interscience Publishers: New York, 1957.

63. Schilling, W.; Ehrhart, P.; Sonnenberg, K. In Fundamental Aspects of Radiation Damage in Metals, CONF-751006-P1; Robinson, M. T., Young, F. W., Jr., Eds. National Tech. Inform. Service: Springfield, VA, 1975; Vol. I, pp 470-492.

64. Seeger, A. K. In Radiation Damage in Solids; IAEA: Vienna, 1962; Vol. 1, pp 101-127.

65. Agullo-Lopez, F.; Catlow, C. R. A.; Townsend, P. D. Point Defects in Materials. Academic Press: San Diego, CA, 1988; p 445

66. Hautojarvi, P.; Pollanen, L.; Vehanen, A.; Yli-Kauppila, J. J. Nucl. Mater. 1983, 114(2-3), 250-259.

67. Lefevre, J.; Costantini, J. M.; Esnouf, S.; Petite, G. J. Appl. Phys. 2009, 106(8), 083509.

68. Schultz, H. Mater. Sci. Eng. A 1991, 141, 149-167.
69. Xu, Q.; Yoshiie, T.; Mori, H. J. Nucl. Mater. 2002, 307-311(2), 886-890

70. Mansur, L. K. J. Nucl. Mater. 1993, 206, 306-323.

71. Sizmann, R. J. Nucl. Mater. 1978, 69-70, 386-412.

72. Walker, R. M. In Radiation Damage in Solids; Billington, D. S., Ed. Academic Press: New York, 1962; pp 594-629.

73. Makin, M. J.; Minter, M. J. Acta Metall. 1960, 8, 691-699.

74. Shimomura, Y. J. Nucl. Mater. 1990, 174(2-3), 210-219.

75. Zee, R. H.; Wilkes, P. Philos. Mag. A 1980, 42(4), 463-482.

76. Jiang, W.; Weber, W. J.; Lian, J.; Kalkhoran, N. M. J. Appl. Phys. 2009, 105(1), 013529.

77. Schmitz, G.; Ewert, J. C.; Harbsmeier, F.; Uhrmacher, M. Phys. Rev. B 2001, 63(22), 224113.

78. Birtcher, R. C.; Averback, R. S.; Blewitt, T. H. J. Nucl. Mater. 1978, 75(1), 167-176.

79. Horak, J. A.; Blewitt, T. H. J. Nucl. Mater. 1973, 49, 161-180.

80. Horak, J. A.; Blewitt, T. H. Nucl. Technol. 1975, 27(3), 416-438.

81. Nakagawa, M.; Böning, K.; Rosner, P.; Vogl, G. Phys. Rev. B 1977, 16(12), 5285-5302.

82. Nakagawa, M.; Mansel, W.; Boning, K.; Rosner, P.; Vogl, G. Phys. Rev. B 1979, 19(2), 742-748.

83. Birtcher, R. C.; Blewitt, T. H. J. Nucl. Mater. 1981, 98 , 63-70.

84. Birtcher, R. C.; Blewitt, T. H. J. Nucl. Mater. 1988, 152(2-3), 204-211.

85. Weber, W. J. J. Am. Ceram. Soc. 1993, 76(7), 1729-1738.

86. Hobbs, L. W.; Sreeram, A. N.; Jesurum, C. E.; Berger, B. A. Nucl. Instrum. Methods B 1996, 116, 18-25.

87. Lam, N.; Okamoto, P. R.; Li, M. J. Nucl. Mater. 1997, 251 89-97.

88. Sabochick, M. J.; Lam, N. Phys. Rev. B 1991, 43(7), 5243-5252.

89. Wendler, E.; Bilani, O.; Gärtner, K.; et al. Nucl. Instrum. Methods Phys. Res. B 2009, 267(16), 2708-2711.

90. Yoshida, N.; Kiritani, M. J. Phys. Soc. Jpn. 1973, 35(5), 1418-1429.

91. Zinkle, S. J.; Snead, L. L.; Eatherly, W. S.; Jones, J. W.; Hensley, D. K. In Microstructural Processes During Irradiation; Zinkle, S. J., Lucas, G. E., Ewing, R. C. Williams, J. S., Eds. Materials Research Society: Warrendale, PA, 1999; Vol. 540, pp 305-310.

92. Singh, B. N.; Evans, J. H. J. Nucl. Mater. 1995, 226 , 277-285.

93. Singh, B. N.; Zinkle, S. J. J. Nucl. Mater. 1993, 206, 212-229.

94. Zinkle, S. J. Radiat. Eff. Defects Solids 1999, 148, 447-477.

95. Hashimoto, N.; Byun, T. S.; Farrell, K.; Zinkle, S. J. J. Nucl. Mater. 2004, 329-333, 947-952.

96. Hashimoto, N.; Byun, T. S.; Farrell, K. J. Nucl. Mater. 2006, 351(1-3), 295-302.

97. Diaz de la Rubia, T.; Averback, R. S.; Hsieh, H.; Benedek, R. J. Mater. Res. 1989, 4(3), 579-586.

98. Flynn, C. P.; Averback, R. S. Phys. Rev. B 1988, 38(10), 7118-7120.

99. Eldrup, M.; Singh, B. N.; Zinkle, S. J.; Byun, T. S.; Farrell, K. J. Nucl. Mater. 2002, 307-311, 912-917.

100. Zinkle, S. J.; Singh, B. N. J. Nucl. Mater. 2006, 351, 269-284.

101. Li, M.; Eldrup, M.; Byun, T. S.; Hashimoto, N.; Snead, L. L.; Zinkle, S. J. J. Nucl. Mater. 2008, 376(1), 11-28.

102. Eldrup, M.; Li, M.; Snead, L. L.; Zinkle, S. J. Nucl. Instrum. Methods Phys. Res. B 2008, 266(16), 3602-3606.

103. Rowcliffe, A. F.; Lee, E. H. J. Nucl. Mater. 1982, 108-109, 306-318. 
104. Kai, J. J.; Klueh, R. L. J. Nucl. Mater. 1996, 230 , 116-123.

105. Klueh, R. L.; Harries, D. R. High-Chromium Ferritic and Martensitic Steels for Nuclear Applications. American Society for Testing and Materials: West Conshohocken, PA, 2001; p 221.

106. Maziasz, P. J. J. Nucl. Mater. 1989, 169, 95-115.

107. Zinkle, S. J.; Farrell, K.; Kanazawa, H. J. Nucl. Mater. 1991, 179-181, 994-997.

108. Garner, F. A.; Hamilton, M. L.; Shikama, T.; Edwards, D. J.; Newkirk, J. W. J. Nucl. Mater. 1992, 191-194, 386-390.

109. Garner, F. A.; Toloczko, M. B.; Sencer, B. H. J. Nucl. Mater. 2000, 276, 123-142.

110. Zinkle, S. J.; Farrell, K. J. Nucl. Mater. 1989, 168, 262-267.

111. Maksimkin, O. P.; Tsai, K. V.; Turubarova, L. G.; Doronina, T.; Garner, F. A. J. Nucl. Mater. 2004, 329-333, 625-629.

112. Maksimkin, O. P.; Tsai, K. V.; Turubarova, L. G.; Doronina, T.; Garner, F. A. J. Nucl. Mater. 2007, 367-370, 990-994.

113. Porollo, S. I.; Konobeev, Y. V.; Dvoriashin, A. M.; Vorobjev, A. N.; Krigan, V. M.; Garner, F. A. J. Nucl. Mater. 2002, 307-311, 339-342.

114. Adda, Y. In Radiation-Induced Voids in Metals; Corbett, J. W., Ianniello, L. C., Eds. National Technical Information Service: Springfield, VA, 1972; pp 31-81.

115. Budylkin, N.; Mironova, E. G.; Chernov, V. M.; Krasnoselov, V. A.; Porollo, S. I.; Garner, F. A. J. Nucl. Mater. 2008, 375(3), 359-364.

116. Garner, F. A.; Greenwood, L. R.; Edwards, D. J. J. Nucl. Mater. 1994, 212-215, 426-430.

117. Garner, F. A.; Stubbins, J. F. J. Nucl. Mater. 1994, 212-215, 1298-1302.

118. Singh, B. N.; Trinkaus, H. J. Nucl. Mater. 1992, 186, 153-165.

119. Trinkaus, H.; Singh, B. N. J. Nucl. Mater. 2003, 323(2-3), 229-242.

120. Ullmaier, H. Nucl. Fusion 1984, 24(8), 1039-1083.

121. Klabunde, C. E.; Coltman, R. R., Jr. J. Nucl. Mater. 1982 108-109, 183-193.

122. Jenkins, M. L.; Kirk, M. A.; Phythian, W. J. J. Nucl. Mater. 1993, 205, 16-30.

123. Phythian, W. J.; English, C. A.; Yellen, D. H.; Bacon, D. J. Philos. Mag. A 1991, 63(5), 821-833.

124. Zinkle, S. J. In 15th Int. Symp. on Effects of Radiation on Materials, ASTM STP 1125, Stoller, R. E., Kumar, A. S., Gelles, D. S., Eds. American Society for Testing and Materials: Philadelphia, PA, 1992; pp 749-763.

125. Bacon, D. J. J. Nucl. Mater. 1993, 206(2-3), 249-265.

126. Griffiths, M. J. Nucl. Mater. 1993, 205, 225-241.

127. Roof, R. B., Jr.; Ranken, W. A. J. Nucl. Mater. 1975, 55, 357-358.

128. Woo, C. H. J. Nucl. Mater. 2000, 276, 90-103.

129. Keilholtz, G. W.; Moore, R. E. Nucl. Applic. 1967, 3, 686-691.

130. Fukumoto, K.; Kimura, A.; Matsui, H. J. Nucl. Mater. 1996, 258-263, 1431-1436.

131. Garner, F. A.; Gelles, D. S.; Takahashi, H.; Ohnuki, S.; Kinoshita, H.; Loomis, B. A. J. Nucl. Mater. 1992, 191-194, 948-951.

132. Snead, L. L.; Burchell, T. D.; Katoh, Y. J. Nucl. Mater. 2008, 381(1-2), 55-61.

133. Gelles, D. S. J. Nucl. Mater. 1996, 233-237, 293-298.

134. Lee, E. H.; Mansur, L. K. Metall. Trans. A 1990, 21(5), 1021-1035.

135. Kim, I.-S.; Hunn, J. D.; Hashimoto, N.; et al. J. Nucl. Mater. 2000, 280(3), 264-274.

136. Naguib, H. M.; Kelly, R. Radiat. Effects 1975, 25, 1-12.
137. Trachenko, K. J. Phys.: Condens. Matter 2004, 16(49), R1491-R1515.

138. Inui, H.; Mori, H.; Fujita, H. Acta Metall. 1989, 37(5), 1337-1342.

139. Zinkle, S. J.; Snead, L. L. Nucl. Instrum. Methods B 1996, 116, 92-101.

140. Sickafus, K. E.; Grimes, R. W.; Valdez, J. A.; et al. Nature Mater. 2007, 6(3), 217-223.

141. Sickafus, K. E.; Minervini, L.; Grimes, R. W.; et al. Science 2000, 289(5480), 748-751.

142. Schroeder, K. Radiat. Effects 1970, 5, 255-263.

143. Thompson, L. J.; Youngblood, G.; Sosin, A. Radiat. Effects 1973, 20, 111-134.

144. Wollenberger, H. J. In Vacancies and Interstitials in Metals; Seeger, A., Schumacher, D., Schilling, W., Diehl, J., Eds. North-Holland: Amsterdam, 1970; pp 215-254.

145. Kiritani, M. J. Nucl. Mater. 1989, 169, 89-94.

146. Zinkle, S. J. J. Nucl. Mater. 1987, 150, 140-158.

147. Motta, A. T.; Olander, D. R. Acta Metall. Mater. 1990, 38(11), 2175-2185.

148. Snead, L. L.; Zinkle, S. J.; Eatherly, W. S.; Hensley, D. K.; Vaughn, N. L.; Jones, J. W. In Microstructural Processes During Irradiation; Zinkle, S. J., Lucas, G. E., Ewing, R. C., Williams, J. S., Eds. Materials Research Society: Warrendale, PA, 1999; Vol. 540, pp 165-170.

149. Mansur, L. K. Nucl. Technol. 1978, 40(1), 5-34.

150. Mansur, L. K. J. Nucl. Mater. 1994, 216, 97-123.

151. Mansur, L. K.; Coghlan, W. A. J. Nucl. Mater. 1983, 119(1), 1-25.

152. Trinkaus, H. J. Nucl. Mater. 1983, 118(1), 39-49.

153. Trinkaus, H. J. Nucl. Mater. 1985, 133-134, 105-112.

154. Garner, F. A. J. Nucl. Mater. 1983, 117, 177-197.

155. Glowinski, L. D.; Fiche, C.; Lott, M. J. Nucl. Mater. 1973, 47(3), 295-310.

156. Lanore, J. M.; Glowinski, L.; Risbet, A.; et al. In Fundamental Aspects of Radiation Damage in Metals, CONF-751006-P2; Robinson, M. T., Young, F. W., Jr., Eds. National Tech. Inform. Service: Springfield, VA, 1975; Vol. II, pp 1169-1180.

157. Singh, B. N.; Zinkle, S. J. J. Nucl. Mater. 1994, 217(1-2), 161-171.

158. Smidt, F. A., Jr.; Reed, J. R.; Sprague, J. A. In Radiation Effects in Breeder Reactor Structural Materials; Bleiberg, M. L., Bennett, J. W., Eds. TMS-AIME: New York, 1977; pp 337-346.

159. Zinkle, S. J.; Skuratov, V. A.; Hoelzer, D. T. Nucl. Instrum Methods B 2002, 191, 758-766.

160. Egerton, R. F.; Li, P.; Malac, M. Micron 2004, 35(6), 399-409.

161. Itoh, N.; Stoneham, A. M. Materials Modification by Electronic Excitation. Cambridge University Press: Cambridge, UK, 2001; pp 1-536.

162. Itoh, N.; Tanimura, K.; Nakai, Y. Nucl. Instrum. Methods B 1992, 65, 21-25.

163. Sibley, W. A. Nucl. Instrum. Methods B 1984, 1(2-3), 419-426.

164. Bourgoin, J. C. Radiat. Eff. Defects Solids 1989, 111-112(1-2), 29-36.

165. Bourgoin, J. C.; Corbett, J. W. J. Chem. Phys. 1973, 59(8), 4042-4046.

166. Bourgoin, J. C.; Corbett, J. W. Radiat. Effects 1978, 36, 157-188.

167. Corbett, J. W.; Bourgoin, J. C. IEEE Trans. Nucl. Sci. 1971, 18(6), 11-20.

168. Kimerling, L. C. Solid-State Electron 1978, 21, 1391-1401.

169. Zinkle, S. J. J. Nucl. Mater. 1995, 219, 113-127.

170. Zinkle, S. J. In Microstructure Evolution During Irradiation; Robertson, I. M., Was, G. S., Hobbs, L. W., 
Diaz de la Rubia, T., Eds. Materials Research Society: Pittsburgh, PA, 1997; Vol. 439, pp 667-678.

171. Dammak, H.; Dunlop, A.; Lesueur, D. Nucl. Instrum. Methods Phys. Res. B 1996, 107(1-4), 204-211.

172. Szenes, G. Phys. Rev. B 1995, 51(13), 8026-8029.

173. Toulemonde, M.; Dufour, C.; Meftah, A.; Paumier, E. Nucl. Instrum. Methods B 2000, 166-167, 903-912.

174. Toulemonde, M.; Trautmann, C.; Balanzat, E.; Hjort, K.; Weidinger, A. Nucl. Instrum. Methods Phys. Res. B 2004, 216, 1-8.

175. Wang, Z. G.; Dufour, C.; Paumier, E.; Toulemonde, M. J. Phys.: Condens. Matter 1994, 6(34), 6733-6750.

176. Zinkle, S. J.; Skuratov, V. A. Nucl. Instrum. Methods B 1998, 141(1-4), 737-746.

177. Ramos, S. M. M.; Bonardi, N.; Canut, B.; Della-Negra, S. Phys. Rev. B 1998, 57(1), 189-193.

178. Szenes, G. J. Nucl. Mater. 2005, 336(1), 81-89.

179. Toulemonde, M.; Bouffard, S.; Studer, F. Nucl. Instrum. Methods B 1994, 91(1-4), 108-123.

180. Wesch, W.; Kamarou, A.; Wendler, E. Nucl. Instrum. Meth. B 2004, 225(1-2), 111-128.

181. Pellerin, N.; Dodane-Thiriet, C.; Montouillout, V.; Beauvy, M.; Massiot, D. J. Phys. Chem. B 2007, 111(44), 12707-12714.

182. Zinkle, S. J.; Matzke, H.; Skuratov, V. A. In Microstructural Processes During Irradiation; Zinkle, S. J., Lucas, G. E., Ewing, R. C., Williams, J. S., Eds. Materials Research Society: Warrendale, PA, 1999; Vol. 540, pp 299-304.

183. Audouard, A.; Mamy, R.; Toulemonde, M.; Szenes, G.; Thome, L. Nucl. Instrum. Methods Phys. Res. B 1998, 146(1-4), 217-221.

184. Skuratov, V. A.; Zinkle, S. J.; Efimov, A. E.; Havancsak, K Surf. Coat. Technol. 2005, 196(1-3), 56-62.

185. Dunlop, A.; Lesueur, D.; Legrand, P.; Dammak, H. Nucl. Instrum. Methods Phys. Res. B 1994, 90(1-4), 330-338.

186. Iwase, A.; Ishino, S. J. Nucl. Mater. 2000, 276, 178-185.

187. Itoh, N.; Duffy, D. M.; Khakshouri, S.; Stoneham, A. M. J. Phys.: Condens. Matter 2009, 21(47), 474205.

188. Matzke, H.; Lucuta, P. G.; Wiss, T. Nucl. Instrum. Methods B 2000, 166-167, 920-926.

189. Sickafus, K. E.; Matzke, H.; Yasuda, K.; et al. Nucl. Instrum. Methods B 1998, 141, 358-365.

190. Szenes, G.; Horvath, Z. E.; Pecz, B.; Paszti, F.; Toth, L. Phys. Rev. B 2002, 65(4), 045206

191. Matzke, H. Nucl. Instrum. Methods $B$ 1996, 116, 121-125.

192. Toulemonde, M.; Costantini, J. M.; Dufour, C.; Meftah, A.; Paumier, E.; Studer, F. Nucl. Instrum. Methods B 1996, 116(1-4), 37-42.

193. Johnson, R. A.; Lam, N. Q. Phys. Rev. B 1976, 13(10), 4364-4375.

194. Johnson, R. A.; Lam, N. Q. J. Nucl. Mater. 1978, 69-70, 424-433.

195. Marwick, A. D. J. Phys. F: Metal Phys. 1978, 8(9), 1849-1861.

196. Okamoto, P. R.; Rehn, L. E. J. Nucl. Mater. 1979, 83(1), 2-23.

197. Okamoto, P. R.; Wiedersich, H. J. Nucl. Mater. 1974, 53(1), 336-345.

198. Wiedersich, H.; Okamoto, P. R.; Lam, N. Q. J. Nucl. Mater. 1979, 83(1), 98-108.

199. Lee, E. H.; Maziasz, P. J.; Rowcliffe, A. F. In Phase Stability during Irradiation; Holland, J. R., Mansur, L. K., Potter, D. I., Eds. The Metallurgical Society of AIME: New York, 1981; pp 191-218.

200. Maziasz, P. J. J. Nucl. Mater. 1993, 205, 118-145.

201. Badger, B., Jr.; Plumton, D. L.; Zinkle, S. J.; et al. In 12th Int. Symp. on Effects of Radiation on Materials, ASTM
STP 870; Garner, F. A., Perrin, J. S., Eds. American Society for Testing and Materials: Philadelphia, PA, 1985; Vol. I, pp 297-316.

202. Plumton, D. L.; Wolfer, W. G. J. Nucl. Mater. 1984 120(2-3), 245-253.

203. Whitley, J. B. Depth Dependent Damage in Heavy lon Irradiated Nickel. University of Wisconsin, Madison, 1978.

204. Brager, H. R.; Garner, F. A. J. Nucl. Mater. 1978, 73(1), 9-19.

205. Lee, E. H.; Rowcliffe, A. F.; Kenik, E. A. J. Nucl. Mater. 1979, 83(1), 79-89.

206. Williams, T. M.; Titchmarsh, J. M.; Arkell, D. R. J. Nucl. Mater. 1982, 107(2-3), 222-244.

207. Porter, D. L. J. Nucl. Mater. 1979, 79(2), 406-411.

208. Mansur, L. K.; Lee, E. H. J. Nucl. Mater. 1991, 179-181, 105-110.

209. Snead, L. L.; Zinkle, S. J.; Hay, J. C.; Osborne, M. C. Nucl. Instrum. Methods B 1998, 141, 123-132.

210. Jackson, K. A. J. Mater. Res. 1988, 3(6), 1218-1226.

211. Jagielski, J.; Thome, L. Vacuum 2007, 81(10), 1352-1356.

212. Trinkaus, H. Mater. Sci. Forum 1997, 248-249, 3-12.

213. Weber, W. J. Nucl. Instrum. Methods Phys. Res. B 2000 166, 98-106.

214. Koike, J.; Mitchell, T. E.; Parkin, D. M. Appl. Phys. Lett. 1991, 59(20), 2515-2517.

215. Bement, A. L., Jr. In Radiation Effects (Metallurgical Society Conf.); Sheely, W. F., Ed. Gordon and Breach: New York, 1967; Vol. 37, pp 671-725.

216. Byun, T. S.; Farrell, K. Acta Mater. 2004, 52, 1597-1608.

217. Diehl, J.; Seidel, G. P. In Radiation Damage in Reactor Materials; IAEA: Vienna, 1969; Vol. I, pp 187-214.

218. Little, E. A. Int. Met. Rev. 1976, 21, 25-60.

219. Lucas, G. E. J. Nucl. Mater. 1993, 206, 287-305.

220. Maki, M. J. In Radiation Effects (Metallurgical Society Conf.); Sheely, W. F., Ed. Gordon and Breach: New York, 1967; Vol. 37, pp 627-669.

221. Wechsler, M. S. In Fundamental Aspects of Radiation Damage in Metals, CONF-751006-P2; Robinson, M. T., Young, F. W., Jr., Eds. National Tech. Inform. Service: Springfield, VA, 1975; Vol. II, pp 991-1009.

222. Zinkle, S. J.; Lucas, G. E. In Fusion Materials Semiann. Progress Report for Period ending June 30, 2003, DOE/ER-0313/34; Oak Ridge National Lab, 2003; pp 101-125.

223. Majumdar, S.; Kalinin, G. J. Nucl. Mater. 2000, 283-287, 1424-1428.

224. Rice, P. M.; Zinkle, S. J. J. Nucl. Mater. 1998, 258-263, 1414-1419.

225. Rowcliffe, A. F.; Zinkle, S. J.; Stubbins, J. F.; Edwards, D. J.; Alexander, D. J. J. Nucl. Mater. 1998, 258-263, 183-192.

226. Izumi, K.; Yasuda, K.; Kinoshita, C.; Katsuwada, M. J. Nucl. Mater. 1998, 258-263, 1817-1821.

227. Zinkle, S. J. J. Am. Ceram. Soc. 1989, 72(8), 1343-1351.

228. Katoh, Y.; Snead, L. L.; Nozawa, T.; Kondo, T.; Busby, J. T. J. Nucl. Mater. 2010, 403(1-3), 48-61.

229. Dienst, W. J. Nucl. Mater. 1992, 191-194, 555-559.

230. Dienst, W.; Zimmermann, H. J. Nucl. Mater. 1994, 212-215, 1091-1095.

231. Hollenberg, G. W.; Henager, C. H., Jr.; Youngblood, G. E.; et al. J. Nucl. Mater. 1995, 219, 70-86.

232. Oliver, W. C.; McHargue, C. J.; Zinkle, S. J. Thin Solid Films 1987, 153, 185-196.

233. Fabritsiev, S. A.; Pokrovsky, A. S.; Zinkle, S. J.; et al. J. Nucl. Mater. 1996, 233-237, 526-533.

234. Frost, H. M.; Kennedy, J. C. J. Nucl. Mater. 1986, 141-143, 169-173. 
235. Zinkle, S. J.; Fabritsiev, S. A. Atomic Plasma Mater. Interact. Data Fusion (supplement to Nucl. Fusion) 1994, 5, 163-192.

236. Edwards, D. J.; Garner, F. A.; Greenwood, L. R. J. Nucl. Mater. 1994, 212-215, 404-409.

237. Snead, L. L.; Zinkle, S. J.; White, D. P. J. Nucl. Mater. 2005, 340, 187-202.

238. Hillel, A. J.; Rossiter, P. L. Philos. Mag. B 1981, 44(3), 383-388.

239. Klaffky, R. W.; Rose, B. H.; Goland, A. N.; Dienes, G. J. Phys. Rev. B 1980, 21(8), 3610-3634.

240. Pells, G. P. J. Nucl. Mater. 1991, 184(3), 183-190.

241. Rose, A. Concepts in Photoconductivity and Allied Problems. Interscience: New York, 1963; p 168.

242. van Lint, V. A. J.; Flanagan, T. M.; Leadon, R. E.; Nabor, J. A.; Rogers, V. C. Mechanisms of Radiation Effects in Electronic Materials; Wiley: New York, 1980; Vol. 1, p 359.

243. Zinkle, S. J.; Hodgson, E. R. J. Nucl. Mater. 1992, 191-194, 58-66.

244. Klemens, P. G.; Hurley, G. F.; Clinard, F. W., Jr. In Proc. 2nd Topical Meeting on the Technology of Controlled Nuclear Fusion, CONF-760935; Kulcinski, G. L., Burleigh, N. M., Eds. National Tech. Inform. Service: Springfield, VA, 1976; pp 957-964.

245. Morelli, D. T.; Perry, T. A.; Farmer, J. W. Phys. Rev. B 1993, 47(1), 131-139.

246. White, D. P. J. Appl. Phys. 1993, 73(5), 2254-2258.

247. Odette, G. R.; Nanstad, R. K. J. Met. 2009, 61(7), 17-23.

248. Phythian, W. J.; English, C. A. J. Nucl. Mater. 1993, 205, 162-177.

249. Boothby, R. M. J. Nucl. Mater. 1996, 230(2), 148-157.

250. Dubuisson, P.; Gilbon, D.; Seran, J. L. J. Nucl. Mater. 1993, 205, 178-189.

251. Nemoto, Y.; Hasegawa, A.; Satou, M.; Abe, K.; Hiraoka, Y. J. Nucl. Mater. 2004, 324(1), 62-70.

252. Odette, G. R.; Lucas, G. E. Radiat. Eff. Defects Solids 1998, 144, 189-231.

253. Bruemmer, S. M.; Simonen, E. P.; Scott, P. M.; Andresen, P. L.; Was, G. S.; Nelson, J. L. J. Nucl. Mater. 1999, 274(3), 299-314.

254. Bruemmer, S. M.; Was, G. S. J. Nucl. Mater. 1994, 216, 348-363.

255. Scott, P. J. Nucl. Mater. 1994, 211(2), 101-122.

256. Was, G. S.; Busby, J. T. Philos. Mag. 2005, 85(4-7), 443-465.

257. Johnson, R. A.; Lam, N. Q. Phys. Rev. B 1977, 15(4), 1794-1800.

258. Lam, N. Q.; Okamoto, P. R.; Wiedersich, H. J. Nucl. Mater. 1978, 74(1), 101-113.

259. Holt, R. A. J. Nucl. Mater. 1980, 90(1-3), 193-204.

260. Garner, F. A.; Toloczko, M. B.; Greenwood, L. R.; Eiholzer, C. R.; Paxton, M. M.; Puigh, R. J. J. Nucl. Mater. 2000, 283-287, 380-385.

261. Hickman, B. S.; Walker, D. S. Proc. Br. Ceram. Soc. 1967, 7, 381-389.

262. Hickman, B. S. In Studies in Radiation Effects, Series A: Physical and Chemical; Dienes, G. J., Ed. Gordon and Breach: New York, 1966; Vol. 1, pp 72-158.

263. Snead, L. L.; Zinkle, S. J. In Space Technology and Applications International Forum-STAIF 2005 (AIP Conf. Proc.); El-Genk, M. S., Ed. American Institute of Physics: Melville, NY, 2005; Vol. 746, pp 768-775.

264. Matthews, J. R.; Finnis, M. W. J. Nucl. Mater. 1988, 159, 257-285.

265. Grossbeck, M. L.; Ehrlich, K.; Wassilew, C. J. Nucl. Mater. 1990, 174, 264-281.

266. Jung, P. J. Nucl. Mater. 1993, 200(1), 138-140.
267. Jung, P. J. Nucl. Mater. 1983, 113(2-3), 133-141.

268. Stoller, R. E.; Grossbeck, M. L.; Mansur, L. K. In 15th Int. Symp. on Effects of Radiation on Materials; Stoller, R. E., Kumar, A. S., Gelles, D. S., Eds. American Society for Testing and Materials: Philadelphia, PA, 1992; pp 517-529.

269. Mattas, R. F.; Garner, F. A.; Grossbeck, M. L.; Maziasz, P. J.; Odette, G. R.; Stoller, R. E. J. Nucl. Mater. 1984, 122-123, 230-235.

270. Garner, F. A. In Nuclear Materials; Frost, B. R. T., Ed. VCH: New York, 1994; Vol. 10A, pp 419-543.

271. Fish, R. L.; Straalsund, J. L.; Hunter, C. W.; Holmes, J. J. In Effects of Radiation on Substructure and Mechanical Properties of Metals and Alloys; Moteff, J., Ed. American Society for Testing and Materials: Philadelphia, PA, 1973; pp 149-164.

272. Clinard, F. W., Jr.; Hurley, G. F.; Hobbs, L. W. J. Nucl. Mater. 1982, 108-109, 655-670.

273. Yamada, R.; Zinkle, S. J.; Pells, G. P. J. Nucl. Mater. 1994, 209, 191-203.

274. Schroeder, H.; Stamm, U. In Effects of Radiation on Materials: 14th International Symposium, ASTM STP 1046; Packan, N. H., Stoller, R. E., Kumar, A. S., Eds. American Society for Testing \& Materials: Philadelphia, PA, 1990; Vol. 1046, pp 223-245.

275. Ullmaier, H. J. Nucl. Mater. 1985, 133-134, 100-104.

276. Schroeder, H.; Batfalsky, P. J. Nucl. Mater. 1983, 117, 287-294

277. Mansur, L. K.; Grossbeck, M. L. J. Nucl. Mater. 1988, 155-157, 130-147.

278. van der Schaaf, B.; de Vries, M. I.; Elen, J. D. In Radiation Effects in Breeder Reactor Structural Materials; Bleiberg, M. L., Bennett, J. W., Eds. TMS-AIME: New York, 1977; pp 307-316.

279. Braski, D. N.; Schroeder, H.; Ullmaier, H. J. Nucl. Mater 1979, 83, 265-277.

280. Bloom, E. E.; Wiffen, F. W. J. Nucl. Mater. 1975, 58(2), 171-184.

281. Kramer, D.; Brager, H. R.; Rhodes, C. G.; Pard, A. G. J. Nucl. Mater. 1968, 25(2), 121-131.

282. Kesternich, W. J. Nucl. Mater. 1985, 127(2-3), 153-160.

283. Schroeder, H. J. Nucl. Mater. 1988, 155-157, 1032-1037.

284. Yamamoto, N.; Nagakawa, J.; Murase, Y.; Shiraishi, H. J. Nucl. Mater. 1998, 258-263, 1634-1638.

285. Kimura, A.; Kasada, R.; Morishita, K.; et al. J. Nucl. Mater. 2002, 307-311, 521-526.

286. Schroeder, H.; Ullmaier, H. J. Nucl. Mater. 1991, 179-181, 118-124.

287. Yamamoto, N.; Murase, Y.; Nagakawa, J. Fusion Eng. Des. 2006, 81(8-14), 1085-1090.

288. Shiraishi, H.; Yamamoto, N.; Hasegawa, A. J. Nucl. Mater. 1989, 169, 198-205.

289. Atteridge, D. G.; Charlot, L. A.; Johnson, A. B., Jr.; Remark, J. F. In Radiation Effects and Tritium Technology for Fusion Reactors, CONF-750989; Watson, J. S., Wiffen, F. W., Eds. USERDA: Gatlinburg, TN, 1976; pp 307-330.

290. Sagues, A. A.; Auer, J. In Radiation Effects and Tritium Technology for Fusion Reactors, CONF-750989; Watson, J. S., Wiffen, F. W., Eds. USERDA: Gatlinburg, TN, 1976; pp 331-343.

291. Wiffen, F. W. In Radiation Effects and Tritium Technology for Fusion Reactors, CONF-750989; Watson, J. S., Wiffen, F. W., Eds. USERDA: Gatlinburg, TN, 1976; Vol. II, pp 344-361.

292. Carpenter, G. J. C.; Nicholson, R. B. In Radiation Damage in Reactor Materials; IAEA: Vienna, 1969; Vol. II, pp 383-400. 
293. Fabritsiev, S. A.; Pokrovsky, A. S.; Zinkle, S. J.; Edwards, D. J. In 19th Int. Symp. on Effects of Radiation on Materials; Hamilton, M. L., Kumar, A. S., Rosinski, S. T., Grossbeck, M. L., Eds. American Society for Testing and Materials: West Conshohocken, PA, 2000; pp 1226-1242.

294. Kirk, M. A.; Robertson, I. M.; Jenkins, M. L.; English, C. A.; Black, T. J.; Vetrano, J. S. J. Nucl. Mater. 1987, 149, 21-28.

295. Gelles, D. S.; Garner, F. A.; Brager, H. R. In 10th Int. Symp. on Effects of Radiation on Materials; Kramer, D., Brager, H. R., Perrin, J. S., Eds. American Society for Testing and Materials: Philadelphia, PA, 1981; pp 735-753.

296. Zinkle, S. J. J. Nucl. Mater. 1992, 191-194, 645-649.

297. Ghoniem, N. M.; Walgraef, D.; Zinkle, S. J. J. Comp.-Aided Mater. Des. 2001, 8(1), 1-38.

298. Jäger, W.; Trinkaus, H. J. Nucl. Mater. 1993, 205, 394-410.

299. Seeger, A.; Jin, N. Y.; Phillipp, F.; Zaiser, M. Ultramicroscopy 1991, 39, 342-354.

300. Katoh, Y.; Hashimoto, N.; Kondo, S.; Snead, L. L.; Kohyama, A. J. Nucl. Mater. 2006, 351, 228-240.

301. Zinkle, S. J.; Pells, G. P. J. Nucl. Mater. 1998, 253, 120-132.

302. Zinkle, S. J.; Horsewell, A.; Singh, B. N.; Sommer, W. F. J. Nucl. Mater. 1994, 212-215, 132-138.

303. Zinkle, S. J.; Singh, B. N. J. Nucl. Mater. 2000, 283-287, 306-312.

304. Zinkle, S. J.; Snead, L. L. J. Nucl. Mater. 1995, 225, 123-131.

305. Satoh, Y.; Yoshiie, T.; Mori, H.; Kiritani, M. Phys. Rev. B 2004, 69, 0941081-11.

306. Jenkins, M. L.; Zhou, Z.; Dudarev, S. L.; Sutton, A. P.; Kirk, M. A. J. Mater. Sci. 2006, 41(14), 4445-4453.

307. Kojima, S.; Satoh, Y.; Taoka, H.; Ishida, I.; Yoshiie, T.; Kiritani, M. Philos. Mag. A 1989, 59(3), 519-532.

308. Yao, Z.; Schäublin, R.; Victoria, M. J. Nucl. Mater. 2003, 323(2-3), 388-393.

309. Yoshida, N.; Muroga, T.; Watanabe, H.; Araki, K. Miyamoto, Y. J. Nucl. Mater. 1988, 155-157, 1222-1226.

310. Dai, Y. Mechanical properties and microstructures of copper, gold and palladium single crystals irradiated with $600 \mathrm{MeV}$ protons. Lausanne, EPFL, 1995.

311. Horsewell, A.; Singh, B. N.; Proennecke, S.; Sommer, W. F.; Heinisch, H. L. J. Nucl. Mater. 1991, 179-181, 924-927.

312. Victoria, M.; Baluc, N.; Bailat, C.; et al. J. Nucl. Mater. 2000, 276, 114-122.

313. Horiki, M.; Arai, S.; Satoh, Y.; Kiritani, M. J. Nucl. Mater. 1998, 255(2-3), 165-173.

314. Okada, A.; Kanao, K.; Yoshiie, T.; Kojima, S. Mater. Trans. JIM 1989, 30(4), 265-272.

315. Byun, T. S.; Hashimoto, N.; Farrell, K. J. Nucl. Mater. 2006, 351(1-3), 303-315.

316. Farrell, K.; Byun, T. S.; Hashimoto, N. J. Nucl. Mater. 2004, 335(3), 471-486.

317. Wechsler, M. S. In The Inhomogeneity of Plastic Deformation; Reed-Hill, R. E., Ed. American Society for Metals: Metals Park, OH, 1972; pp 19-54.

318. Byun, T. S.; Farrell, K.; Hashimoto, N. J. Nucl. Mater. 2004, 329-333, 998-1002.

319. Hashimoto, N.; Ando, M.; Tanigawa, H.; Sawai, T.; Shiba, K.; Klueh, R. L. Fusion Sci. Technol. 2003, 44(2), 490-494.

320. Hashimoto, N.; Zinkle, S. J.; Rowcliffe, A. F.; Robertson, J. P.; Jitsukawa, S. J. Nucl. Mater. 2000, 283-287, 528-534.
321. Luft, A. Prog. Mater. Sci. 1991, 35, 97-204.

322. Byun, T. S.; Farrell, K.; Li, M. Acta Mater 2008, 56(5), 1044-1055.

323. Byun, T. S.; Farrell, K.; Li, M. Acta Mater 2008, 56(5), 1056-1064.

324. Byun, T. S.; Hashimoto, N.; Farrell, K. Acta Mater. 2004 52, 3889-3899.

325. Sharp, J. V. Radiat. Effects 1972, 14, 71-75.

326. Byun, T. S.; Hashimoto, N.; Farrell, K.; Lee, E. H. J. Nucl. Mater. 2006, 349, 251-264.

327. Matsukawa, Y.; Osetsky, Y. N.; Stoller, R. E.; Zinkle, S. J. Philos. Mag. 2008, 88(4), 581-597.

328. Osetsky, Y. N.; Rodney, D.; Bacon, D. J. Philos. Mag. 2006, 86(16), 2295-2313.

329. Lee, H.-J.; Wirth, B. D. Philos. Mag. 2009, 89(9), 821-841.

330. Nogaret, T.; Rodney, D.; Fivel, M.; Robertson, C. J. Nucl. Mater. 2008, 380(1-3), 22-29.

331. Rodney, D. Nucl. Instrum. Methods Phys. Res. B 2005, 228, 100-110.

332. Foreman, A. J. E.; Sharp, J. V. Philos. Mag. 1969, 19, 931.

333. Lee, E. H.; Byun, T. S.; Hunn, J. D.; Yoo, M. H.; Farrell, K.; Mansur, L. K. Acta Mater. 2001, 49, 3277-3287.

334. Jaouen, C.; Delafond, J.; Riviere, J. P. J. Phys. F: Metal Phys. 1987, 17(2), 335-350.

335. Jencic, I.; Bench, M. W.; Robertson, I. M.; Kirk, M. A. J. Appl. Phys. 1995, 78(2), 974-982.

336. Wang, S. X.; Wang, L. M.; Ewing, R. C. Phys. Rev. B 2001, 63(2), 024105.

337. Wang, L. M.; Wang, S. X.; Ewing, R. C.; et al. Mater. Sci. Eng. A 2000, 286, 72-80.

338. English, C. A.; Jenkins, M. L. J. Nucl. Mater. 1981, 96(3), 341-357.

339. Jiang, W.; Bae, I. T.; Weber, W. J. J. Phys.: Condens. Matter 2007, 19(35), 356207.

340. Kondo, S.; Katoh, Y.; Snead, L. L. Appl. Phys. Lett. 2008, 93(16), 163110.

341. Mruzik, M. R.; Russell, K. C. Surf. Sci. 1977, 67, 205-225.

342. Gelles, D. S.; Claudson, R. M.; Thomas, L. E. Quantitative Analysis of Void Swelling. Fusion Reactor Materials Semiannual Progress Report for Period ending September 30, 1987, DOE/ER-0313/3, Oak Ridge National Lab, 1987; pp 131-136.

343. Mansur, L. K.; Lee, E. H.; Maziasz, P. J.; Rowcliffe, A. F. J. Nucl. Mater. 1986, 141-143, 633-646.

344. Evans, J. H. Nature 1971, 229(5284), 403-404.

345. Evans, J. H. In Patterns, Defects and Materials Instabilities; Walgraef, D., Ghoniem, N. M., Eds. Kluwer Academic: Amsterdam, 1990; pp 347-370.

346. Risbet, A.; Levy, V. J. Nucl. Mater. 1974, 50(1), 116-118.

347. Zinkle, S. J.; Kojima, S. J. Nucl. Mater. 1991, 179-181, 395-398.

348. Chen, L. J.; Ardell, A. J. J. Nucl. Mater. 1978, 75, 177-185.

349. Farrell, K.; Packan, N. H. J. Nucl. Mater. 1979, 85-86, 683-687.

350. Horsewell, A.; Singh, B. N. Radiat. Effects 1987, 102, 1-5.

351. Mazey, D. J.; Francis, S.; Hudson, J. A. J. Nucl. Mater. 1973, 47, 137-142.

352. Semenov, A. A.; Woo, C. H.; Frank, W. Appl. Phys. A 2008, 93(2), 365-377.

353. Loomis, B. A.; Gerber, S. B.; Taylor, A. J. Nucl. Mater. 1977, 68, 19-31. 